\title{
Avaliação de Critérios e Ferramentas de Teste para Programas OO
}

André Luís dos Santos Domingues

Dissertação apresentada ao Instituto de Ciências Matemáticas e de Computação de São Carlos USP, como parte dos requisitos para a obtenção do título de Mestre na Área de Ciências de Computação e Matemática Computacional.

Orientador: Prof. Dr. José Carlos Maldonado

São Carlos/SP

Setembro/2002 

A minha namorada Camila Maria, aos meus pais, Plínio e Maria Cecília, a meu irmão Alfredo e a minha tia Neusa. 



\section{Agradecimentos}

Agradeço inicialmente a DEUS, pelo dom da vida e por me acompanhar em todos os momentos.

Ao meu orientador, Prof. Dr. José Carlos Maldonado, pelo apoio, sugestões e profissionalismo na orientação durante todo o período deste trabalho.

Aos meus familiares, em especial ao meus pais Plínio e Maria Cecília, meu irmão Alfredo, minha tia Neusa e minhas avós Izabel e Maria, pelo amor, incentivo e constante apoio em todos os momentos da minha vida.

A minha namorada Camila pelo amor, apoio, carinho, incentivo, etc., os quais foram de fundamental importância para que esse trabalho pudesse ser concluído.

Aos demais Professores do grupo de Engenharia de Software: Prof. ${ }^{a}$ Dr. $^{a}$ Rosely Sanches, Prof. Dr. Paulo Cesar Masiero e Prof. ${ }^{a}$ Dr. $^{a}$ Renata P. M. Fortes.

Aos meus amigos: Adenilso, Andrea, Ana Cláudia, Aline, Auri, Camilo, Débora, Elisa, Ellen, Emerson, Érica, Fernando, Gelza, Erald, Juliana, Luciana, Luciano, Marcelo, Maria Istela, Mayb, Matheus, Monique, Percy, Rejane, Richard, Rogério, Rosana, Silvio, Simone, Thaise, Tatiana, Valéria, Vangrei e Viviane.

Aos companheiros de República: Gustavo, Kleber, Reginaldo, Ricardo e Rodrigo, pelos bons momentos que passamos juntos e que sempre estarão guardados em meu coração.

Aos professores e funcionários do ICMC, pela disposição e atenção.

A todos aqueles que, de certa forma, me apoiaram neste trabalho.

Ao CNPq pelo apoio financeiro. 

$\begin{array}{ll}\text { Lista de Figuras } & \text { vii }\end{array}$

$\begin{array}{ll}\text { Lista de Tabelas } & \text { ix }\end{array}$

Resumo $\quad$ xi

$\begin{array}{lll}\text { Abstract } & \text { xiii }\end{array}$

1 Introdução $\quad 1$

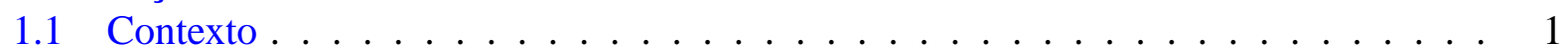

1.2 Motivação e Relevância . . . . . . . . . . . . . . . . . . . . . . . . . . . . . . . . . . . . . .

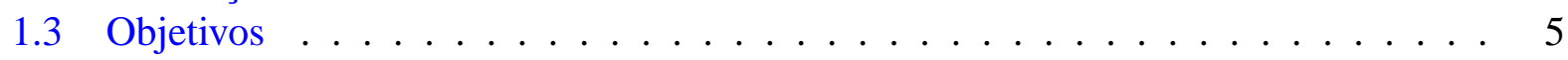

1.4 Organização do Trabalho . . . . . . . . . . . . . . . 5

2 Revisão Bibliográfica $\quad 7$

2.1 Considerações Iniciais . . . . . . . . . . . . . . . . . . . 7

2.2 Visão Geral de Teste de Software . . . . . . . . . . . . . . . . . . . . . . 7

2.2.1 Fases do Teste de Software . . . . . . . . . . . . . . . . . . 9

2.2.2 Técnicas de Teste de Software . . . . . . . . . . . . . . . . . 10

2.2.3 Ferramentas de Teste de Software . . . . . . . . . . . . . . . . . . . . 14

2.3 Teste de Software Orientado a Objetos . . . . . . . . . . . . . . . . . 15

2.3.1 Orientação a Objetos: Terminologia e Conceitos Básicos . . . . . . . . . . 15

2.3.2 Efeitos Colaterais no Contexto Orientado a Objetos . . . . . . . . . . . . . 17

2.3.3 Fases do Teste de Software Orientado a Objetos . . . . . . . . . . . . . . 18

2.3.4 Técnicas de Teste de Software Orientado a Objetos . . . . . . . . . . . . . 20

2.3.5 Ferramentas de Teste de Software Orientado a Objetos . . . . . . . . . . . 21

2.4 Considerações Finais . . . . . . . . . . . . . . . . . . . . . . 24

3 Ferramentas de Teste de Software OO: Definição do Ambiente EvalTool 25

3.1 Considerações Iniciais . . . . . . . . . . . . . . . . . . . . . . . . . . . . . . . . . . . . . .

3.2 Definição do Ambiente EvalTool . . . . . . . . . . . . . . . . . . . . 26

3.2.1 Questionário de Avaliação . . . . . . . . . . . . . . . . . 26

3.2 .2 Revisões de Usuários . . . . . . . . . . . . . . . . . . . . . 27 
3.2.3 Avaliações Comparativas . . . . . . . . . . . . . . . . . . . 27

3.2 .4 Coleta e Análise dos Dados . . . . . . . . . . . . . . . . 28

3.3 Processo de Desenvolvimento . . . . . . . . . . . . . . . . . . . 31

3.3.1 Modelagem do Domínio . . . . . . . . . . . . . . . 32

3.3 .2 Projeto Navegacional . . . . . . . . . . . . . . . . 33

3.3 .3 Projeto de Interface Abstrata . . . . . . . . . . . . . . 36

3.3 .4 Implementação . . . . . . . . . . . . . . . . . . . . . . . . . . . . 39

3.4 Exemplo de Uso . . . . . . . . . . . . . . . . . . . . . . . . . . . 41

3.5 Considerações Finais . . . . . . . . . . . . . . . . . 46

4 Teste Estrutural de Software OO: Uma Avaliação Comparativa 47

4.1 Considerações Iniciais . . . . . . . . . . . . . . . . . . . . 47

4.2 Etapas da Avaliação Comparativa . . . . . . . . . . . . . . . . . . . . . 47

4.2.1 Seleção dos Programas . . . . . . . . . . . . . . . . . . . . 48

4.2.2 Seleção de Ferramentas de Teste . . . . . . . . . . . . . . . . . . . . . . . 48

4.2.3 Geração dos Conjuntos de Casos de Teste . . . . . . . . . . . . . . . . . . 48

4.2.4 Aplicação da Avaliação Comparativa . . . . . . . . . . . . . . . . . . . . 49

4.2.5 Coleta e Análise dos Dados . . . . . . . . . . . . . . . . . . . . . 49

4.3 Descrição da Avaliação Comparativa . . . . . . . . . . . . . . . . . . . . . . . 49

4.3.1 Avaliação Comparativa das Ferramentas de Teste . . . . . . . . . . . . . . 54

4.3.2 Avaliação Comparativa entre as Linguagens de Programação . . . . . . . . 55

4.4 Considerações Finais . . . . . . . . . . . . . . . . . . . . 57

5 Conclusão $\quad 59$

5.1 Contribuições . . . . . . . . . . . . . . . . . . 60

5.2 Trabalhos Futuros . . . . . . . . . . . . . . . . . 61

$\begin{array}{ll}\text { Referências Bibliográficas } & 63\end{array}$

$\begin{array}{ll}\text { A Questionário de Avaliação } & \mathbf{7 3}\end{array}$

A.1 Informações Gerais . . . . . . . . . . . . . . . . . . . . 73

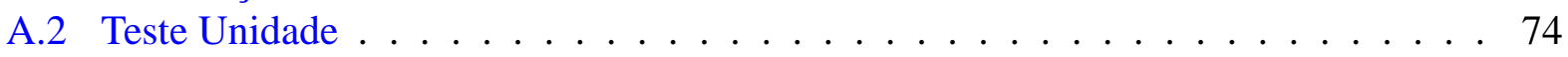

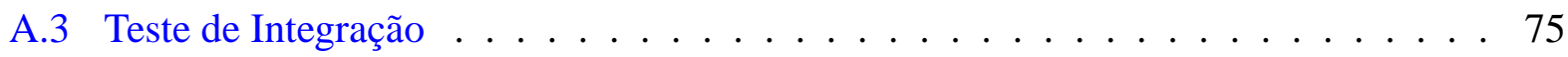

A.3.1 Teste de Classe . . . . . . . . . . . . . . . . . . . . . 75

A.3.2 Teste de Hierarquia . . . . . . . . . . . . . . . . . 75

A.3.3 Teste de Cluster . . . . . . . . . . . . . . . . . 76

A.4 Teste de Sistema . . . . . . . . . . . . . . . . . . . . 76

A.5 Teste de Regressão . . . . . . . . . . . . . . . . . . . . . . . . . . 77

A.6 Suporte para Experimentação . . . . . . . . . . . . . . . . . . . . . . 77 


\section{Lista de Figuras}

3.1 Gráfico do Suporte às Linguagens de Programação . . . . . . . . . . . . . . . . . . 28

3.2 Gráfico do Suporte às Plataformas de Desenvolvimento . . . . . . . . . . . . . . . 29

3.3 Gráfico do Suporte às Categorias de Teste . . . . . . . . . . . . . . . . . . 30

3.4 Gráfico do Suporte às Características da Orientação a Objetos . . . . . . . . . . . 31

3.5 Esquema Conceitual do Ambiente EvalTool . . . . . . . . . . . . . . . . . . . . 33

3.6 Esquema de Classes Navegacionais do Ambiente EvalTool . . . . . . . . . . . . . . 34

3.7 Estrutura Navegacional do Ambiente EvalTool . . . . . . . . . . . . . . . . . 35

3.8 ADV do Ambiente EvalTool . . . . . . . . . . . . . . . . . . . . . . . 36

3.9 ADV's Tela Principal, Questionário de Avaliação, Revisão de Usuário, Avaliação Comparativa, Consulta Dados e Resultados . . . . . . . . . . . . . . . . . 37

3.10 ADV's Inserir, Alterar, Identificar e Selecionar . . . . . . . . . . . . . . . . 37

3.11 ADV's Consultar Questionário de Avaliação, Revisão de Usuário e Avaliação Com-

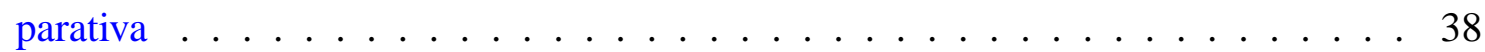

3.12 ADV's Charts Inserir, Alterar, Identificar e Selecionar . . . . . . . . . . . . . . 38

3.13 ADV's Charts Consultar Questionário de Avaliação, Revisão de Usuário e Avaliação Comparativa . . . . . . . . . . . . . . . . . . . . . . 39

3.14 Arquitetura Utilizada para a Execução do Ambiente EvalTool . . . . . . . . . . . . 39

3.15 Tela Principal do Ambiente EvalTool . . . . . . . . . . . . . . . . . . . . . 41

3.16 Tela Formulário de Entrada de Dados . . . . . . . . . . . . . . . . . . . . . 42

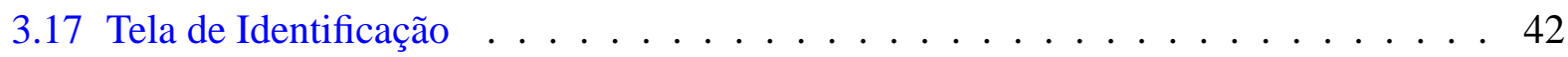

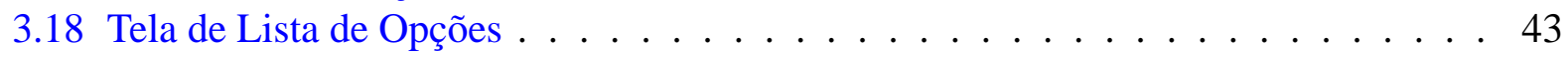

3.19 Tela de Consulta aos Dados . . . . . . . . . . . . . . . . . . . 44

3.20 Tela de Resultados . . . . . . . . . . . . . . . . . . . . . . 45

4.1 Exemplo de Dado de Teste para o Programa Stack . . . . . . . . . . . . . . . 51

4.2 Gráfico da Cardinalidade Média dos Conjuntos de Casos de Teste . . . . . . . . 53 



\section{Lista de Tabelas}

2.1 Relação entre Fases de Teste e o Teste de Software Orientado a Objetos . . . . . . 19

2.2 Síntese de Alguns Critérios de Teste para Programas Orientados a Objetos . . . . . 21

3.1 Sumário das Fases do Método OOHDM . . . . . . . . . . . . . . . . . 32

4.1 Conjunto de Programas da Avaliação Comparativa . . . . . . . . . . . . . . 50

4.2 Critérios de Teste Apoiados pelas Ferramentas e Linguagens a que se Destinam . . 50

4.3 Cardinalidade dos Conjuntos Todas-Funções Adequados . . . . . . . . . . . . 52

4.4 Cardinalidade dos Conjuntos Todos-Nós Adequados . . . . . . . . . . . . . . . . 52

4.5 Cardinalidade dos Conjuntos Todos-Arcos Adequados . . . . . . . . . . . . . . 52

4.6 Escore de Adequação que cada Ferramenta Determina em Relação às Demais . . . 54

4.7 Média Escore de Adequação: Linguagem C++ . . . . . . . . . . . . . . . . . . . 55

4.8 Média Escore de Adequação: Linguagem Java . . . . . . . . . . . . . . . . . . . . 55

4.9 Escore de Satisfação que cada Critério de Teste Determina em Relação ao Mesmo . 56

4.10 Média Escore de Satisfação: Linguagem C++ vs. Linguagem Java . . . . . . . . . 56

4.11 Média Escore de Satisfação: Linguagem Java vs. Linguagem C++ . . . . . . . . . 56 

Tendo em vista a grande atenção e aceitação que vem sendo dadas ao Paradigma Orientado a Objetos (OO) por parte de pesquisadores e desenvolvedores de software, uma das preocupações atuais do grupo de Engenharia de Software do ICMC-USP é o estabelecimento e validação de estratégias de teste de programas $\mathrm{OO}$.

Entre os interesses de pesquisa do grupo de Engenharia de Software do ICMC estão o Teste Baseado em Fluxo de Dados e o Teste de Mutação, que tiveram sua origem na década de 70. Considerando que o paradigma OO vem se destacando como uma das tendências de desenvolvimento de software, o que pode ser observado pelo grande número de programas desenvolvidos à luz desse paradigma, o presente trabalho visa a caracterizar o estado atual do teste de software $\mathrm{OO}$ tanto em termos de técnicas e critérios correntemente utilizados como em termos de ferramentas de teste de software disponíveis.

A identificação e avaliação de critérios e ferramentas de suporte para o teste de software OO darão subsídios para a definição de novos estratégias de teste e para a especificação e implementação de ferramentas de apoio no contexto de software OO. 

Having in mind the great attention and acceptance that have been given to de Object-Oriented (OO) paradigm by researches and developers, one of the current concerns of the ICMC-USP Software Engineering Group is the establishment and validation of testing strategies of $\mathrm{OO}$ programs.

Among the research interests of the ICMC-USP Software Engineering Group are the Data Flow and Mutation based testing that had their origin in the 70's. Considering that the paradigm OO has been highlighted as one of the software development tendencies, what can be observed by the great number of programs developed in the light of this paradigm, the aim of this work is to characterize the current state of OO software test both in terms of available tools and the underlying techniques and criteria.

The identification and evaluation of criteria and tools for the OO software test will provide subsidies for the definition of new testing strategies and for the specification and implementation of supporting tools in the context of OO software. 


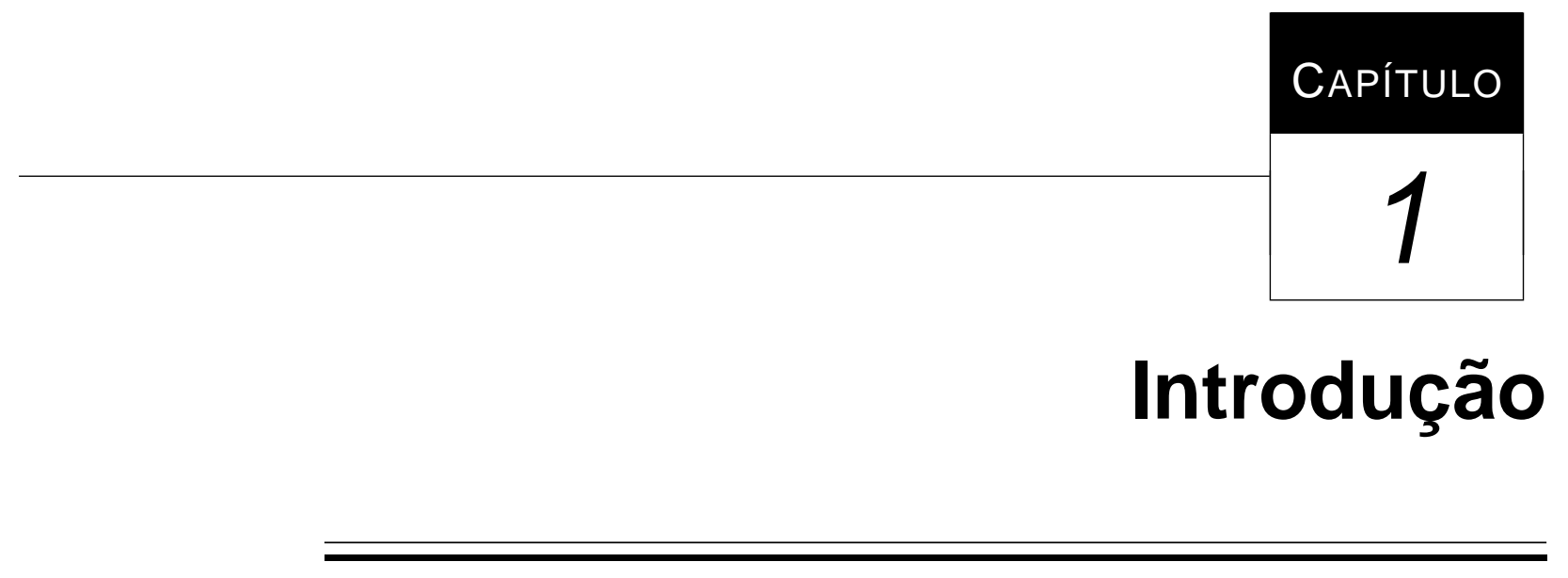

Neste Capítulo serão apresentados o contexto no qual este trabalho está inserido, a motivação e relevância para realizá-lo, os objetivos a serem atingidos e uma visão geral da organização desta dissertação.

\subsection{Contexto}

O processo de desenvolvimento de software envolve uma série de atividades, sendo que, mesmo com o uso de métodos, técnicas e ferramentas de desenvolvimento, ainda podem permanecer erros no produto, os quais podem ocasionar dificuldades e custos adicionais para o seu aperfeiçoamento (Pressman, 2000). A fim de minimizar esses aspectos são necessárias atividades de Garantia de Qualidade, dentre elas, verificação, validação e teste (VV\&T), durante todo o processo de desenvolvimento de software, visando a reduzir a ocorrência de erros e riscos associados.

Dentre as atividades de VV\&T, o teste é uma das atividades mais utilizadas, sendo de grande importância para a identificação e eliminação de erros ou defeitos que persistem (Maldonado, 1991). O teste de produtos de software envolve, basicamente, quatro etapas: planejamento de teste, projeto de casos de teste, execução e avaliação dos resultados de teste (Beizer, 1990; Myers, 1979; Pressman, 2000). Essas etapas devem ser desenvolvidas em todas as fases da atividade de teste, as quais podem ser consideradas como uma atividade incremental realizada em três etapas: teste de unidade, integração e sistema (Pressman, 2000). Essas fases tradicionalmente caracterizam o teste de programas procedimentais, no qual o teste de unidade é intraprocedimental e o teste 
de integração é interprocedimental. Algumas variações são consideradas para o teste de programas desenvolvidos com base no contexto OO, como discutido por Vincenzi (2000), pois há uma divergência em relação à menor unidade a ser testada, podendo ser uma classe ou um método.

A atividade de teste de software é uma das atividades mais onerosas do processo de desenvolvimento de software, chegando a consumir 50\% dos custos (Harrold, 2000). Na tentativa de reduzir esses custos, têm sido propostos técnicas e critérios que auxiliam na condução e avaliação do teste de software. As técnicas de teste são, em geral, classificadas em funcional, estrutural e baseada em erros. A diferença entre essas técnicas está na origem da informação que é utilizada para avaliar ou construir conjunto de casos de teste sendo que cada técnica possui uma variedade de critérios para esse fim. Esses critérios podem ser utilizados tanto para a geração de conjunto de casos de teste, quanto para a avaliação da adequação desses conjuntos.

Offutt \& Irvine (1995) comentam que apesar da diversidade de técnicas e critérios de teste existentes, poucas são as iniciativas que buscam avaliar a adequação de técnicas e critérios de teste procedimentais no contexto de orientação a objetos. Os autores consideram que antes que novos critérios sejam desenvolvidos, tal avaliação faz-se necessária, inclusive para identificar como os critérios de teste procedimentais podem ser adaptados para o teste de software OO.

Além dessas técnicas, do ponto de vista comportamental do sistema, têm-se o teste baseado em Máquinas de Estados Finitos, muito utilizadas na área de protocolo de comunicações e no contexto de programas OO (Vincenzi, 2000).

É importante notar que nenhum das técnicas de teste é completa, no sentido de que nenhuma delas é, em geral, suficiente para garantir a qualidade da atividade de teste. Por isso, essas técnicas devem ser aplicadas em conjunto para assegurar um teste de melhor qualidade (Maldonado, 1991).

Devido à diversidade de critérios de teste existentes e a necessidade desses critérios serem aplicadas em conjunto surge a questão de qual estratégia de teste utilizar, ou seja, como escolher os critérios de teste, de forma que as vantagens de cada um desses critérios sejam combinadas para se obter o melhor resultado com o menor custo. Na tentativa de responder a dúvidas que surgem no momento de decidir se um programa está ou não suficientemente testado, vários estudos teóricos e empíricos vêm sendo realizados. Identificam-se diversos esforços na comunidade científica nessa direção para programas procedimentais (Barbosa, 1998; Barbosa et al., 2000, 2001; Delamaro, 1997; Jorge et al., 2001; Maldonado et al., 2000; Mathur \& Wong, 1993, 1994; Offutt et al., 1996b,a; Souza, 1996; Vincenzi, 1998; Vincenzi et al., 2000, 2001; Wong et al., 1994a,b; Wood et al., 1997) e algumas iniciativas no contexto de programas OO (Martins \& Toyota, 1999; Offutt \& Irvine, 1995; Yanagawa \& Martins, 2000).

Além disso, após a atividade de manutenção, que envolve qualquer modificação no software depois deste ter sido entregue ao usuário, novos testes devem ser realizados, denominados testes 
de regressão, com o objetivo de testar o software modificado a fim de evidenciar a presença de defeitos introduzidos durante as alterações (Pressman, 2000).

Para aplicação efetiva de um critério de teste, é necessária a existência de uma ferramenta automatizada de apoio. Através do uso de ferramentas, é possível obter uma maior eficácia e uma redução do esforço necessário para a realização do teste, bem como diminuir o número de erros causados pela condução manual nessa atividade. Além disso, a existência de ferramentas de teste viabiliza a realização de estudos empíricos e auxilia na realização dos testes de regressão. Assim sendo, a disponibilidade de ferramentas de teste propicia maior qualidade e produtividade para a atividade de teste. Na literatura podem ser encontrados diversos esforços da comunidade científica nessa direção, tanto para o teste de programas procedimentais (Beizer, 1990; Chaim, 1991; Delamaro, 1993, 1997; Demillo, 1980; DeMillo et al., 1988; Fabbri et al., 1995a; Frankl \& Weyuker, 1985; Horgan \& London, 1991; Horgan \& Mathur, 1992; Korel \& Laski, 1985; Luts, 1990; Maldonado et al., 1989; Ostrand \& Weyuker, 1996; Souza, 1996; Vilela et al., 1997), como para o teste de programas OO (Agrawal et al., 1998; Doong \& Frankl, 1994; Gramatech, Inc., 1999; International Software Automation, 1999a,b; Martins \& Toyota, 1999; Rational Software Corporation, 2000a,b; Parasoft Corporation, 1999a,b, 2000a,b; Software Research, Inc., 2001a,b; Telcordia Technologies, Inc., 1998).

Conforme destacado por Harrold (2000), o teste de software OO constitui, atualmente, uma das principais direções para a área de teste de software. Entretanto, o teste de software OO deve lidar com novos problemas introduzidos pelas características das linguagens OO, tais como, o encapsulamento, herança, polimorfismo e acoplamento dinâmico (McDaniel \& McGregor, 1994). Atualmente, a maioria das empresas desenvolvedoras de software ainda estão no processo de transição para o contexto de orientação a objetos e, a medida que mais empresas adotarem tal abordagem, maior será a demanda por técnicas, critérios e ferramentas de teste para programas OO (Kung et al., 1998; Harrold, 2000).

\subsection{Motivação e Relevância}

O principal objetivo da atividade de teste é aumentar a confiabilidade e garantir a qualidade dos produtos de software desenvolvidos. Conceitos pertinentes ao contexto de orientação a objetos, tais como, encapsulamento, herança, polimorfismo e acoplamento dinâmico, ao mesmo tempo em que podem facilitar o desenvolvimento de programas para diversas classes de aplicações, demandam uma análise de adequabilidade das técnicas e critérios utilizados usualmente no teste e validação para programas procedimentais.

Procurando reduzir o custo e o tempo despendido com atividade de teste, bem como aumentar a sua eficácia, várias técnicas e critérios de teste têm sido propostos. Observa-se que, no contexto 
de orientação a objetos também podem ser identificados diversos trabalhos nessa direção (Binder, 1996a,b, 1999; Hoffman \& Strooper, 1993, 1997; Kung et al., 1996a; McDaniel \& McGregor, 1994; McGregor, 1994; Turner \& Robson, 1993). Segundo Offutt \& Irvine (1995), os critérios de teste utilizados no contexto procedimental precisam ser avaliados no contexto de orientação a objetos e, quando necessário, passarem por adaptações que permitam que os mesmos possam ser utilizados no contexto da orientação a objetos.

O grupo de Engenharia de Software do ICMC/USP, em colaboração com os grupos de pesquisa na área de teste do DCA/FEEC/UNICAMP em Campinas e do DIN/UEM em Maringá, vem desenvolvendo atividades de pesquisa concentradas no estudo de princípios, estratégias, métodos e critérios de teste e validação de software, bem como na especificação e implementação de ferramentas de teste que apóiem a realização das atividades de teste e viabilizem a avaliação do aspecto complementar dos critérios de teste por meio de estudos empíricos. Dois critérios de teste bastante explorados pelo grupo são os critérios baseados em fluxo de dados e os critérios baseados em mutação. No contexto de fluxo de dados destacam-se o desenvolvimento da família de critérios Potenciais-Usos que pode ser utilizada tanto no teste de unidade (Maldonado, 1991) quanto no teste de integração (Vilela, 1998), com o suporte automatizado da ferramenta PokeTool (Chaim, 1991). No contexto do teste baseado em mutação, para o teste de programas, destacam-se o desenvolvimento do critério Mutação de Interface (Delamaro, 1997) destinado ao teste de integração e o desenvolvimento das ferramentas Proteum (Delamaro, 1993; Delamaro \& Maldonado, 1996) e Proteum/IM (Delamaro \& Maldonado, 1999; Delamaro, 1997), que apóiam a aplicação dos critérios Análise de Mutantes e Mutação de Interface, respectivamente. No contexto do teste de especificações destaca-se o desenvolvimento dos critérios de mutação para o teste de Máquinas de Estados Finitos (Fabbri et al., 1994, 1999a), Statecharts (Fabbri et al., 1997, 1999b), Redes de Petri (Fabbri et al., 1995b; Simão \& Maldonado, 2000) e Estelle (Souza et al., 2000a,b, 2001), apoiados pelas ferramentas Proteum/FSM (Fabbri et al., 1999a), Proteum/ST (Fabbri et al., 1999b; Sugeta, 1999) e Proteum/PN (Fabbri et al., 1995b; Simão \& Maldonado, 2000; Simão et al., 2000).

Entretanto, em nível de programas, as ferramentas e critérios de teste desenvolvidos e utilizados pelo grupo apóiam a realização dos teste em programas procedimentais. Assim sendo, o grupo tem interesse em avaliar e estender os recursos de teste existentes para o teste de programas OO.

Observa-se que vários critérios de teste para validar o aspecto comportamental de programas OO vêm sendo desenvolvidos (Binder, 1996a,b, 1999; Hoffman \& Strooper, 1993, 1997; Kung et al., 1996b; McGregor, 1994; McDaniel \& McGregor, 1994; Turner \& Robson, 1993), entretanto, como destaca Binder (1996a,b), o teste baseados em estado não detecta todos os tipos de erros, exigindo que critérios de teste complementares, tais como critérios das técnicas estruturais e baseada em erros sejam desenvolvidos e aplicados para assegurar um teste de melhor qualidade. 
Assim sendo, a diversidade de critérios de teste existentes e a necessidade de se avaliar e desenvolver recursos de teste e validação para programas OO, motivam a realização deste trabalho cujo objetivo é descrito a seguir.

\subsection{Objetivos}

O objetivo principal deste trabalho é contribuir para a identificação do estado da arte e da prática para o teste de software OO por meio da definição e implementação de um ambiente que auxilie na avaliação e seleção de ferramentas de teste. Tal sistema é de grande importância, principalmente, no contexto de micro e pequenas empresas que, muitas vezes, não possuem recursos para serem investidos em inovação tecnológica dentro desse contexto. Visa-se também estabelecer um procedimento básico para viabilizar a comparação empírica entre as ferramentas existentes; e entre os critérios e linguagens apoiadas por essas ferramentas.

Nesta perspectiva, espera-se como resultado:

- o ambiente EvalTool de apoio a avaliação e seleção de ferramentas de teste;

- a identificação de características e necessidades das ferramentas de teste;

- dados comparativos entre critérios e ferramentas de teste que apóiam a mesma linguagem de programação; e

- dados comparativos dos critérios apoiados pelas ferramentas de teste entre as linguagens de programação $\mathrm{C}++$ e Java.

\subsection{Organização do Trabalho}

Este capítulo apresentou o contexto no qual este trabalho está inserido, a motivação para realizá-lo e o objetivo a ser atingido. No Capítulo 2 é feita uma revisão bibliográfica sobre os principais tópicos relacionados a este trabalho sendo dada maior ênfase ao teste de programas OO. No Capítulo 3 é apresentado a definição e a implementação de um ambiente para avaliação e seleção de ferramentas de teste para programas OO. No Capítulo 4 são apresentadas as atividades necessárias para a condução dos experimentos, objetivando avaliar as critérios e ferramentas de teste para programas $\mathrm{OO}$ utilizando algumas ferramentas de teste apresentadas no Capítulo 3. O Capítulo 5 apresenta as contribuições deste trabalho e perspectivas de trabalhos futuros. No Apêndice A é apresentado o Questionário de Avaliação utilizado no ambiente para avaliação de ferramentas de teste apresentado no Capítulo 3. 



\section{CAPÍTULO}

\section{2}

Revisão Bibliográfica

\subsection{Considerações Iniciais}

Neste Capítulo são apresentados alguns conceitos envolvendo a atividade de teste. Inicialmente, são feitas considerações a respeito da importância do teste durante o processo de desenvolvimento. Em seguida são apresentadas as fases do teste e as principais técnicas e critérios que podem ser utilizadas em cada uma delas. A importância da existência de ferramentas automatizadas que auxiliem na condução da atividade de teste e na realização de estudos empíricos é também discutida.

Atenção especial é dada ao teste de software OO, por constituir o alvo do presente trabalho. Finalmente, é apresentada uma breve descrição das ferramentas de teste identificadas para o teste estrutural de programas $\mathrm{OO}$, cuja avaliação de suas características e avaliação dos critérios apoiados pelas mesmas motivam a realização deste trabalho.

\subsection{Visão Geral de Teste de Software}

Embora durante todo o processo de desenvolvimento de software sejam utilizadas técnicas, critérios e ferramentas a fim de evitar que erros sejam introduzidos no produto, a atividade de teste continua sendo de fundamental importância para a eliminação de erros que persistem (Maldonado, 1991). Por isso, o teste de software é um elemento crítico para a garantia da qualidade do produto e representa a última revisão de especificação, projeto e codificação (Pressman, 2000). 
Segundo Myers (1979), o objetivo da atividade de teste é o processo de executar um programa com a intenção de descobrir um erro através de um bom caso de teste. Um bom caso de teste pode ser definido como aquele que tem uma alta probabilidade de revelar defeitos no software e, um caso de teste bem sucedido é aquele capaz de revelar erros ainda não descobertos.

Idealmente, o programa deveria ser exercitado com todos os valores possíveis do domínio de entrada. Sabe-se, entretanto, que o teste exaustivo é impraticável devido a restrições de tempo e custo para realizá-lo. Dessa forma, é necessário determinar quais casos de teste utilizar, de modo que a maioria dos erros existentes possa ser encontrada e que o número de casos de teste não seja tão grande a ponto de ser impraticável (Maldonado, 1997; Maldonado et al., 1998).

Apesar de não ser possível, através de testes, provar que um programa está correto, os testes, se conduzidos sistemática e criteriozamente, contribuem para aumentar a confiança de que o software desempenha as funções especificadas e evidenciar algumas características mínimas do ponto de vista da qualidade do produto (Vincenzi, 2000).

Nesse sentido, técnicas e critérios de teste têm sido elaborados com o objetivo de fornecer uma maneira sistemática e rigorosa para selecionar um subconjunto do domínio de entrada e ainda assim ser eficiente para apresentar os erros existentes, respeitando-se as restrições de tempo e custo associado a um projeto de software (Vincenzi, 1998). As principais técnicas e critérios de teste são descritas na Seção 2.2.2.

Além da utilização de técnicas e critérios de teste, para facilitar a condução do teste de software, este é, em geral, dividido em várias fases. Devido ao aspecto complementar das técnicas de teste de software, destaca-se que, dependendo da fase do teste e, conseqüentemente, dos tipos de erros que se deseja revelar, critérios de diferentes técnicas devem ser utilizados para assegurar o teste de boa qualidade. As principais fases do teste de software são descritas a seguir na Seção 2.2.1.

Duas abordagens são utilizadas com o objetivo de encontrar formas econômicas e produtivas para desenvolver os testes: a abordagem teórica e a abordagem empírica. Na abordagem teórica, procuram-se estabelecer propriedades e características dos critérios de teste, tais como, a eficácia de uma estratégia de teste ou a relação de inclusão entre os critérios. Na abordagem empírica, dados e estatísticas são coletados, os quais registram, por exemplo, a frequiência na qual diferentes estratégias de teste revelam a presença de erros em uma determinada coleção de programas, fornecendo diretrizes para a escolha entre os diversos critérios disponíveis (Howden, 1978).

A realização de estudos empíricos intensificou-se nos últimos anos, procurando avaliar as diferentes técnicas e critérios de teste existentes, de modo a definir uma estratégia de teste confiável e econômica para a realização dos testes, em que o custo, eficácia e dificuldade de satisfação (strenght) são fatores básicos para comparar a adequação de um critério. O fator custo se reflete o esforço necessário para que o critério seja utilizado; em geral é medido pelo número de casos de teste necessários para satisfazer o critério. A eficácia refere-se à capacidade que um critério 
possui de detectar erros. O fator strength refere-se a probabilidade de satisfazer um critério tendo sido satisfeito um outro critério (Mathur \& Wong, 1994). No Capítulo 4 é descrita uma avaliação comparativa envolvendo critérios e ferramentas de teste para programas OO.

Na prática, a aplicação de um critério de teste está fortemente condicionado à sua automatização. O desenvolvimento de ferramentas de teste é de fundamental importância uma vez que o teste de software é muito propenso a erros, além de improdutivo, se aplicado manualmente. Além disso, a existência de ferramentas de teste viabiliza a realização de estudos empíricos e auxilia a condução dos testes de regressão. Exemplos de algumas ferramentas de teste são apresentados na Seção 2.2.3.

Mesmo utilizando as técnicas e critérios existentes, dividindo a atividade de teste em várias fases e utilizando ferramentas de teste, não se pode garantir um software livre de erros. Os testes somente contribuem para aumentar a confiança de que o software funciona de acordo com o esperado, de modo que grande parte dos defeitos já foram detectados (Beizer, 1995).

\subsubsection{Fases do Teste de Software}

Como mencionado anteriormente, a atividade de teste pode ser considerada como uma atividade incremental realizada em três fases: teste de unidade, integração e sistema (Pressman, 2000). Variações são identificadas no contexto de software OO, descritas mais detalhadamente na Seção 2.3.3.

Com a divisão da atividade de teste em várias fases, o testador pode se concentrar em aspectos diferentes do software e em diferentes tipos de erros e utilizar diferentes estratégias de seleção de dados de teste e medidas de cobertura em cada uma delas (Linnenkugel \& Müllerburg, 1990).

Os testes de unidade e de integração concentram-se na verificação funcional de um módulo e na incorporação de módulos na estrutura de um programa, respectivamente. $\mathrm{O}$ teste de sistema valida o software assim que ele é incorporado a um sistema maior (Pressman, 2000). A seguir é apresentado uma descrição de cada uma dessas fases.

\section{Teste de Unidade}

O teste de unidade concentra-se na verificação da menor unidade de projeto de software: o módulo. Usando a descrição do projeto como guia, caminhos de controle importantes são testados para descobrir erros dentro das fronteiras do módulo (Pressman, 2000). Durante esta fase utiliza-se muito a técnica de teste estrutural. A técnica de teste baseada em erros também tem sido usada nesta fase (Vincenzi, 2000).

Uma vez que, em geral, um módulo não é um programa por si só, drivers e/ou stubs devem ser desenvolvidos para esta fase de teste. Na maioria das aplicações, um driver nada mais é do que um "programa principal" que aceita dados de casos de teste, passa tais dados para o módulo a ser 
testado e imprime os dados relevantes. Os stubs servem para substituir módulos que estejam subordinados ao módulo a ser testado e que ainda não foram implementados e/ou testados (Pressman, 2000).

\section{Teste de Integração}

O teste de integração é uma técnica sistemática para a construção da estrutura do programa, realizando-se, ao mesmo tempo, teste para descobrir erros associados nas integrações das unidades. O objetivo é, a partir dos módulos testados no nível de unidade, construir a estrutura do programa que foi determinada pelo projeto. Existem dois tipos de integração, a não incremental e a incremental.

Na integração não incremental, todos os módulos são combinados antecipadamente e o programa é testado como um todo. Na integração incremental, o programa é construído e testado em pequenos segmentos, nos quais os erros são mais fáceis de serem isolados e corrigidos. Existem duas estratégias de integração incremental, a integração top-down e a integração bottom-up.

Segundo Pressman (2000), as técnicas de projeto de casos de teste funcional, são as mais utilizadas durante esta fase. No entanto, iniciativas de utilização de critérios utilizados no teste de unidade para o teste de integração são identificadas na literatura, tais como a extensão de critérios baseados em fluxo de dados e de critérios baseados na análise de mutantes (Delamaro, 1997; Haley \& Zweben, 1984; Harrold \& Soffa, 1991; Jin \& Offut, 1995; Linnenkugel \& Müllerburg, 1990; Vilela, 1998).

\section{Teste de Sistema}

Depois que o software foi integrado, o sistema funciona como um todo, são realizados os testes de sistema. O objetivo é assegurar que o software e os demais elementos que compõem o sistema, tais como, hardware e banco de dados, combinam-se adequadamente e que a função/desempenho global desejada é obtida. A técnica de teste funcional é que tem sido mais utilizada nesta fase de teste (Pressman, 2000).

\subsubsection{Técnicas de Teste de Software}

As técnicas e critérios de teste fornecem ao desenvolvedor uma abordagem sistemática e teoricamente fundamentada para se conduzir e avaliar a qualidade do teste de software. Dentre as várias técnicas propostas encontram-se as técnicas de teste funcional, estrutural e baseada em erros. Além disso, do ponto de vista comportamental, têm-se também a técnica de teste baseada em máquinas de estados finitos. 
Segundo Howden (1987) o teste pode ser classificado de duas maneiras: teste baseado em especificação e teste baseado em programa. De acordo com tal classificação, têm-se que critérios da técnica funcional e baseada em máquinas de estado finito são baseados em especificação e os critérios da técnica estrutural e baseada em erros são considerados critérios baseados em programa.

É importante ressaltar que as técnicas de teste devem ser vistas como complementares e a questão está em como utilizá-las de forma que as vantagens de cada uma sejam melhor exploradas em uma estratégia de teste que leve a uma atividade de teste de boa qualidade, ou seja, eficaz e de baixo custo. A seguir, é apresentada uma descrição de cada uma dessas técnicas.

\section{Técnica Funcional}

O teste funcional ou caixa preta tem esse nome pelo fato de tratar o software como uma caixa do qual o conteúdo é desconhecido é só é possível visualizar o lado externo (Pressman, 2000).

Deste modo, o testador utiliza essencialmente a especificação funcional do programa para derivar os casos de teste que serão empregados, sem se importar com os detalhes de implementação (Beizer, 1990). Assim, uma especificação correta e de acordo com os requisitos do usuário é essencial para esse tipo de teste (Vincenzi, 1998).

O teste funcional procura revelar erros nas seguintes categorias: funções incorretas ou ausentes; erros de interface; erros nas estruturas de dados ou no acesso a banco de dados externo; erros de desempenho; e erros de inicialização e término. Alguns exemplos de critérios de teste funcional são (Pressman, 2000):

Particionamento de Equivalência: divide o domínio de entrada de um programa em classes de equivalências válidas e inválidas, a partir das condições de entrada de dados identificadas na especificação. Em seguida, selecionam-se casos de teste, baseando-se na hipótese de que um elemento de uma dada classe seria representativo da classe toda, sendo que para cada uma das classes inválidas deve ser gerado um caso de teste distinto. O uso de particionamento permite examinar os requisitos mais sistematicamente e restringir o número de casos de teste necessários;

Análise de Valor Limite: é um complemento ao critério particionamento de equivalência, sendo que os limites associados às condições de entrada são exercitadas de forma mais rigorosa; ao invés de selecionar-se qualquer elemento de uma classe, os casos de teste são escolhidos nas fronteiras das classes, pois nesses pontos pode-se concentrar um grande número de erros. O espaço de saída do programa também é particionado e são exigidos casos de teste que produzam resultados nos limites dessas classes de saída; e 
Grafo de Causa-Efeito: estabelece requisitos de teste baseado nas possíveis combinações das condições de entrada que os critérios anteriores não exploram. Primeiramente, são levantadas as possíveis condições de entrada (causas) e as possíveis ações (efeitos) do programa. A seguir é construído um grafo relacionando as causas e efeitos levantados. Esse grafo é convertido em uma tabela de decisão a partir do qual são derivados os casos de teste.

Destaca-se que, como os critérios desta técnica baseiam-se exclusivamente na especificação do software para derivar os requisitos de teste, esses critérios podem ser aplicados indistintamente a programas procedimentais e a programas OO (Hoffman \& Strooper, 1997).

\section{Técnica Estrutural}

O teste estrutural ou caixa branca, é uma técnica de projeto de casos de teste que usa a estrutura de controle e fluxo de dados para derivar os requisitos de teste (Pressman, 2000). Os critérios de teste estrutural baseiam-se em diferentes tipos de estruturas para determinar quais partes do programa têm sua execução requerida. Esses critérios podem ser classificados em baseados na complexidade; baseados no fluxo de controle; e baseados em fluxo de dados.

Em geral, a maioria dos critérios desta técnica utiliza uma representação de programa conhecida como grafo de fluxo de controle ou grafo de programa. Um grafo de programa é um grafo dirigido, com um único nó de entrada e um único nó de saída, no qual cada arco representa um possível desvio de um bloco para outro. Cada bloco tem as seguintes características: uma vez que o primeiro comando do bloco é executado, todos os demais são executados seqüencialmente; e não existe desvio de execução para nenhum comando dentro do bloco. Através do grafo de programa podem ser escolhidos os componentes que devem ser executados.

Os critérios baseados na complexidade utilizam informações sobre a complexidade do programa para derivar os requisitos de teste. Um critério desta classe é o critério de McCabe, que utiliza a complexidade ciclomática para derivar os requisitos de teste.

A complexidade ciclomática é uma métrica de software que proporciona uma medida quantitativa de complexidade lógica de uma programa. Nesse contexto, o valor computado da complexidade ciclomática define o número de caminhos independentes do conjunto básico do programa, oferecendo um limite máximo para o número de testes que deve ser realizado para garantir que todas as instruções sejam executadas pelo menos uma vez (Pressman, 2000).

Os critérios baseados no fluxo de controle utilizam apenas características de controle da execução do programa, como comandos ou desvios, para derivar os requisitos de teste necessários. Os critérios mais conhecidos desta classe são:

Todos-Nós: exige que a execução do programa passe, ao menos uma vez, em cada nó do grafo de fluxo, ou seja, que cada comando do programa seja executado pelo menos uma vez; 
Todos-Arcos: requer que cada arco do grafo, ou seja, cada desvio do programa, seja exercitada pelo menos uma vez; e

Todos-Caminhos: requer que todos os caminhos possíveis do programa sejam executados.

Os critérios baseados no fluxo de dados utilizam informações do fluxo de dados do programa para determinar os requisitos de teste. Esses critérios exploram as interações que envolvem definições de variáveis e referências a tais definições (Rapps \& Weyuker, 1985). Exemplos desta classe de critérios são os critérios de Rapps e Weyuker (Rapps \& Weyuker, 1982, 1985) e os critérios potenciais-usos (Maldonado, 1991).

Os casos de teste obtidos durante a aplicação dos critérios funcionais podem ser utilizados como um conjunto inicial para os testes estruturais. Como, em geral, esse conjunto não é suficiente para satisfazer totalmente um critério estrutural, novos casos de teste são gerados e adicionados ao conjunto até que se atinja o grau de satisfação desejado, explorando-se, desse modo, os aspectos complementares das duas técnicas (Souza, 1996).

Na Seção 2.3.4 são descritos mais detalhadamente alguns critérios de fluxo de dados destinados ao teste de programas $\mathrm{OO}$.

\section{Técnica Baseada em Erros}

O teste baseado em erros utiliza informações sobre os erros mais freqüentes cometidos no processo de desenvolvimento de software e sobre os tipos específicos de erros que se desejam revelar (Demillo, 1987). Dois critérios de teste baseado em erros são:

Semeadura de Erros: nesse critério, uma quantidade conhecida de erros é semeada artificialmente no programa. Após o teste, do total de erros encontrados verificam-se quais são naturais e quais são artificiais. Usando estimativas de probabilidade, o número de erros naturais ainda existentes no programa pode ser calculado (Budd, 1981); e

Análise de Mutantes: é um critério que utiliza um conjunto de programa ligeiramente modificados, obtidos a partir de um determinado programa $P$, para avaliar o quanto um conjunto de casos de teste $T$ é adequado para o teste de $P$. O objetivo é encontrar um conjunto de casos de teste capaz de revelar as diferenças de comportamento existentes entre $P$ e seus mutantes.

\section{Técnica Baseada em Máquinas de Estados Finitos}

O teste baseado em Máquinas de Estados Finitos utiliza uma Máquina de Estados Finitos (MEF) para modelar o comportamento do sistema. Tendo criado a MEF, os casos de teste serão as sequiências de eventos válidas da mesma. No entanto, existem vários critérios de geração de sequiências 
de teste baseados em MEF, cada um deles exige que a MEF satisfaça algumas propriedades, além de selecionar diferentemente as seqüências de eventos válidas.

Fujiwara et al. (1991) afirmam que um critério de geração de seqüências de teste tem como objetivo oferecer a possibilidade de executar atividades de teste e validação em sistemas modelados de acordo com alguma técnica de modelagem, de forma sistemática, usando procedimentos bem definidos para a geração dessas seqüências e fazendo com que os produtos se apresentem de forma mais segura e com maior qualidade.

Esses critérios de geração de sequiências de teste baseadas em MEF devem apresentar as seguintes características: um número pequeno de seqüências, cada seqüência tendo uma aplicação rápida e de fácil execução; e as sequiências de teste devem identificar todas as falhas que a especificação possa conter.

Alguns exemplos de critérios de teste baseados em MEF são: W (Chow, 1978); DS (Gönenç, 1970); UIO (Sabnani \& Dahbura, 1988); e Wp (Fujiwara et al., 1991).

Os critérios baseados em MEF são também bastante utilizados no contexto de orientação a objetos para representar o aspecto comportamental dos objetos (Hoffman \& Strooper, 1993; Turner \& Robson, 1993; Kung et al., 1996b; McGregor, 1994; McDaniel \& McGregor, 1994; Hoffman \& Strooper, 1997; Binder, 1994, 1995, 1996a,b, 1999). Na Seção 2.3.4 são descritos alguns trabalhos que utilizam o conceito de MEF no teste de programas OO.

\subsubsection{Ferramentas de Teste de Software}

A qualidade e produtividade da atividade de teste são dependentes do critério de teste utilizado e da existência de uma ferramenta que o suporte. Sem a existência de uma ferramenta, a aplicação de um critério torna-se uma atividade propensa a erros e limitada a programas muito simples.

A disponibilidade de ferramentas de teste permite a transferência de tecnologia para a indústria e contribui para uma contínua evolução de tais ambientes, fatores indispensáveis para a produção de software de alta qualidade. Além disso, a existência de ferramentas auxilia pesquisadores e alunos de Engenharia de Software a adquirirem os conceitos básicos e experiência na comparação, seleção e estabelecimento de estratégias de teste (Vincenzi, 2000).

Outro fator importante é o suporte oferecido pelas ferramentas aos testes de regressão. Os casos de teste utilizados durante a atividade de teste podem ser facilmente obtidos para revalidação do software após uma modificação. Com isso, é possível checar se a funcionalidade do software foi alterada, reduzir o custo para gerar os testes de regressão e comparar os resultados obtidos nos testes de regressão com os resultados do teste original (Maldonado, 1997; Maldonado et al., 1998).

Como comentado anteriormente, diversos trabalhos vêm sendo realizados nessa direção. Por exemplo, como ferramentas de apoio à aplicação dos critérios baseado em análise de fluxo de 
controle e de dados em programas procedimentais pode-se citar as ferramentas PokeTool (Chaim, 1991; Maldonado et al., 1989), ATACOBOL (Sze, 2000) e xSuds (Agrawal et al., 1998; Telcordia Technologies, Inc., 1998), sendo que esta última também pode ser utilizada no teste de programas em $\mathrm{C}++$.

No que se refere ao teste baseado em erros para programas procedimentais, as principais ferramentas desenvolvidas são a Mothra (Demillo, 1980; DeMillo et al., 1988), a Proteum (Delamaro, 1993) e a Proteum/IM (Delamaro, 1997), sendo que essas duas últimas foram integradas em um único ambiente (Proteum/IM 2.0) de teste que apóia a realização dos teste de unidade e de integração em programas procedimentais (Delamaro et al., 2000).

Para o teste de programas OO, além da ferramenta xSuds (Agrawal et al., 1998; Telcordia Technologies, Inc., 1998), existem outras ferramentas disponíveis, como por exemplo, as ferramentas Panorama (International Software Automation, 1999a,b) e a ferramenta PureCoverage (Rational Software Corporation, 2000a). Uma descrição resumida dessas e de outras ferramentas destinadas ao teste de programas OO é apresentada na Seção 2.3.5.

\subsection{Teste de Software Orientado a Objetos}

Nesta seção, inicialmente são apresentadas algumas definições sobre a terminologia OO e quais os problemas mais comuns que podem ocorrer no teste de software OO.

Posteriormente, são apresentadas as fases e as técnicas e critérios de teste que vêm sendo desenvolvidos para o teste de programas OO. Apresentam-se também algumas ferramentas de teste que apóiam o teste estrutural de programas OO.

\subsubsection{Orientação a Objetos: Terminologia e Conceitos Básicos ${ }^{1}$}

Historicamente, criar software envolve definir processos que agem sobre um conjunto de dados separados. A orientação a objetos muda o foco do processo de programação de procedimentos para objetos, classes e clusters, além de incorporar outras características, tais como, encapsulamento, herança, polimorfismo e acoplamento dinâmico.

Um cluster pode ser definido como um conjunto de classes que cooperam entre si na implementação de determinada(s) funcionalidade(s). Uma classe consiste de uma interface que caracteriza os objetos e define a lista de operações permitidas a um objeto daquela classe. Uma classe contém atributos (ou dados) e métodos (ou funções membro) que representam operações que podem ser realizadas sobre os dados.

\footnotetext{
${ }^{1}$ Esta Seção foi parcialmente extraída de (Colanzi, 1999).
} 
Um objeto é dito ser uma instância de uma classe que contém tanto os atributos como os métodos. Os objetos podem agir e serem ativados por mensagens de outros objetos. Uma mensagem é uma solicitação para que o objeto execute um de seus métodos.

A capacidade que um objeto tem de impedir que outros objetos tenham acesso aos seus dados é denominada encapsulamento. O encapsulamento, também chamado de ocultamento de informações, consiste na separação dos aspectos externos de um objeto, acessíveis por outros objetos, dos detalhes internos da implementação daquele objeto, que ficam ocultos dos demais objetos. $\mathrm{O}$ encapsulamento impede que um programa se torne tão interdependente que uma pequena modificação possa causar grandes efeitos de propagação. A implementação de um objeto pode ser modificada sem que isso afete as aplicações que o utilizam.

Novas classes podem ser definidas em função de classes já existentes. Tal relacionamento entre classes é obtido por meio de herança. A herança é o compartilhamento de atributos e métodos entre classes com base em um relacionamento hierárquico, de modo que uma classe mais especializada herde, ou incorpore todas as propriedades da classe mais genérica e acrescente suas próprias e exclusivas características. À classe mais genérica dá-se o nome de superclasse, classe pai ou classe base e à classe mais específica dá-se o nome de subclasse ou classe filha. Nesse contexto, cada classe é declarada como uma subclasse de uma ou mais superclasses. Quando existe mais de uma superclasse, a relação é denominada herança múltipla. Entretanto, tal mecanismo pode trazer problemas quando duas superclasses oferecem atributos ou métodos com o mesmo nome.

O termo polimorfismo significa que a mesma operação pode atuar de modos diversos em classes diferentes. Uma operação é uma ação ou transformação que um objeto executa ou a qual ele está sujeito. Quando aplicado a linguagens de programação indica que um mesma construção de linguagem pode assumir diferentes tipos ou manipular objetos de diferentes tipos. Por exemplo, o operador "+" pode ser utilizado para fazer a adição de dois valores inteiros ou ponto-flutuante, bem como para concatenar duas strings.

Uma característica fortemente relacionada com herança e polimorfismo é o acoplamento dinâmico. Devido ao fato do sistema "amarrar" os seletores de mensagens aos métodos que os implementam em tempo de execução, podem ser tiradas vantagens práticas, principalmente para a reutilização de métodos por diversas classes. O mesmo nome de método pode ser sobrecarregado com diferentes semânticas e implementações. Por exemplo, um método print pode ser implementado de três formas diferentes: uma para imprimir uma variável do tipo inteiro, outra para imprimir uma variável ponto-flutuante e outra para imprimir uma matriz ou cadeia de caracteres. A escolha de qual método será invocado é feita em tempo de execução com base no parâmetro passado para o método. 


\subsubsection{Efeitos Colaterais no Contexto Orientado a Objetos}

Ao mesmo tempo em que conceitos pertinentes ao contexto de orientação a objetos, tais como, encapsulamento, herança, polimorfismo e acoplamento dinâmico, facilitam o desenvolvimento de programas para diversas classes de aplicações, eles podem trazer uma série de problemas para a atividade de teste. A seguir, é apresentada a descrição dos principais problemas que o uso dessas características podem causar.

\section{Encapsulamento}

Como definido anteriormente, o encapsulamento refere-se ao mecanismo de controle de acesso que determina, por exemplo, a visibilidade de atributos e métodos dentro de uma classe. Com o controle de acesso previnem-se dependências indesejadas entre uma classe cliente e uma classe servidora, por exemplo, tornando somente a interface da classe visível ao cliente, ocultando detalhes de implementação. O encapsulamento auxilia no ocultamento de informação e na obtenção da modularidade do sistema sendo desenvolvido.

Embora o encapsulamento não contribua diretamente com a ocorrência de erros, ela pode apresentar-se como um obstáculo para a atividade de teste. A atividade de teste requer um relatório completo do estado concreto e abstrato de um objeto, bem como a possibilidade de alterar esse estado facilmente (Binder, 1999). As linguagens OO dificultam a atividade de se obter (get) ou instanciar (set) o estado de um objeto. No caso específico de $\mathrm{C}++$, as funções amigas (friend functions) foram desenvolvidas para solucionar esses problemas. Entretanto, no caso de linguagens que não possui esse recurso, outras providências devem ser tomadas. Harrold (2000), comentando a respeito do teste de componentes de software, diz que uma solução seria a implementação de métodos get e set para todos os atributos de uma classe.

\section{Herança}

Herança é essencial à programação $\mathrm{OO}$ pois ela permite a reusabilidade via o compartilhamento de características presentes em uma classe já definida anteriormente.

Entretanto, como destacado por Binder (1999), a herança enfraquece o encapsulamento e pode ser responsável pela criação de um risco de erro similar ao uso de variáveis globais em programas procedimentais. Quando se está implementando uma classe que faz uso de herança, é de fundamental importância compreender os detalhes de implementação das classes ancestrais. Sem tomar esse cuidado é possível o desenvolvimento de classes que aparentemente funcionam corretamente, mas violam condições implícitas requeridas para garantir a corretitude das classes ancestrais. Grandes hierarquias de herança podem dificultar a compreensão, aumentar a chance de ocorrência de erros e reduzir a testabilidade das classes. 
Segundo Offutt \& Irvine (1995), a utilização de herança pode levar a uma falsa conclusão de que subclasses que herdam características de superclasses não precisam ser testadas, reduzindo assim o esforço com os testes. Perry \& Kaiser (1990) dizem que mesmo que um método seja herdado integralmente de uma superclasse, sem nenhuma modificação, ele deverá ser retestado no contexto da subclasse. Harrold et al. (1992) utilizaram os resultados de Perry \& Kaiser (1990) e desenvolveram uma estratégia de teste incremental baseada na hierarquia de herança das classes. A idéia é identificar quais métodos herdados necessitam de novos casos de teste para serem testados e quais métodos podem ser retestados, aproveitando os casos de teste elaborados para o teste da superclasse. Com essa estratégia, o esforço requerido para o teste é reduzido, visto que muitos casos de teste que já foram elaborados podem ser reutilizados no teste das subclasses.

\section{Polimorfismo}

Polimorfismo é a capacidade de se poder fazer referência a mais de um tipo de objeto. O polimorfismo permite que, em tempo de execução, associações com diferentes tipos de objetos sejam realizadas. Métodos polimórficos utilizam o recurso de acoplamento dinâmico para determinar, em tempo de execução, qual método deve responder a determinada mensagem baseado no conjunto de parâmetros sendo enviado junto com a mensagem.

Embora o polimorfismo possa ser utilizado para produzir código elegante e extensível, alguns aspectos problemáticos podem ser detectados na sua utilização. Suponha a existência de um método $x$ em uma superclasse que precisa ser testado. Posteriormente, o método $x$ é sobrescrito. A corretitude do método $x$ na subclasse não é garantida pois as pré-condições e pós-condições na subclasse para a execução do método $x$ podem não ser as mesmas da superclasse (Binder, 1999).

Cada possibilidade de acoplamento de uma mensagem polimórfica é uma computação única. $\mathrm{O}$ fato de diversos acoplamentos polimórficos trabalharem corretamente não garante que todos irão trabalhar. Objetos polimórficos com acoplamento dinâmico podem facilmente resultar no envio de mensagens para a classe errada e pode ser difícil identificar e executar todas as combinações de associações.

\subsubsection{Fases do Teste de Software Orientado a Objetos ${ }^{2}$}

Conforme mencionado anteriormente, as fases do teste de software podem ser divididas em: teste de unidade, integração e sistema. Entretanto, algumas variações são identificados no contexto de software OO.

Do ponto de vista do teste de unidade, pode-se considerar que em programas OO, a menor unidade a ser testada é um método, sendo que a classe à qual o método pertence pode ser vista

\footnotetext{
${ }^{2}$ Esta Seção foi parcialmente extraída de (Vincenzi, 2000).
} 
como o driver do método. O teste de unidade para programas OO também é chamado de teste intra-método (Harrold \& Rothermel, 1994).

Por definição, uma classe engloba um conjunto de atributos e métodos que manipulam esses atributos. Assim sendo, considerando uma única classe, já é possível pensar-se em teste de integração. Métodos da mesma classe podem interagir entre si para desempenhar funções específicas, caracterizando uma integração entre métodos que deve ser testada: teste inter-método (Harrold \& Rothermel, 1994).

Harrold \& Rothermel (1994) definem ainda outros dois tipos de teste de integração para programas OO: teste intra-classe e teste inter-classe. No teste intra-classe são testadas interações entre métodos públicos fazendo chamada a esses métodos em diferentes sequiências. O objetivo é identificar possíveis sequiências de ativação de métodos inválidas que levem o objeto a um estado inconsistente. No teste inter-classe o mesmo conceito de invocação de métodos públicos em diferentes seqüências é utilizado, entretanto, esses métodos públicos não necessitam estar na mesma classe.

Finalmente, após realizados os testes anteriormente citados, o sistema todo é integrado e podem ser realizados os testes de sistema que, por ser baseado em critérios funcionais, não apresentam diferenças fundamentais entre o teste procedimental e OO.

Alguns autores entendem que a classe é a menor unidade no contexto de software OO (Arnold \& Fuson, 1994; Binder, 1999; McDaniel \& McGregor, 1994; Perry \& Kaiser, 1990). Nessa direção o teste de unidade poderia envolver o teste intra-método, inter-método e intra-classe e, o teste de integração corresponderia ao teste inter-classe.

Na Tabela 2.1, adaptada de Vincenzi (2000), são sintetizados os tipos de teste de software OO que podem ser aplicados em cada uma das fases de teste considerando o método ou a classe como sendo a menor unidade.

Tabela 2.1: Relação entre Fases de Teste e o Teste de Software OO (Vincenzi, 2000)

\begin{tabular}{|c|c|}
\hline \hline \multicolumn{2}{|c|}{ Menor Unidade: Método } \\
\hline Fase & Teste de Software Orientado a Objetos \\
\hline \hline Unidade & Intra-método \\
\hline Integração & Inter-método, Intra-classe e Inter-classe \\
\hline Sistema & Toda aplicação \\
\hline \hline & Menor Unidade: Classe \\
\hline Fase & Teste de Software Orientado a Objetos \\
\hline \hline Unidade & Intra-método, Inter-método e Intra-classe \\
\hline Integração & Inter-classe \\
\hline Sistema & Toda aplicação \\
\hline \hline
\end{tabular}


No caso desse trabalho, para qualquer referência às fases do teste de software $\mathrm{OO}, \mathrm{o}$ método será considerado como a menor unidade a ser testada.

\subsubsection{Técnicas de Teste de Software Orientado a Objetos}

Conforme mencionado anteriormente, técnicas e critérios de teste têm sido elaborados visando a fornecer uma maneira sistemática e rigorosa para selecionar um subconjunto do domínio de entrada e, ainda assim, ser eficaz para revelar a presença de erros, respeitando as restrições de tempo e custo associados a um projeto de software.

Apesar da grande maioria dos critérios de teste existentes serem para o teste de programas procedimentais, algumas iniciativas de estender esses critérios de teste para o teste de programas OO já são encontradas. Em consonância com essa perspectiva identificam-se vários trabalhos que exploram critérios funcionais e baseado em máquinas de transição de estados (baseados na especificação); e critérios estruturais e baseado em erros (baseados em programas).

Um exemplo de critério de teste funcional para o teste de software OO é o método de partiçãocategoria (Offutt \& Irvine, 1995). Entretanto, visto que tais critérios não dependem do código fonte para serem aplicados e sim da especificação de requisitos, todos os critérios funcionais podem ser aplicados para programas OO (Beizer, 1990).

Observa-se que uma grande quantidade de critérios de teste para validar o aspecto comportamental de programas OO vêm sendo desenvolvidos. Entretanto, com destaca Binder (1996a,b), o teste baseado em estados não detecta todos os tipos de erros, exigindo que critérios de teste complementares, tais como critérios estruturais também sejam desenvolvidos e aplicados para assegurar um teste de melhor qualidade. Nesse sentido, duas estratégias foram desenvolvidas: Free (Binder, 1995) e a teste modal (Binder, 1996b). Embora o foco principal das estratégias de teste Free e teste modal seja o teste baseado em estados, elas também possuem alguns critérios estruturais para o teste de unidade e de integração de uma única classe.

Em complemento aos critérios estruturais, tem-se o trabalho desenvolvido por Harrold \& Rothermel (1994), que estenderam os critérios teste de fluxo de dados para as classes denominado fluxo de dados em classes. Os autores comentam que os critérios de fluxo de dados destinados ao teste de programas procedimentais (Harrold \& Soffa, 1989; Rapps \& Weyuker, 1985) podem ser utilizados tanto para o teste de métodos individuais quanto para o teste de métodos que interagem entre si dentro de uma mesma classe. Entretanto, para testar os métodos que são acessíveis fora da classe e que podem ser utilizados por outras classes, uma nova representação, denominada grafo de fluxo de controle de classe, foi desenvolvida a partir da qual novas associações inter-método e intra-classe podem ser derivadas.

Especificamente no que diz respeito ao teste de programas OO, o teste baseado em erros vem sendo utilizado para o teste de aspectos referentes a concorrência, comunicação entre processos e 
teste de programas Java em nível de unidade e de integração. Kim et al. (1999) utilizaram uma técnica denominada Hazop (Hazzard and Operability Studies) para a definição de um conjunto de operadores de mutação para o teste de programas Java; Ghosh \& Mathur (2001) definiram um conjunto de operadores de mutação visando ao teste de interfaces de comunicação entre componentes distribuídos (CORBA); e Delamaro et al. (2001) se preocuparam em definir operadores específicos para o teste de programas concorrentes implementados em Java.

A Tabela 2.2 sintetiza os principais critérios de teste para programa OO identificados na literatura e as fases de teste nos quais cada um deles pode ser aplicado.

Tabela 2.2: Síntese de Alguns Critérios de Teste para Programas Orientados a Objetos

\begin{tabular}{|c|c|c|c|c|}
\hline \hline \multirow{2}{*}{ Técnica } & \multirow{2}{*}{ Critério } & \multicolumn{3}{|c|}{ Fase } \\
\cline { 3 - 5 } & & Unidade & Integração & Sistema \\
\hline \hline Funcional & Método de Partição-Categoria & $X$ & $X$ & $X$ \\
\hline \multirow{3}{*}{ Estrutural } & Fluxo de Dados & $X$ & $X$ & \\
\cline { 2 - 5 } & Free & $X$ & $X$ & \\
\cline { 2 - 5 } & Teste Modal & $X$ & $X$ & \\
\hline \multirow{2}{*}{$\begin{array}{c}\text { Baseada } \\
\text { em Erros }\end{array}$} & Mutação de Classe & & $X$ & \\
\cline { 2 - 5 } & Mutação em Programas Distribuídos & $X$ & $X$ & $X$ \\
\cline { 2 - 5 } $\begin{array}{c}\text { Baseada } \\
\text { em Estado }\end{array}$ & Mutação em Programas Concorrentes & $X$ & $X$ & $X$ \\
\cline { 2 - 5 } & Free & & & \\
\hline \hline
\end{tabular}

Independentemente do critério de teste utilizado, a existência de ferramentas de teste que apóiem sua aplicação é de fundamental importância. Na próxima seção é apresentado uma breve descrição de algumas ferramentas de teste para programas OO.

\subsubsection{Ferramentas de Teste de Software Orientado a Objetos}

Como mencionado na Seção 2.2.3, a existência de ferramentas é de fundamental importância para a realização da atividade de teste. A seguir é apresentada a descrição de uma série de ferramentas comerciais disponíveis para o teste estrutural de programas $\mathrm{OO}$ escritos em $\mathrm{C}++$ e Java. Essas ferramentas foram obtidas por meio de pesquisa na World Wide Web $(W W W)$ e a descrição apresentada é baseada na documentação existente de cada uma, bem como na execução das mesmas utilizando versões de demonstração que se encontravam disponíveis.

C++ Test (Parasoft Corporation, 2000a) é uma ferramenta de teste de unidade para códigos $\mathrm{C} / \mathrm{C}++$ que executa os seguintes tipos de teste: teste funcional; teste estrutural; e teste de regressão. Esta ferramenta permite aos desenvolvedores testarem suas classes imediatamente após elas terem sido escritas e compiladas através da automatização da criação de driver e de quaisquer stubs necessários, no qual o testador pode personalizar os seus respectivos valores de retorno, ou ainda 
entrar com seus próprios stubs. Esta ferramenta automatiza o teste funcional através da geração automática dos casos de teste e dos resultados esperados, os quais são comparados com os resultados reais. Além disso, o testador pode incluir seus próprios casos de teste e resultados esperados e obter um relatório dos resultados diferentes dos resultados especificados. No teste estrutural, esta ferramenta gera e executa automaticamente casos de teste projetados para testar à classe especificada. Qualquer problema encontrado é assinalado e apresentado em uma estrutura gráfica. Esses casos de teste são automaticamente salvos de forma que eles possam ser usados facilmente no teste de regressão para se ter certeza que modificações nas aplicações não introduzirão novos erros.

JProbe Suite (Gramatech, Inc., 1999) é um conjunto de três ferramentas composto por: JProbe Profiler and Memory Debugger que ajuda a eliminar gargalos de execução causados por algoritmos ineficientes em códigos Java e aponta as causas de perdas de memória nessas aplicações rastreando quais objetos seguram referências para outros; JProbe Threadalyzer que monitora interações entre threads e avisa o testador quando essa interação representar perigo, identificando potenciais perigos de concorrências e deadlocks; e JProbe Coverage que localiza códigos não testados e mede quanto do código está sendo exercitado, permitindo ao testador estimar qual a confiança dos testes executados.

Jtest (Parasoft Corporation, 1999b) é uma ferramenta de teste de classes para códigos Java que executa os seguintes tipos de teste: análise estática; teste funcional; teste estrutural; e teste de regressão. Esta ferramenta pode executar todos esses tipos de teste em uma simples classe ou em um conjunto de classes. No teste funcional, a ferramenta gera automaticamente um conjunto essencial de casos de teste, estrategicamente projetado para alcançar uma cobertura tão completa quanto possível. O testador pode melhorar esse conjunto de casos de teste com seus próprios casos de teste. Em seguida, a ferramenta executa automaticamente todos esses casos de teste e mostra os seus respectivos resultados em uma representação de árvore. O testador pode ainda visualizar esses resultados e validá-los e, quando a ferramenta executar testes subseqüentes nessa classe, a ferramenta será capaz de notificar ao testador quando ocorrerem erros nos testes de regressão e funcional. Esta ferramenta não detecta somente erros, como também pode prevenir erros e assegurar que erros não serão adicionados no código quando ele é modificado de maneira automatizada. A análise estática previne erros padronizando códigos e, que por consequiência, reduz a possibilidade de erros serem inseridos no código.

Panorama C/C++ (International Software Automation, 1999a) e Panorama for Java (International Software Automation, 1999b) é um conjunto de cinco ferramentas composto por: OO-Test; OO-SQA; OO-Analyser; OO-Browser; e OO-Diagrammer. Estas ferramentas são úteis no teste de software, garantia de qualidade e reengenharia e ainda suportam as etapas do projeto de software, codificação e documentação. OO-Test executa a análise de cobertura de arcos, análise das frequiên- 
cias dos arcos executados, análise da eficiência dos casos de teste e minimização do conjunto de casos de teste.

PureCoverage (Rational Software Corporation, 2000a) é uma ferramenta de análise de cobertura para códigos C++ e Java que aponta as áreas do código que foram ou não exercitadas durante os testes. Ela expõe o código não testado em todas as partes da aplicação. Esta ferramenta disponibiliza diversas opções de apresentação que auxiliam ao testador na compreensão de quais partes do código foram ou não testadas através da cobertura de código em arquivos, módulos e linhas de código, permitindo ainda ao testador escolher o nível de cobertura de código por módulos e então focalizar as partes da aplicação que mais lhe interessam.

TCAT C/C++ (Software Research, Inc., 2001a) e TCAT Java (Software Research, Inc., 2001b) é uma ferramenta que fornece medidas para determinar o quanto de código que já foi testado. Esta ferramenta, gera relatórios gráficos e textuais que auxiliam na identificação de que partes do programa foram exercitadas pelos casos de teste.

A xSuds Toolsuite (Agrawal et al., 1998; Telcordia Technologies, Inc., 1998) é um conjunto de sete ferramentas para o entendimento, a análise e o teste de software para códigos $\mathrm{C} / \mathrm{C}++$ composto por: $x A T A C$ que mede o quanto a aplicação está sendo exercitada pelo conjunto de casos de teste, identificando códigos que não foram testados e determinando a cobertura da aplicação com os casos de teste. Essas medidas são usadas para indicar o progresso durante o teste do software e servem de critério de aceitação para subseqüentes estágios do desenvolvimento e da atividade de teste; xRegress que ajuda o testador a identificar um subconjunto representativo de casos de teste que devem ser novamente executados para revalidar as modificações nas aplicações; $x V u e$ que localiza códigos do programa associado a determinadas características. Para determinar onde essas características estão implementadas na aplicação, um pequeno conjunto de casos de teste que envolve a característica deve ser selecionado e executado; $x$ Slice que automatiza e auxilia desenvolvedores na realização da atividade de depuração através da focalização de partes relevante do código; xProf que ajuda desenvolvedores a melhorarem a execução de seus códigos apontando somente as partes relevantes que necessitam ser analisadas, possivelmente reorganizadas e/ou novamente escritas, para que a execução global da aplicação seja melhorada; $x$ Find que localiza regiões de interesse para a realização de testes na aplicação e exporta para as outras ferramentas; e $x$ Diff que mostra diferença entre arquivos, tais como, linhas modificadas, adicionadas ou removidas o que pode ser útil para comparar versões de código, documentos, dados e resultados.

Essas ferramentas serão avaliadas dentro do contexto a ser apresentado no Capítulo 3, com o objetivo de adicionar um conjunto inicial de dados ao ambiente EvalTool proposto. Posteriormente, no Capítulo 4 é apresentado um estudo empírico utilizando algumas dessas ferramentas de teste. 


\subsection{Considerações Finais}

Neste capítulo foi dada uma visão geral a respeito da atividade de teste e da sua importância no processo de desenvolvimento de software. Uma descrição das diversas fases e das principais técnicas e critérios de teste de software também foi apresentada. Considerando o aspecto complementar dessas diferentes técnicas de teste, é importante ressaltar a realização de estudos teóricos e empíricos que visam a comparar os critérios de teste de modo a estabelecer uma estratégia que combine os benefícios de cada uma das técnicas e seja eficaz em revelar a presença de erros, ao mesmo tempo em que apresente um baixo custo de aplicação. Em seguida ressaltou-se a importância da automatização da atividade de teste tanto para permitir a aplicação prática dos critérios de teste e a transferência tecnológica para a indústria, como para dar suporte à realização de estudos empíricos e ao teste de regressão.

Além disso foram apresentadas a terminologia e as definições relacionadas com à orientação a objetos. Foram discutidos quais os problemas do teste de software no contexto de programas OO. Alguns dos critérios de teste de software OO, tanto baseado em especificação quanto baseado em programas, também foram apresentados. Finalmente, algumas das ferramentas de teste que apóiam a aplicação do teste estrutural de programas $\mathrm{OO}$ foram descritas de modo a dar uma visão geral das características básicas que essas ferramentas oferecem.

No próximo capítulo são apresentadas a definição e a implementação do ambiente EvalTool para ferramentas de teste de software OO utilizando o método OOHDM. 


\section{CAPÍTULO \\ 3 \\ Ferramentas de Teste de Software 00: Definição do Ambiente EvalTool}

\subsection{Considerações Iniciais}

Conforme destacado anteriormente, o uso de ferramentas propicia uma maior qualidade e produtividade para o teste de software. Entretanto, identificar a ferramenta de teste que melhor se enquadre às necessidades de uma empresa desenvolvedora de software não é uma atividade trivial. Devido à diversidade de ferramentas existentes, tanto em termos de custo e recursos disponíveis, como dos critérios de teste existentes, essa escolha envolve, em certos casos, a disponibilidade de recursos humanos e financeiros específicos para essa tarefa.

Nesse contexto, a seguir é apresentado a definição e o processo de desenvolvimento de um ambiente de apoio à avaliação e seleção para ferramentas de teste de software OO com interface para a $W W W$ denominado EvalTool. Este ambiente tem como objetivo auxiliar empresas desenvolvedoras de software, principalmente as micro e pequenas empresas, na seleção de ferramentas de teste, em virtude dessas, muitas vezes, não possuírem recursos humanos e financeiros para serem investidos em inovação tecnológica nessa área. 


\subsection{Definição do Ambiente EvalTool}

O ambiente EvalTool proposto é composto por quatro módulos. O primeiro apresenta um questionário de avaliação que visa a obter diversos dados dos fabricantes sobre as suas respectivas ferramentas de apoio ao teste de software. A partir dos dados presentes num questionário de avaliação, o segundo módulo possibilita a adição de revisões de usuários sobre esse dados. O terceiro, possibilita a descrição de avaliações comparativas realizadas envolvendo as ferramentas de teste, visando a fornecer informações sobre estudos comparativos entre critérios e ferramentas de teste. Finalmente, o último módulo apresenta diversos resultados estatísticos provenientes dos dados do questionário de avaliação. A seguir é apresentado cada um desses módulos do ambiente EvalTool.

\subsubsection{Questionário de Avaliação}

Esse questionário de avaliação foi baseado no questionário elaborado pelo Grupo de Trabalho para Teste de Programas Orientados a Objetos da Sociedade Alemã de Computação (Diening et al., 1999), o qual, originalmente, era composto por oito categorias contendo várias questões de múltipla escolha em cada uma delas. Entretanto, com base nas experiências do grupo de Engenharia de Software do ICMC-USP (Colanzi, 1999; Vincenzi, 2000) e, considerando o método como a menor unidade a ser testada, as categorias referente ao teste de classe, hierarquia e cluster do questionário original foram agrupadas em uma única categoria denominada teste de integração. Além disso, uma nova categoria foi adicionada referente a informações sobre o suporte que uma determinada ferramenta oferece a experimentação. Finalmente, o questionário de avaliação ficou dividido em seis categorias mantendo a maior parte das questões de múltipla escolha apresentadas no questionário original. Algumas questões foram adicionadas e outras reposicionadas devido a nova divisão do questionário de avaliação.

A primeira categoria, preocupa-se com informações gerais sobre as ferramentas, tais como, informações administrativas, custo, plataforma, capacidade de integração da ferramenta no ambiente de desenvolvimento, ambiente e linguagem de programação, entre outras. Posteriormente, são apresentadas três categorias, que correspondem ao suporte as diversas fases da atividade de teste, ou seja, unidade, integração e sistema. Finalmente, as duas últimas categorias apresentam informações sobre o teste de regressão e o suporte a experimentação. O questionário completo encontra-se no Apêndice A.

Como mencionado anteriormente, as ferramentas de teste de software OO apresentadas na Seção 2.3.5 foram avaliadas segundo o questionário de avaliação do Apêndice A e os dados obtidos foram adicionados nesse módulo do ambiente EvalTool, os quais podem ser consultados em http: //sapiens07.icmc.sc.usp.br/ aluis/EvalTool/submittedqr. 
php. Para a obtenção desses dados os manuais de usuários das ferramentas de teste foram examinados e algumas mensagens eletrônicas foram enviados aos fabricantes e/ou representantes. Esses dados foram verificados por meio da utilização das versões de avaliação das respectivas ferramentas utilizando o programa fonte de ordenação descrito na Seção 4.2.1 e mais alguns programas fontes exemplos disponibilizados pelos fabricantes quando alguma característica específica da ferramenta não podia ser verificada com esse programa fonte de ordenação.

\subsubsection{Revisões de Usuários}

A partir de qualquer questionário de avaliação para ferramentas de teste inserido no ambiente EvalTool, um usuário pode inserir uma série de revisões, tais como, sugestões, críticas, informações adicionais e/ou comentários sobre experiências obtidas com o uso da ferramenta de teste para cada uma das respostas fornecidas pelos fabricantes. Essas informações serão coletadas no decorrer do tempo e são de grande importância para o apoio à seleção de ferramentas de teste por parte dos usuários e também no aperfeiçoamento e/ou criação de ferramentas por parte dos fabricantes. Os dados adicionados a este módulo do ambiente de avaliação podem ser consultados juntamente com os questionários de avaliação em http://sapiens07.icmc.sc.usp.br/ aluis/ EvalTool/submittedqr.php

\subsubsection{Avaliações Comparativas}

A disponibilidade de ferramentas de teste viabilizam a realização de avaliações comparativas. Por outro lado, as avaliações comparativas fornecem uma variedade de informações sobre as critérios e ferramentas de teste, sendo assim informações importantes aos diversos tipos de usuários do ambiente EvalTool. Além disso, a pessoa que conduz uma avaliação comparativa envolvendo qualquer ferramenta de teste inserida no ambiente EvalTool pode atribuir uma nota para cada uma dessas ferramentas de teste.

No Capítulo 4 é apresentado a descrição de duas avaliações realizadas com o objetivo de realizar uma comparação entre as ferramentas de teste; e identificar diferenças na aplicação de critérios de teste em diferentes linguagens de programação OO. As informações obtidas nessas avaliações comparativas, os programas fontes e os casos de teste utilizados foram adicionadas nesse módulo do ambiente EvalTool e também podem ser consultados em http : / / sapiens 07 . icmc.sc.usp.br/ aluis/EvalTool/submitteds.php. 


\subsubsection{Coleta e Análise dos Dados}

Este módulo do ambiente EvalTool tem por objetivo apresentar uma série de resultados estatísticos baseados nos dados obtidos nos módulos anteriores. Alguns exemplos das informações coletadas até o presente momento são descritos a seguir.

As duas primeiras informações obtidas do questionário de avaliação são quantas e quais ferramentas de teste suportam uma determinada linguagem de programação e plataforma de desenvolvimento, cujos dados são apresentados nos gráficos das Figuras 3.1 e 3.2, respectivamente.

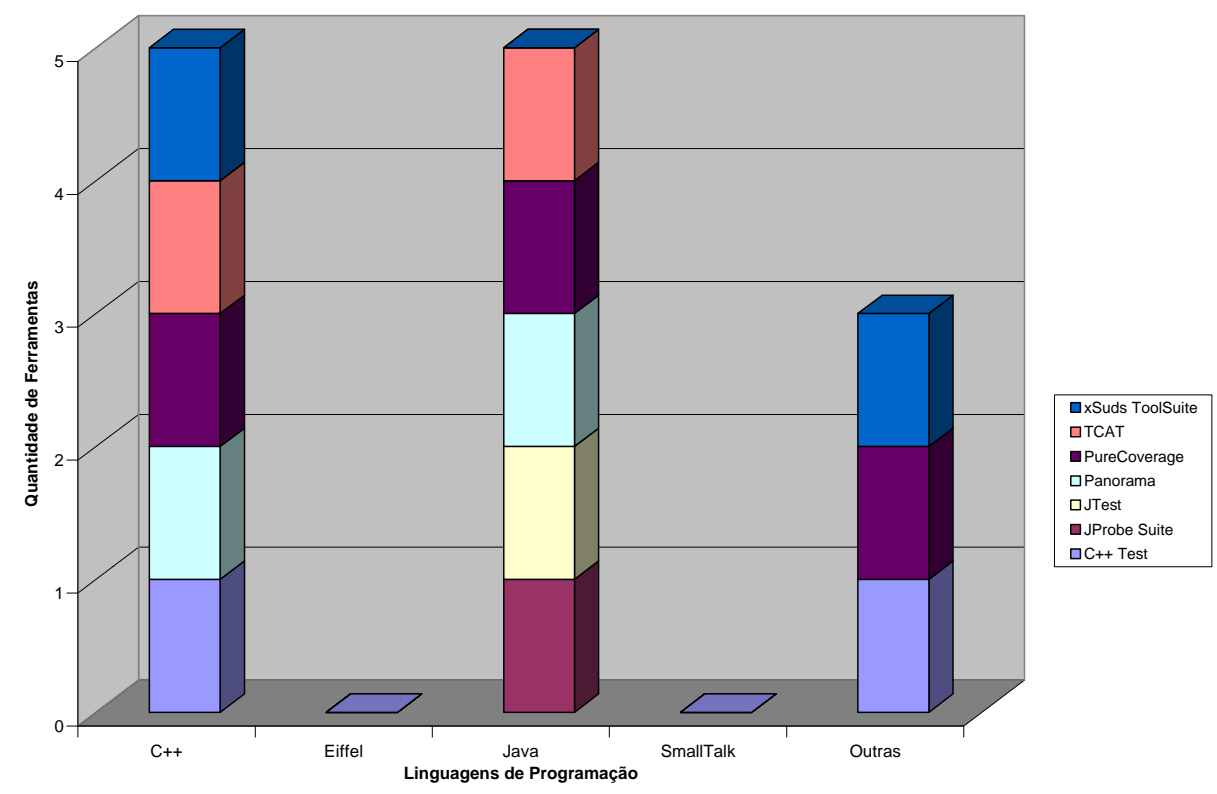

Figura 3.1: Gráfico do Suporte às Linguagens de Programação

Para a avaliação das ferramentas de teste por meio do questionário apresentado no Apêndice A e para a realização dos experimentos descritos no Capítulo 4, a linguagem de programação foi um dos critérios de seleção de ferramentas de teste. Entretanto, mesmo esse critério especificando que as ferramentas de teste deveriam dar suporte as linguagens $C++$ e/ou Java, algumas ferramentas suportam outras linguagens de codificação, tais como $C$ e Visual Basic. Esse critério de seleção foi responsável pela ausência de ferramentas de teste que suportam outras linguagens de programação OO, tais como Eiffel e Smalltalk.

Em complemento às informações do gráfico da Figura 3.2, a ferramenta $C++$ Test possui um módulo adicional para coleta de informações referente ao desempenho e uso de memória denominado Insure++. Entretanto, esse módulo funciona somente na plataforma Windows NT-2000. 


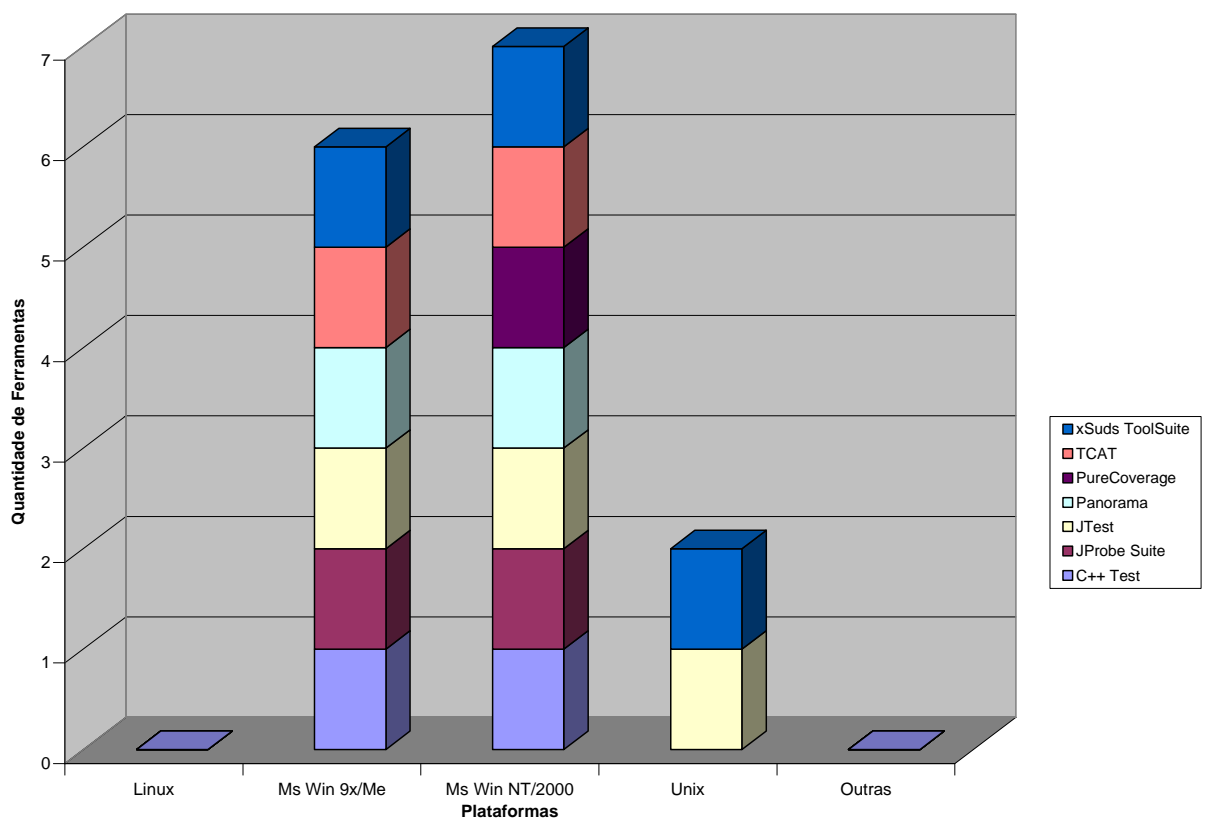

Figura 3.2: Gráfico do Suporte às Plataformas de Desenvolvimento

Além do suporte às linguagens de programação e plataforma de desenvolvimento, o suporte às categorias de teste também podem ser vistos sob dois aspectos: o percentual que cada ferramenta satisfaz em cada categoria de teste e o percentual médio acumulado que todas as ferramentas exibem em cada categoria de teste, apresentados nos gráficos das figuras 3.3(a) e 3.3(b), respectivamente.

Para a obtenção do percentual apresentado no gráfico da Figura 3.3(a) utilizou-se a razão dos requisitos satisfeitos por uma ferramenta de teste pelo total de requisitos da categoria analisada. A média dos percentuais entre todas as ferramentas de teste para cada categoria formam os dados para o gráfico da Figura 3.3(b). Observa-se nesses gráficos uma grande variação nos resultados das diversas categorias entre as diversas ferramentas de teste, mas de maneira geral, as ferramentas apresentam pouco ou nenhum suporte a fase do teste de integração. Esse fator deve ser considerado pelos fabricantes de ferramentas de teste, visto que uma série de critérios para esse fim foram definidos por diversos pesquisadores, como apresentado na Seção 2.3.4.

A última informação apresentada, obtida a partir do questionário de avaliação, é o suporte que as ferramentas de teste possuem em relação à características básicas da orientação a objetos, tais como encapsulamento, herança e polimorfismo. O suporte a uma característica da orientação a objetos significa que a ferramenta satisfez pelo menos um requisito associado a essa característica. O gráfico da Figura 3.4 apresenta quantas e quais ferramentas suportam essas características. 


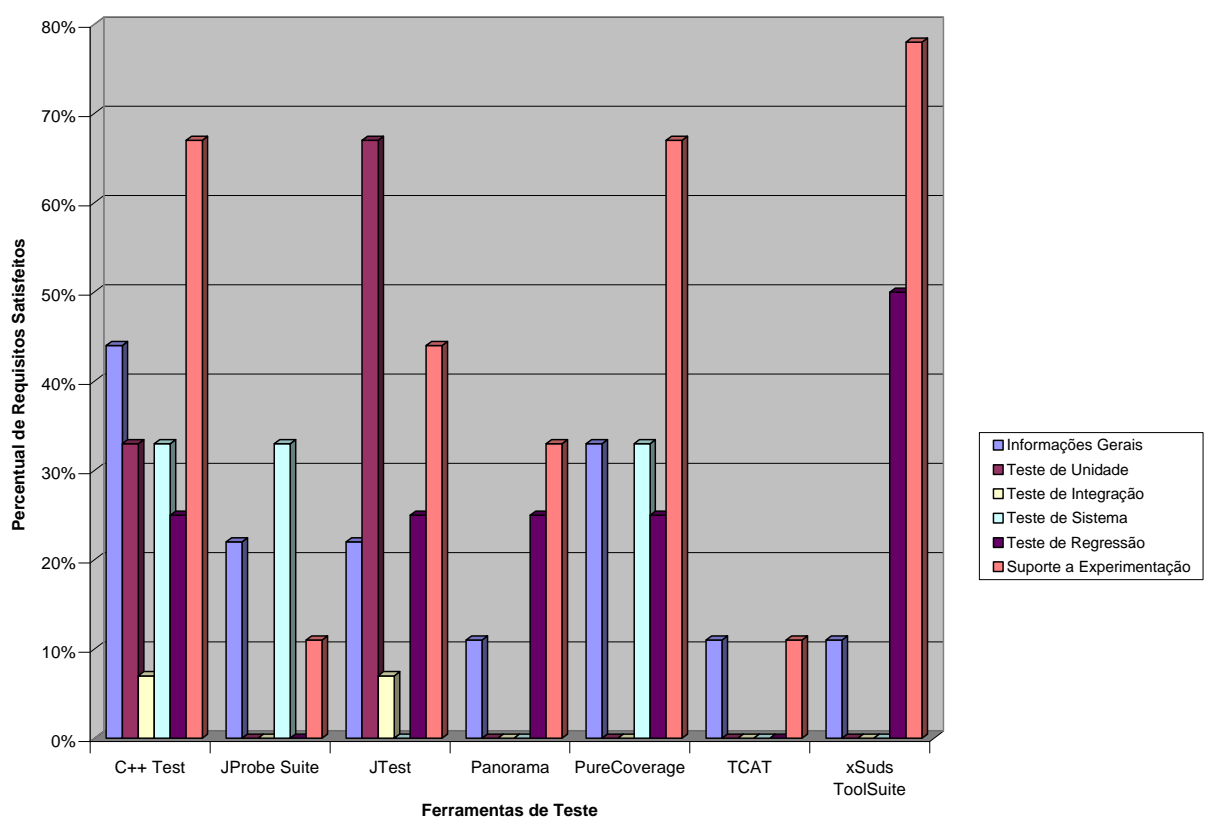

(a) Por Ferramenta

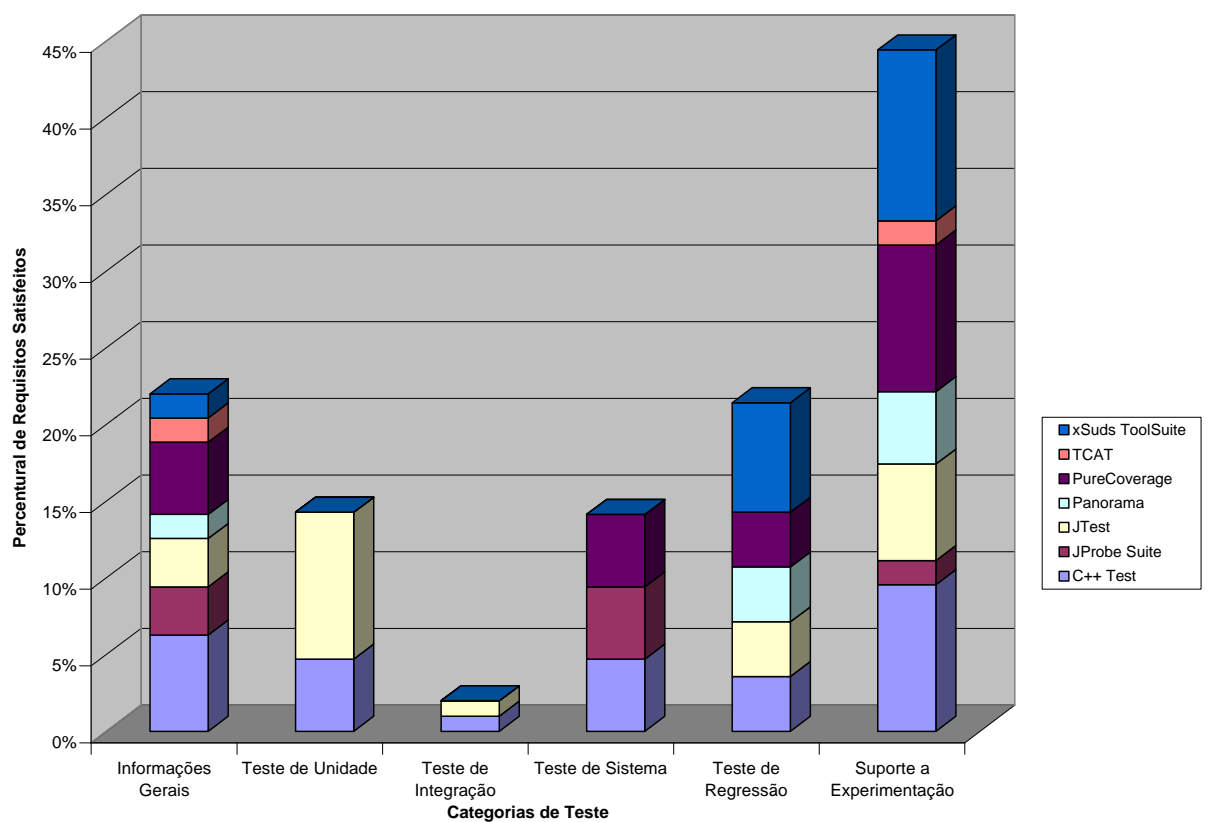

(b) Por Categoria

Figura 3.3: Gráfico do Suporte às Categorias de Teste 


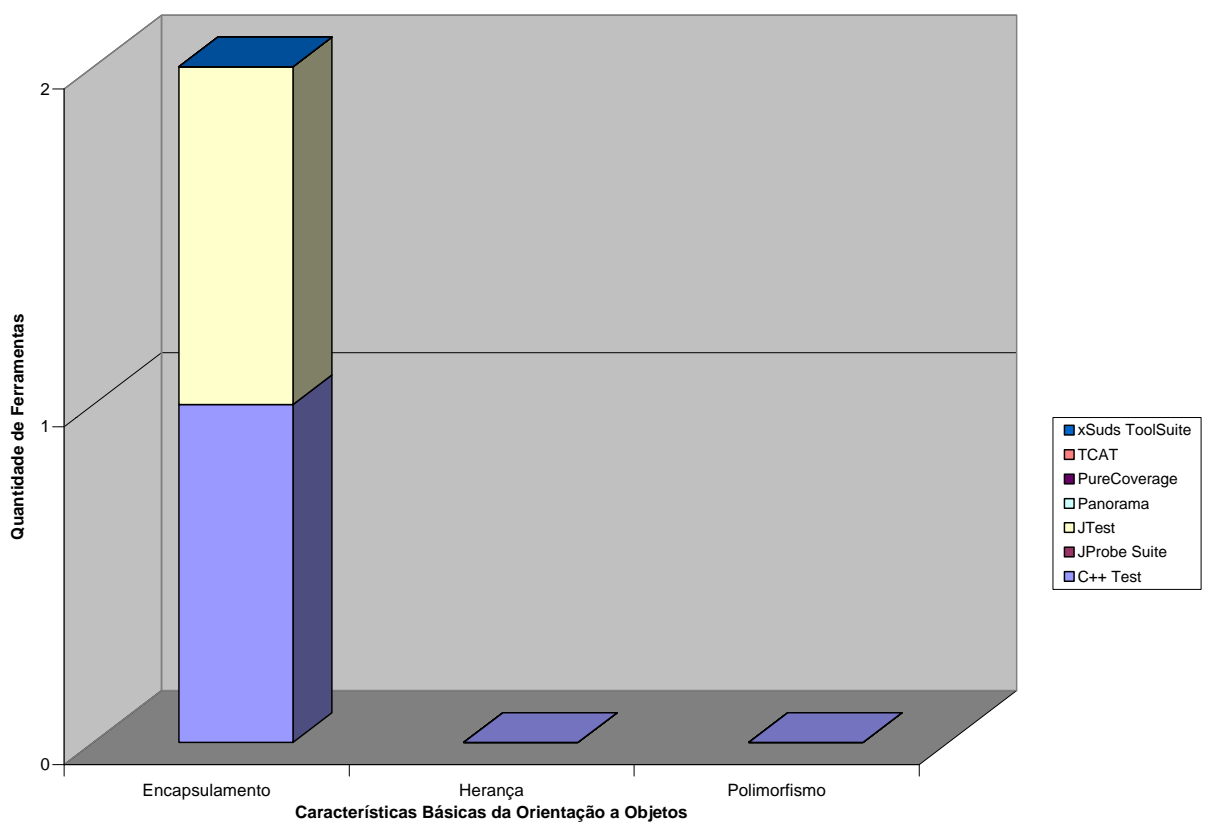

Figura 3.4: Gráfico do Suporte às Características da Orientação a Objetos

Como descrito anteriormente na Seção 2.3.2, essas características da orientação a objetos podem causar uma série de problemas ou dificuldades na condução da atividade de teste, entretanto, como apresentado no gráfico da Figura 3.4, apenas as ferramentas de Teste $C++$ Test e JTest apresentam suporte a característica de encapsulamento da orientação a objetos. As demais características, como herança e polimorfismo não são suportadas por nenhuma das ferramentas de teste.

Esses dados também podem ser consultados em http://sapiens07.icmc.sc.usp. br/ aluis/EvalTool/results.php. A seguir, é apresentado o processo de desenvolvimento para a implementação do ambiente EvalTool.

\subsection{Processo de Desenvolvimento}

O processo de desenvolvimento do ambiente EvalTool foi baseado no método OOHDM (ObjectOriented Hypermedia Design Method), o qual é voltado para a construção de aplicações hipermídia OO. Compreende quatro fases de desenvolvimento: projeto conceitual, projeto navegacional, projeto de interface abstrata e implementação (Rossi, 1996). As atividades de cada fase são executadas ao longo de um ciclo de desenvolvimento que permite processos iterativos, incrementais e de prototipação. A Tabela 3.1 apresenta resumidamente as fases, os produtos, os mecanismos e os interesses do projeto abordados pelo método OOHDM. 
Tabela 3.1: Sumário das Fases do Método OOHDM (Rossi, 1996)

\begin{tabular}{|c|c|c|c|}
\hline Fases & Produtos & Mecanismos & $\begin{array}{l}\text { Interesses do } \\
\text { Projeto }\end{array}$ \\
\hline $\begin{array}{c}\text { Projeto } \\
\text { Conceitual }\end{array}$ & $\begin{array}{c}\text { Classes, subsistemas, } \\
\text { relacionamentos e } \\
\text { perspectivas de } \\
\text { atributos }\end{array}$ & $\begin{array}{l}\text { Classificação, } \\
\text { composição, } \\
\text { generalização e } \\
\text { especialização }\end{array}$ & $\begin{array}{c}\text { Modela a semântica } \\
\text { do domínio de } \\
\text { aplicação }\end{array}$ \\
\hline $\begin{array}{l}\text { Projeto de } \\
\text { Navegação }\end{array}$ & $\begin{array}{l}\text { Nós, ligações, } \\
\text { estruturas de acesso, } \\
\text { contextos de } \\
\text { navegação e } \\
\text { transformações } \\
\text { navegacionais }\end{array}$ & $\begin{array}{l}\text { Mapeamento entre } \\
\text { objetos conceituais e } \\
\text { de navegação Padrões } \\
\text { de navegação para a } \\
\text { descrição da estrutura } \\
\text { geral da aplicação }\end{array}$ & $\begin{array}{l}\text { Considera o perfil do } \\
\text { usuário e as tarefas; } \\
\text { enfatiza os aspectos } \\
\text { cognitivos e } \\
\text { arquiteturais }\end{array}$ \\
\hline $\begin{array}{l}\text { Projeto de } \\
\text { Interface } \\
\text { Abstrata }\end{array}$ & $\begin{array}{l}\text { Objetos de interface } \\
\text { abstrata, reações a } \\
\text { eventos externos e } \\
\text { transformações de } \\
\text { interface }\end{array}$ & $\begin{array}{l}\text { Mapeamento entre } \\
\text { objetos de navegação } \\
\text { e objetos de interface }\end{array}$ & $\begin{array}{c}\text { Modela objetos } \\
\text { perceptíveis, } \\
\text { implementa metáforas } \\
\text { escolhidas, descreve a } \\
\text { interface para objetos } \\
\text { navegacionais }\end{array}$ \\
\hline Implementação & Aplicação executável & $\begin{array}{c}\text { Recursos fornecidos } \\
\text { pela plataforma de } \\
\text { destino }\end{array}$ & $\begin{array}{l}\text { Promove o } \\
\text { desempenho e a } \\
\text { completitude }\end{array}$ \\
\hline
\end{tabular}

A seguir é apresentada cada uma dessas fases, como os respectivos modelos elaborados para o ambiente EvalTool.

\subsubsection{Modelagem do Domínio}

Durante o projeto conceitual, um modelo do domínio da aplicação é construído de acordo com os princípios da orientação a objetos, acrescidos de algumas primitivas, tais como, perspectivas de atributos e subsistemas, usando uma notação semelhante à $U M L$. O resultado desta fase é um esquema composto por subsistemas, classes e relacionamentos. Os mecanismos de agregação e generalização/especialização podem ser usados para especificar classes conceituais. O principal objetivo dessa etapa é capturar a semântica do domínio da aplicação, sem qualquer preocupação com os tipos de usuários ou tarefas do produto final. A Figura 3.5 apresenta o esquema conceitual para o ambiente EvalTool.

O ambiente EvalTool proposto tem por objetivo avaliar ferramentas de teste para programas OO. Entretanto, essa modelagem do domínio apresentada pode ser utilizada em qualquer contexto de avaliação de ferramentas de teste, independentemente da orientação a objetos, pois a única alteração necessária para sua reutilização é a reformulação das questões do questionário de avaliação, que na Figura 3.5 é apresentado de maneira genérica. 


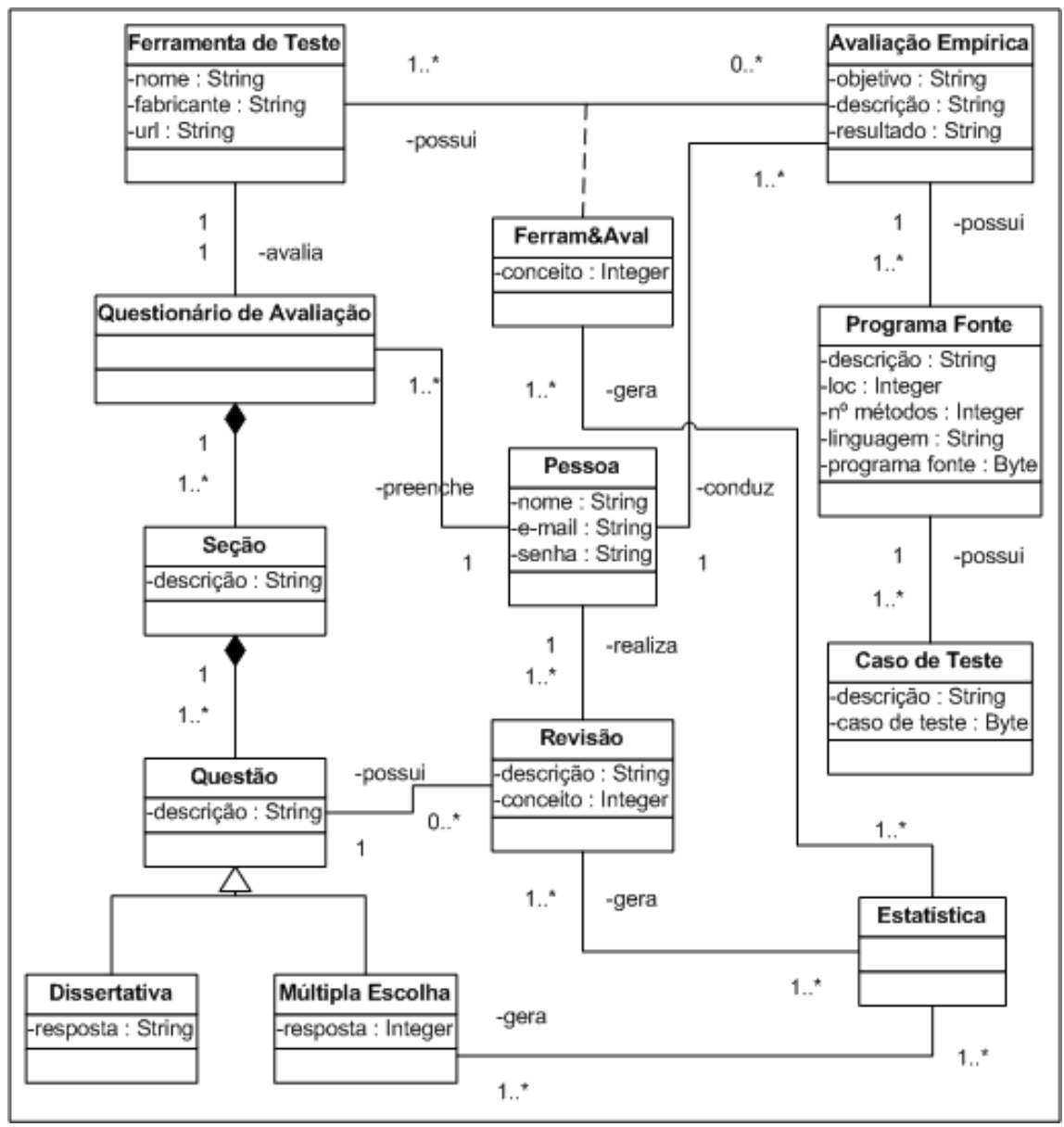

Figura 3.5: Esquema Conceitual do Ambiente EvalTool

\subsubsection{Projeto Navegacional}

Uma aplicação é vista no $O O H D M$ como uma visão navegacional do modelo conceitual. Essa visão é construída durante o projeto de navegação, considerando-se agora os tipos de usuários aos quais a aplicação se destina e o conjunto de tarefas que deverão ser desempenhadas pela mesma. Diferentes modelos navegacionais podem ser construídos para o mesmo esquema conceitual, expressando, dessa forma, visões diferenciadas do mesmo domínio. Observa-se, portanto, a existência dos seguintes usuários no ambiente EvalTool: a pessoa que preenche o questionário de avaliação, normalmente relacionada ao fabricante e/ou distribuidor; a pessoa que realiza revisões sobre os dados de um determinado questionário, normalmente um usuário da ferramenta; a pessoa que conduz avaliações comparativas; e a pessoa interessada em consultar esses dados, normalmente uma pessoa interessada em adquirir uma ferramenta de teste ou um fabricante que deseja obter informações do que os usuários estão interessados ou o que tipo de produto já existe disponível no mercado consumidor. A Figura 3.6 apresenta o esquema de classes navegacionais do ambiente EvalTool para cada uma das visões acima mencionadas. 


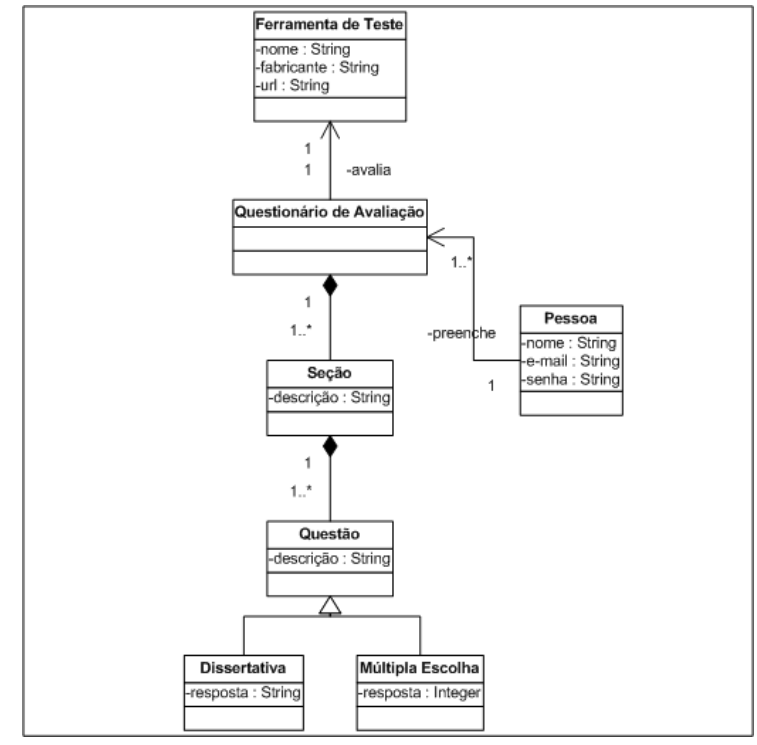

(a) Preenchimento de Questionários

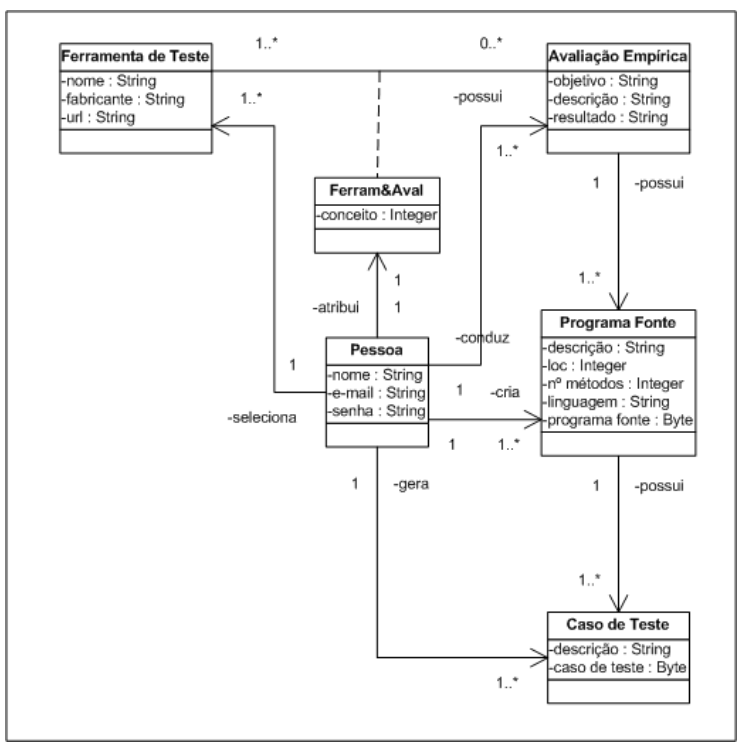

(c) Condução de Avaliações Comparativas

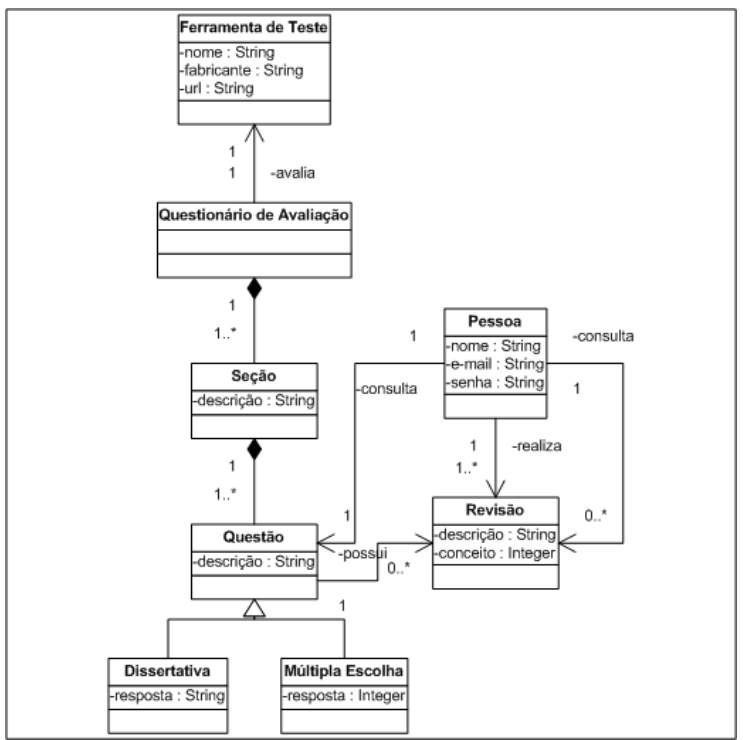

(b) Realização de Revisões

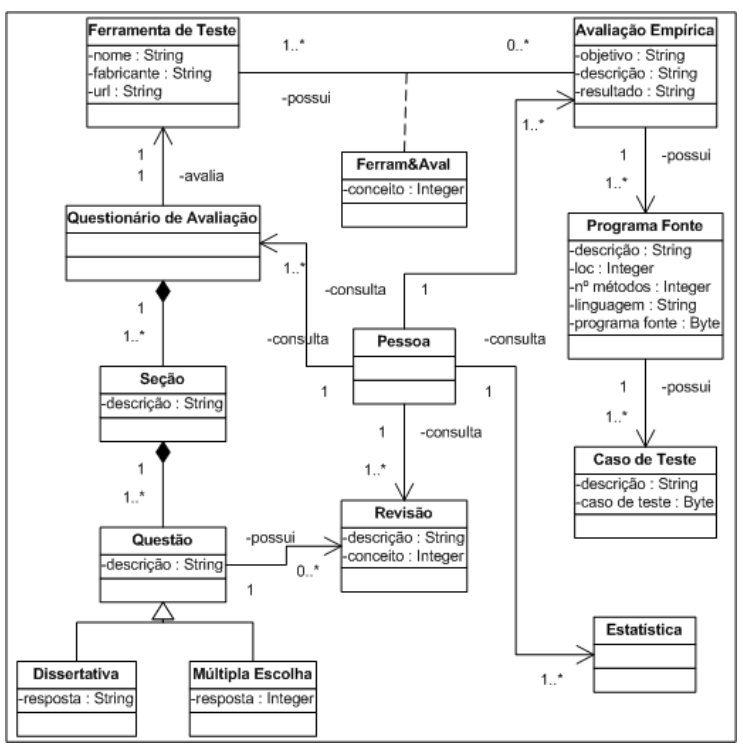

(d) Realização de Consultas aos Dados

Figura 3.6: Esquema de Classes Navegacionais do Ambiente EvalTool

A estrutura navegacional da aplicação é definida em termos de contextos de navegação, que são induzidos a partir de classes navegacionais, tais como, nós, ligações, âncoras e estruturas de acesso, refletindo a visão escolhida. Os contextos navegacionais expressam a estrutura navegacional da aplicação, enquanto as classes especificam os objetos que serão visualizados pelo usuário. A Figura 3.7 apresenta a estrutura navegacional para o ambiente EvalTool. 


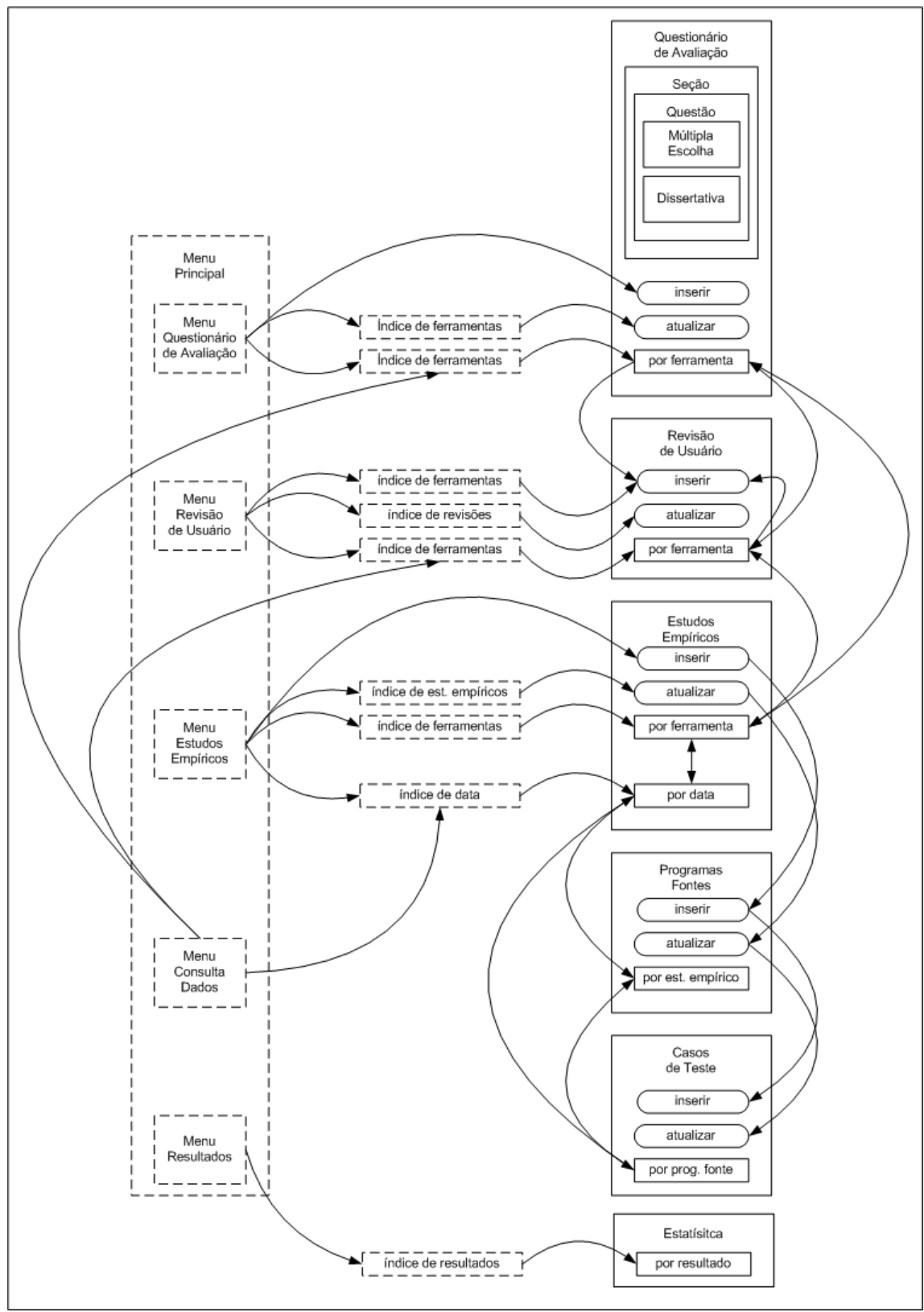

Figura 3.7: Estrutura Navegacional do Ambiente EvalTool

Como pode ser observado na Figura 3.7, a partir do menu principal, o usuário pode escolher entre inserir, alterar ou consultar os questionários de avaliação, revisões de usuários e/ou avaliações comparativas. Como exemplo, a partir do menu do questionário de avaliação, o usuário pode inserir um novo questionário de avaliação, ou por meio de um índice de ferramentas por ele inseridas, selecionar qual questionário deseja alterar e, finalmente, por meio de um índice geral de ferramentas, consultar os dados dos questionários de avaliação. A partir dessa consulta, o usuário pode consultar revisões de usuários ou avaliações comparativas referente a uma determinada ferramenta. 


\subsubsection{Projeto de Interface Abstrata}

Durante o projeto de interface abstrata, um modelo de interface é construído. Tal modelo especifica os objetos de interface que serão visualizados pelo usuário, a forma pela qual esses objetos serão apresentados, quais objetos ativarão a navegação, o modo como os objetos multimídia serão sincronizados e quais transformações ocorrerão na interface. A separação entre interface abstrata e modelo de navegação permite a construção de diferentes interfaces para o mesmo modelo navegacional, o que torna o projeto mais flexível quanto às necessidades ou preferências dos usuários e quanto à tecnologia utilizada para a construção da interface.

Para a especificação de interfaces em OOHDM, são usados ADV's (Abstract Data Views). Os $A D V$ 's são modelos que têm como objetivo separar o projeto de interface da implementação, proporcionando maior reusabilidade. Os $A D V$ 's definem os aspectos estáticos dos objetos de interface, o modo como esses objetos estão relacionados aos objetos navegacionais e como reagem a eventos externos. A Figura 3.8 apresenta o $A D V$ de mais alto nível para o ambiente EvalTool que representa a estrutura geral dos $A D V$ 's. Esse $A D V$ é uma composição de diversos $A D V$ 's, incluindo a Tela Principal, Questionário de Avaliação, Revisão de Usuário, Avaliação Comparativa, Consulta Dados e Resultados, além do Menu Superior e Inferior que são sensíveis ao contexto da informação que está sendo apresentada.

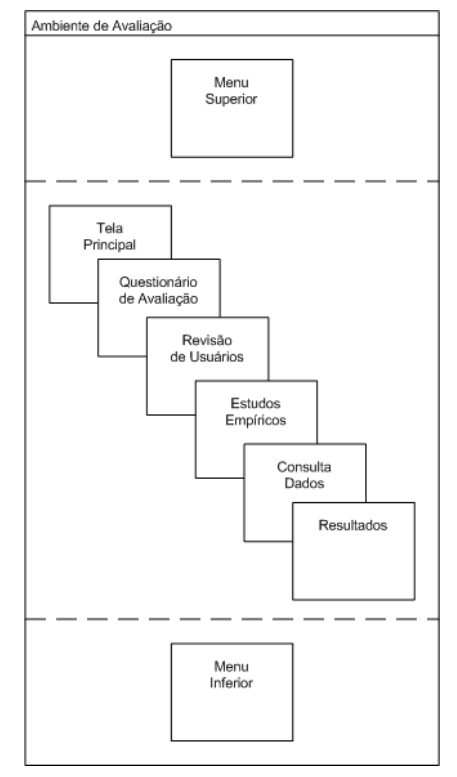

Figura 3.8: ADV do Ambiente EvalTool

A Figura 3.9 detalha os $A D V$ 's presentes no $A D V$ do ambiente EvalTool apresentado na Figura 3.8. Cada um desses $A D V$ 's possuem uma série de tipos de $A D V$ 's, como por exemplo, textos estáticos, textos provenientes de classes, textos ancorados, entre outros. 


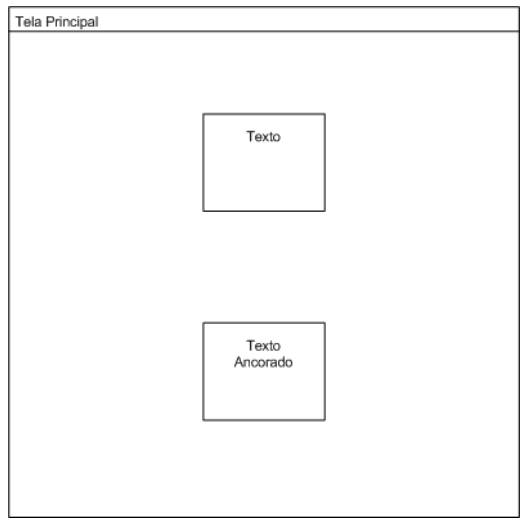

(a) ADV Tela Principal

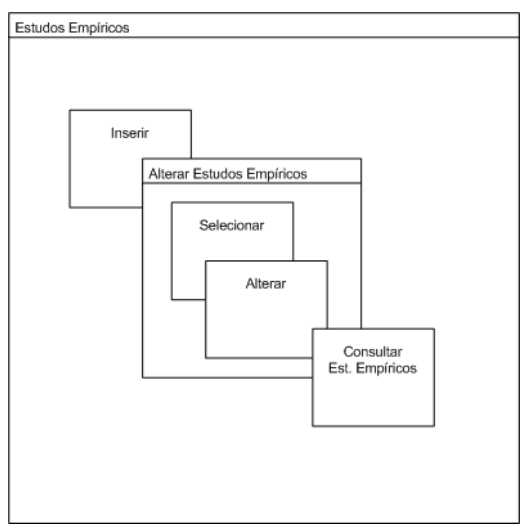

(d) ADV Avaliação Comparativa

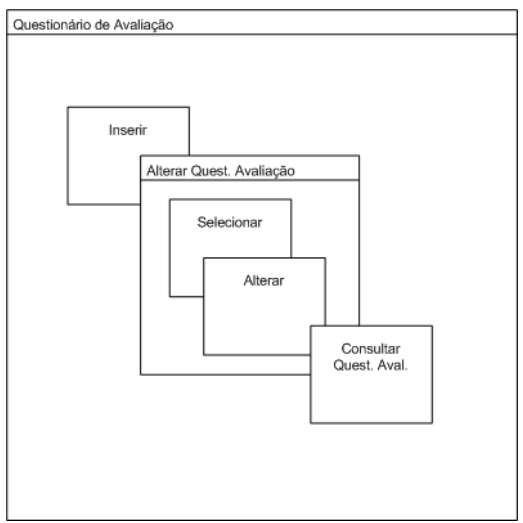

(b) ADV Quest. Avaliação

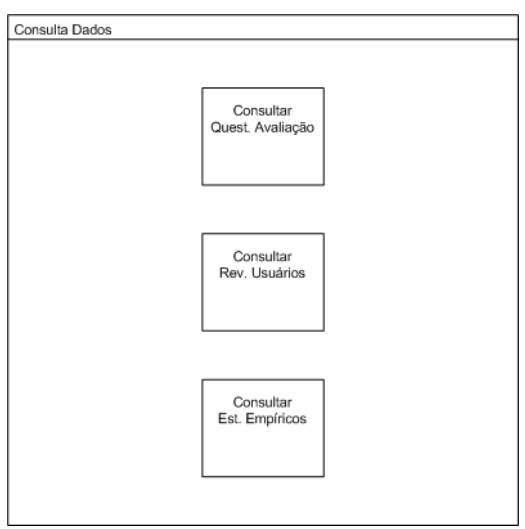

(e) ADV Consulta Dados

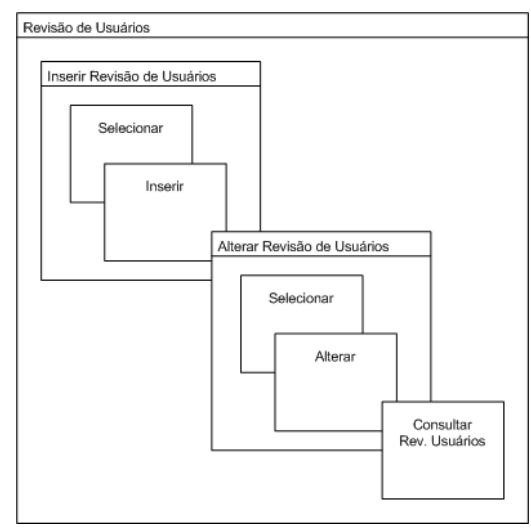

(c) ADV Revisão de Usuário

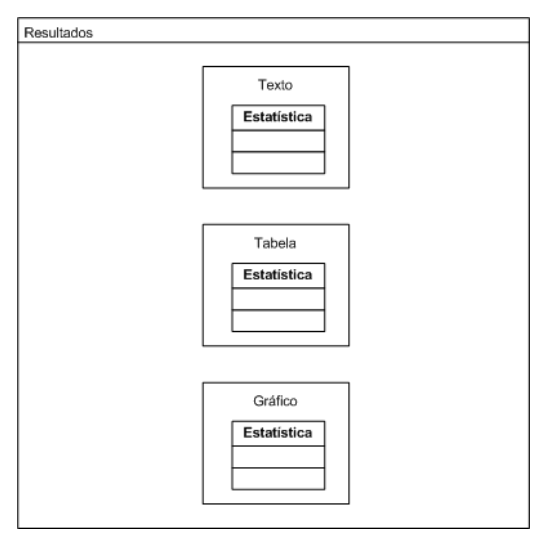

(f) ADV Resultados

Figura 3.9: ADV's Tela Principal, Questionário de Avaliação, Revisão de Usuário, Avaliação Comparativa, Consulta Dados e Resultados

As Figura 3.10 e 3.11 apresentam os $A D V$ 's de mais baixo nível para o ambiente EvalTool e cujos aspectos dinâmicos serão apresentados a seguir.

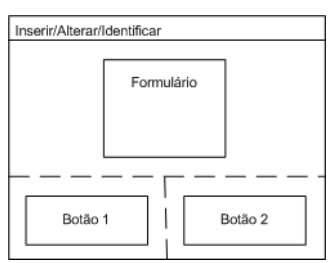

(a) ADV Inserir/Alterar/Identificar

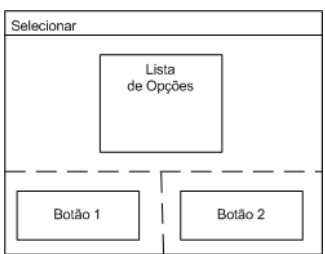

(b) ADV

Selecionar

Figura 3.10: ADV's Inserir, Alterar, Identificar e Selecionar 


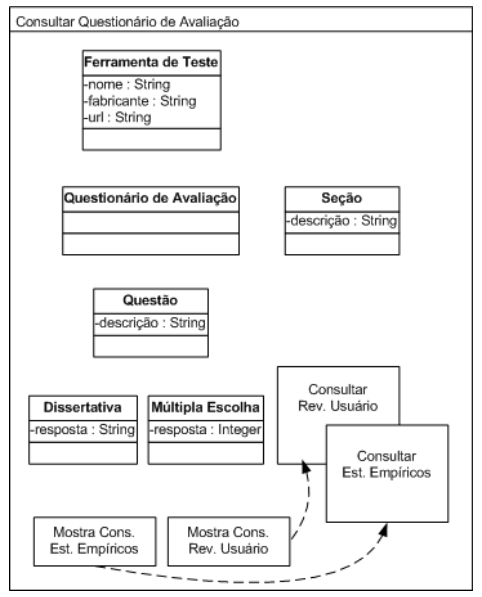

(a) ADV Consultar Questionário de Avaliação

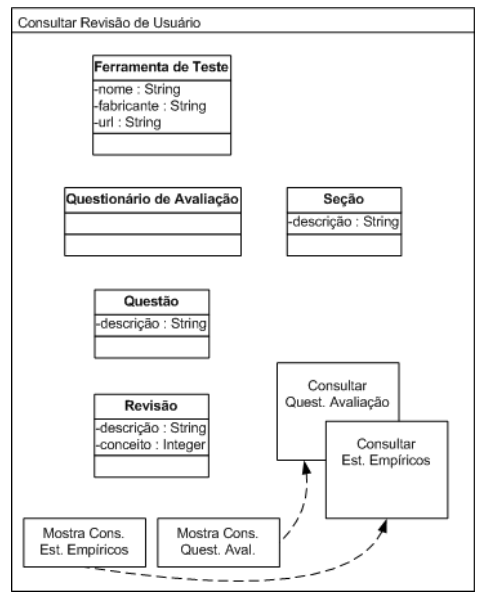

(b) ADV Consultar Revisão de Usuário

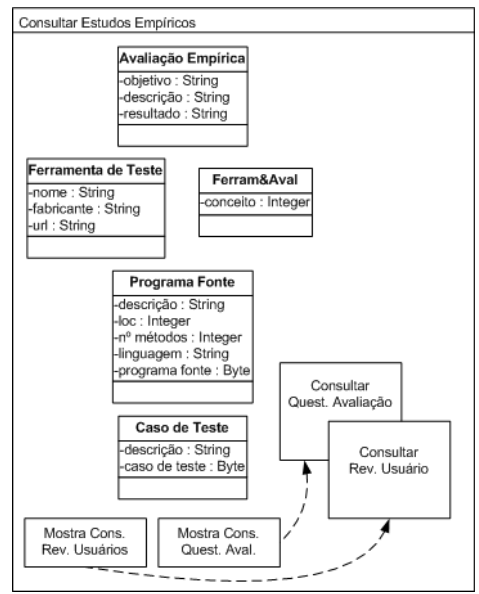

(c) ADV Consultar Avaliação Comparativa

Figura 3.11: ADV's Consultar Questionário de Avaliação, Revisão de Usuário e Avaliação Comparativa

Para a especificação dos aspectos dinâmicos da aplicação são usados $A D V$ Charts. Os $A D V$ 's Charts são uma generalização dos Statecharts, suportando o aninhamento de estados e $A D V$ 's e permitindo a expressão da associação entre eventos externos e $A D V$ 's. Os $A D V$ 's Charts expressam transformações no nível da interface de usuário e seu impacto nos objetos navegacionais. As Figuras 3.12 e 3.13 apresentam os $A D V$ 's Charts para os $A D V$ 's de mais baixo nível do ambiente EvalTool.

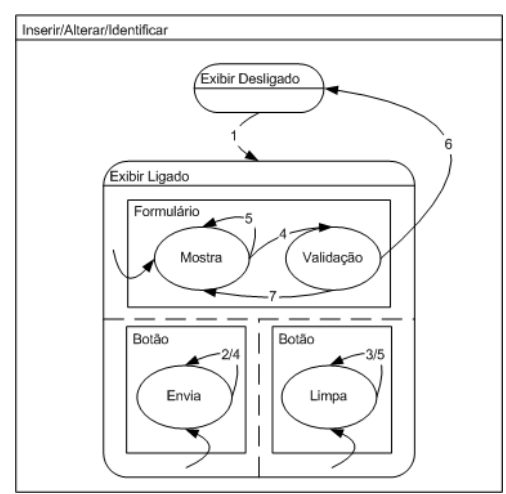

(a) ADV Chart Inserir/Alterar/Identificar

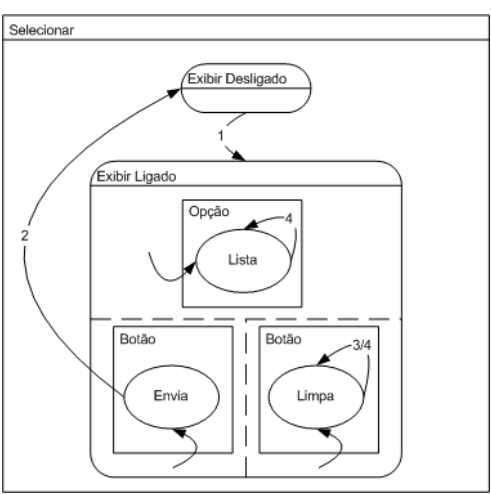

(b) ADV Chart Selecionar

Figura 3.12: ADV's Charts Inserir, Alterar, Identificar e Selecionar 


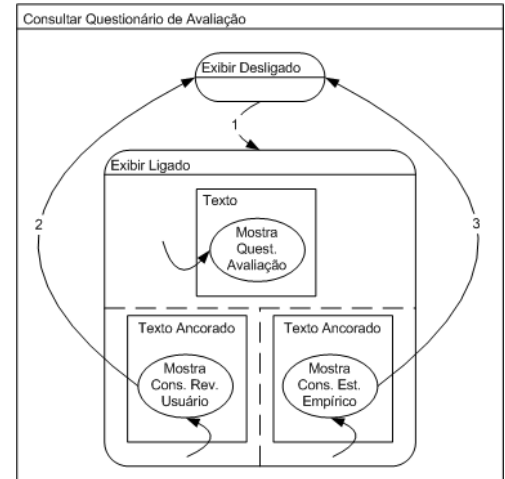

(a) ADV Chart Consultar Questionário de Avaliação

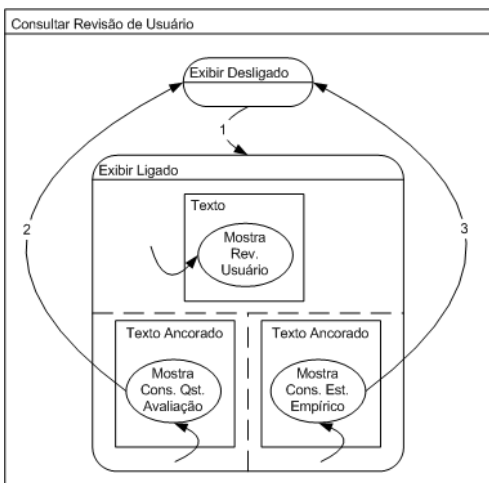

(b) ADV Chart Consultar Revisão de Usuário

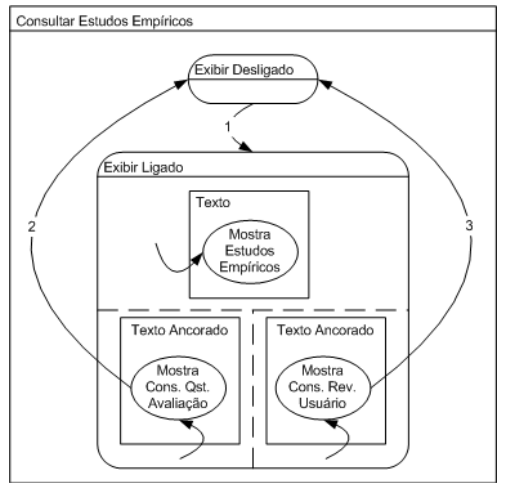

(c) ADV Chart Consultar Avaliação Comparativa

Figura 3.13: ADV's Charts Consultar Questionário de Avaliação, Revisão de Usuário e Avaliação Comparativa

\subsubsection{Implementação}

Os modelos navegacionais e de interface gerados devem ser traduzidos para um ambiente de implementação, produzindo o sistema hipermídia a ser executado. Os modelos gerados podem ser implementados de forma direta sobre plataformas hipermídia disponíveis, tais como, Hypercard, Toolbook e HTML.

Dessa maneira, o ambiente EvalTool foi desenvolvido na linguagem PHP, sobre a plataforma Solaris e, em conformidade com a arquitetura apresentada na Figura 3.14, utiliza o Apache como servidor de $W W W$, o $M y S Q L$ como servidor de banco de dados e a linguagem JavaScript para verificação da consistência de alguns dados de entrada, capturados por meio de um browser nas máquinas clientes.

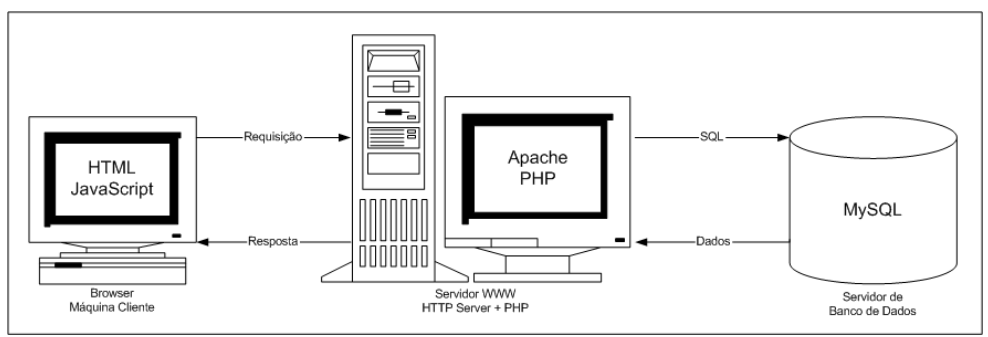

Figura 3.14: Arquitetura Utilizada para a Execução do Ambiente EvalTool

O PHP é uma linguagem de script, cuja sintaxe é baseada nas linguagens $C$, Perl e Java e em primitivas próprias, que permite a criação de aplicações $W W W$ dinâmicas e que possibilita a interação dos usuários por meio de formulários, parâmetros de $U R L$ e ligações. 
O PHP também apresenta vantagens sobre os scripts $C G I$ escritos em $C$ ou Perl pelo fato do seu código ser embutido no próprio código $H T M L$, enquanto, no outro caso, é necessário que o script CGI gere todo o código HTML.

O que diferencia o PHP de linguagens como o JavaScript é o fato do código ser executado pelo servidor e não pelo browser. Desse modo, o código processado gera páginas contendo apenas HTML que são, então, enviadas para o cliente. Com isso os usuários somente têm acesso aos resultados da execução do script PHP e não ao seu código fonte. Isso garante, em parte, a segurança da aplicação.

Uma outra vantagem é a otimização do tempo de resposta ao cliente nos casos em que a base de dados encontra-se na mesma máquina que o servidor de $W W W$, pois todo o processamento ocorre em um mesmo local, eliminando a necessidade de requisições a máquinas remotas. Uma outra característica importante do $P H P$ é a sua simplicidade para a geração de consultas e o seu suporte a vários bancos de dados, tais como, Informix, Ingres, MySQL, Oracle, PostgreSQL, Sybase, entre outros.

O MySQL é um gerenciador e um servidor de banco de dados relacional, implementado em $C$ e $C++$, que utiliza o SQL (Structrued Query Language) padrão para o acesso e a manipulação dos dados armazenados. O MySQL possui as vantagens de ser multiplataforma, podendo ser executado sobre sistemas operacionais como Linux, Unix e Windows, e de possuir o código aberto, podendo ser modificado e adaptado pelos desenvolvedores, de acordo com as necessidades específicas das suas aplicações.

Uma característica do $M Y S Q L$ bastante útil para a implementação de sistemas é a possibilidade de criação de usuários com diferentes níveis ou privilégios de acesso aos dados e de execução das funcionalidade oferecidas pelo servidor. Isso garante, em parte, que as informações armazenadas somente serão modificadas por pessoas autorizadas.

O Apache é um servidor $W W W$ baseado no protocolo HTTP, que pode ser executado e máquinas com os sistemas operacionais Windows, OS/2, Netware e com a maioria das versões do Unix. Sua distribuição é totalmente livre e seu código também é aberto. Arquivos específicos são configurados para que o Apache interprete scripts PHP ou CGI.

Por ter sido implementado em PHP e JavaScript, o ambiente EvalTool pode ser utilizado a partir dos diversos browsers, já que a maioria dos navegadores atuais possuem plug-ins que interpretam a linguagem JavaScript. O código PHP é processado no servidor e, portanto, não exige que nenhum recurso adicional seja instalado nos clientes. 


\subsection{Exemplo de Uso}

A tela principal do ambiente EvalTool, ilustrada na Figura 3.15, possui ligações que possibilitam o acesso à tela do questionário de avaliação, revisão de usuário, avaliação comparativa, consulta a dados e resultados. Esta interface corresponde ao nodo raiz ou nodo default da aplicação e o conjunto de ligações desse nodo forma um menu que permite a navegação pelos diversos contextos de informações.

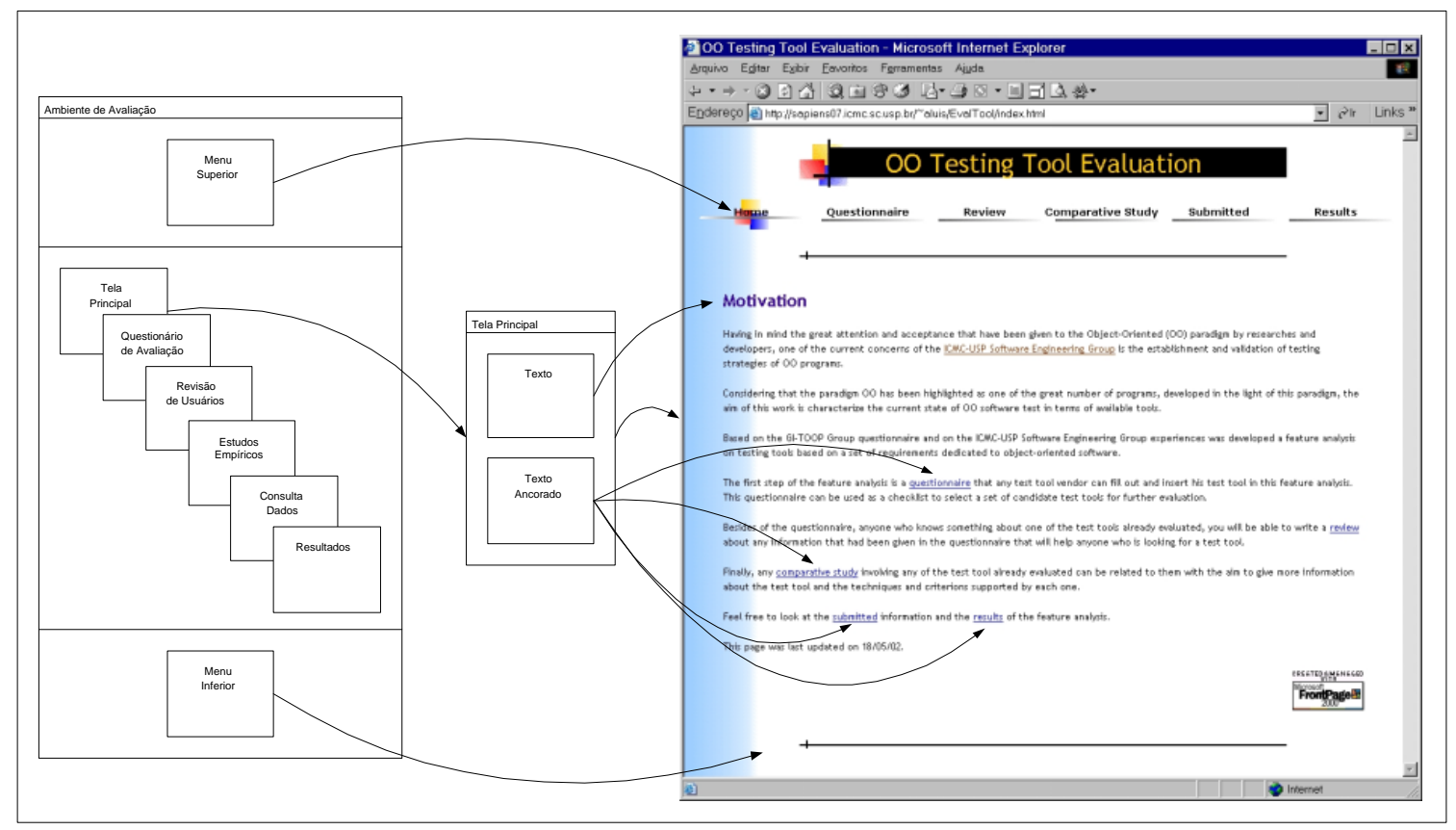

Figura 3.15: Tela Principal do Ambiente EvalTool

Com bases nessas ligações, a primeira ação a ser tomada no ambiente EvalTool é o preenchimento de um questionário de avaliação. Isso porque as ferramentas avaliadas pelo questionário são responsáveis pelo início de todo o processo de realização das revisões de usuários e condução de avaliações comparativas. Essas três atividades são realizadas por meio de uma interface que contém um formulário que permite a inserção e manutenção dos registros no banco de dados, como é apresentado na tela da Figura 3.16.

Entretanto, para a realização das atividades de inserção e manutenção dos dados é necessário a identificação do usuário no ambiente EvalTool por meio de uma tela de identificação, como a apresentada na Figura 3.17. Caso o usuário ainda não seja registrado no ambiente EvalTool, esse o poderá fazer a qualquer momento por meio da ligação presente nessa tela de identificação de usuários. Essa ligação o conduzirá a tela com o formulário para entrada dos dados do usuário como o apresentado na Figura 3.16. 


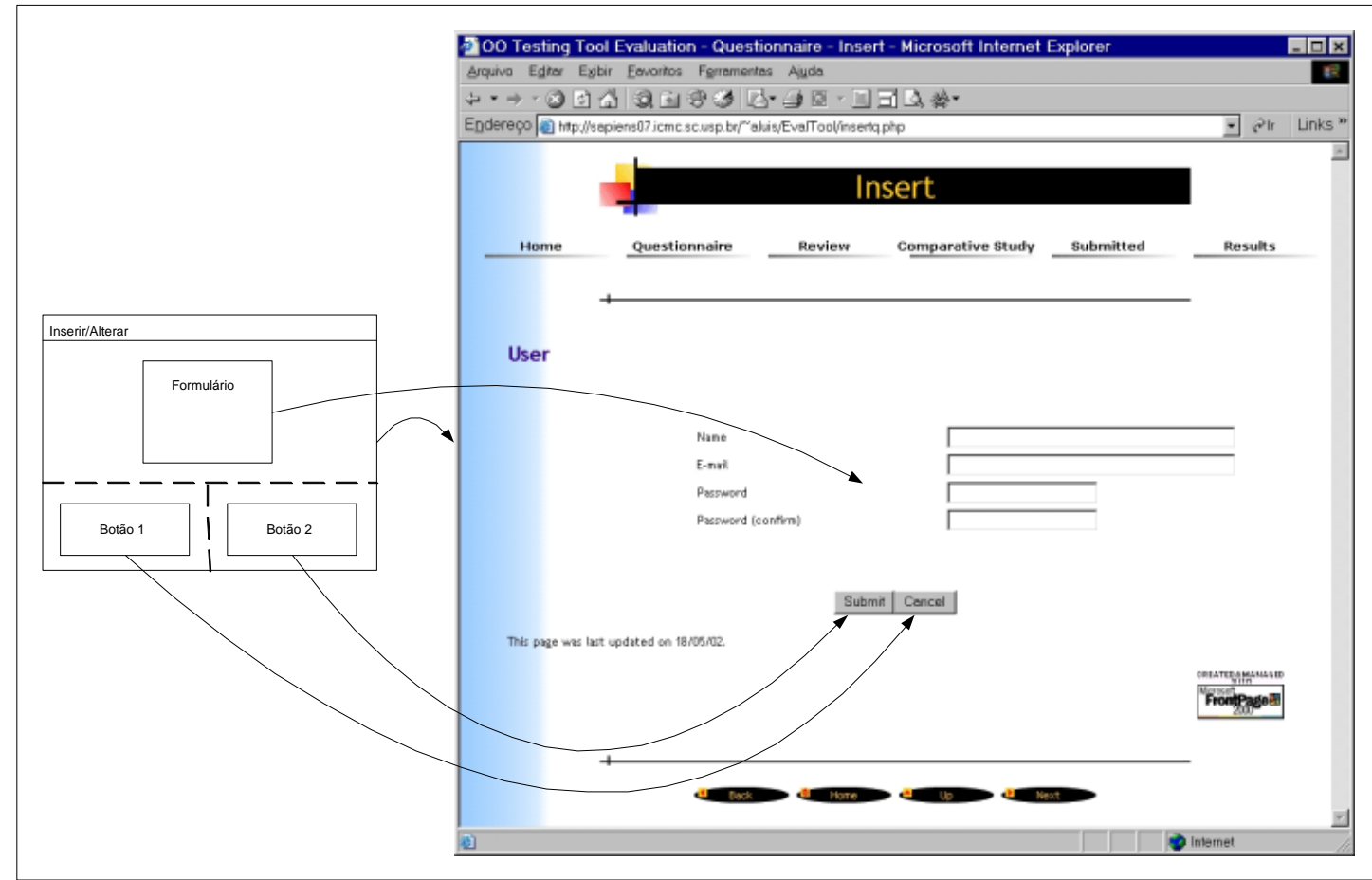

Figura 3.16: Tela Formulário de Entrada de Dados

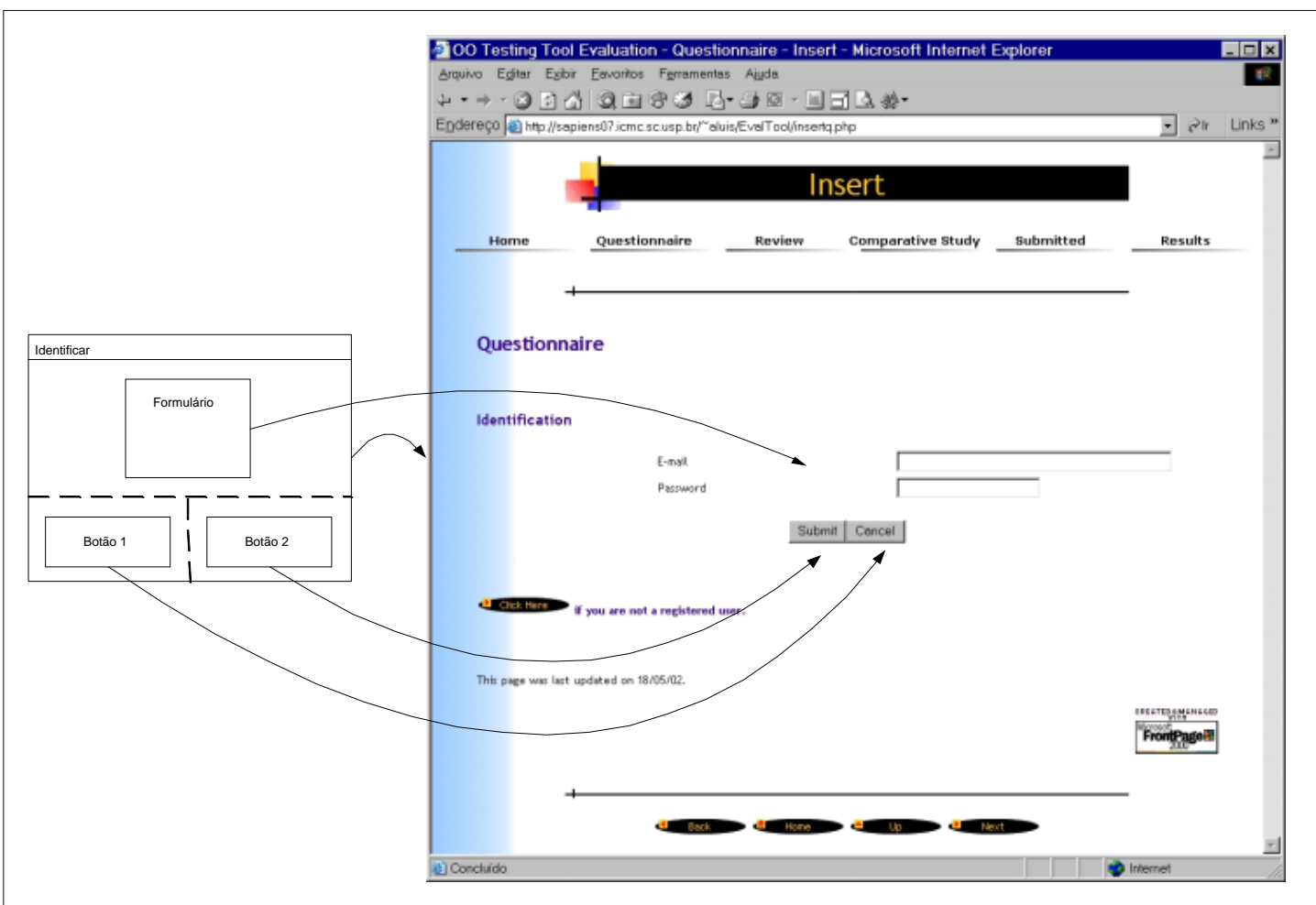

Figura 3.17: Tela de Identificação 
Para a inserção e manutenção de um questionário de avaliação, revisão de usuário e estudo empírico é utilizado um formulário semelhante ao apresentado na Figura 3.16, contendo, no entanto, todos os campos referentes a atividade em questão conforme apresentados na modelagem conceitual do ambiente EvalTool. Para a manutenção dos dados no ambiente EvalTool é necessário selecionar qual informação inserida por um determinado usuário será alterada. A Figura 3.18 apresenta um exemplo de uma tela que mostra a lista de opções de ferramentas de teste adicionadas por um determinado usuário para que esse possa fazer a opção de qual questionário será alterado. Essa tela é omitida quando o usuário somente realizou uma inserção no módulo selecionado passando diretamente para a tela de formulário de dados.

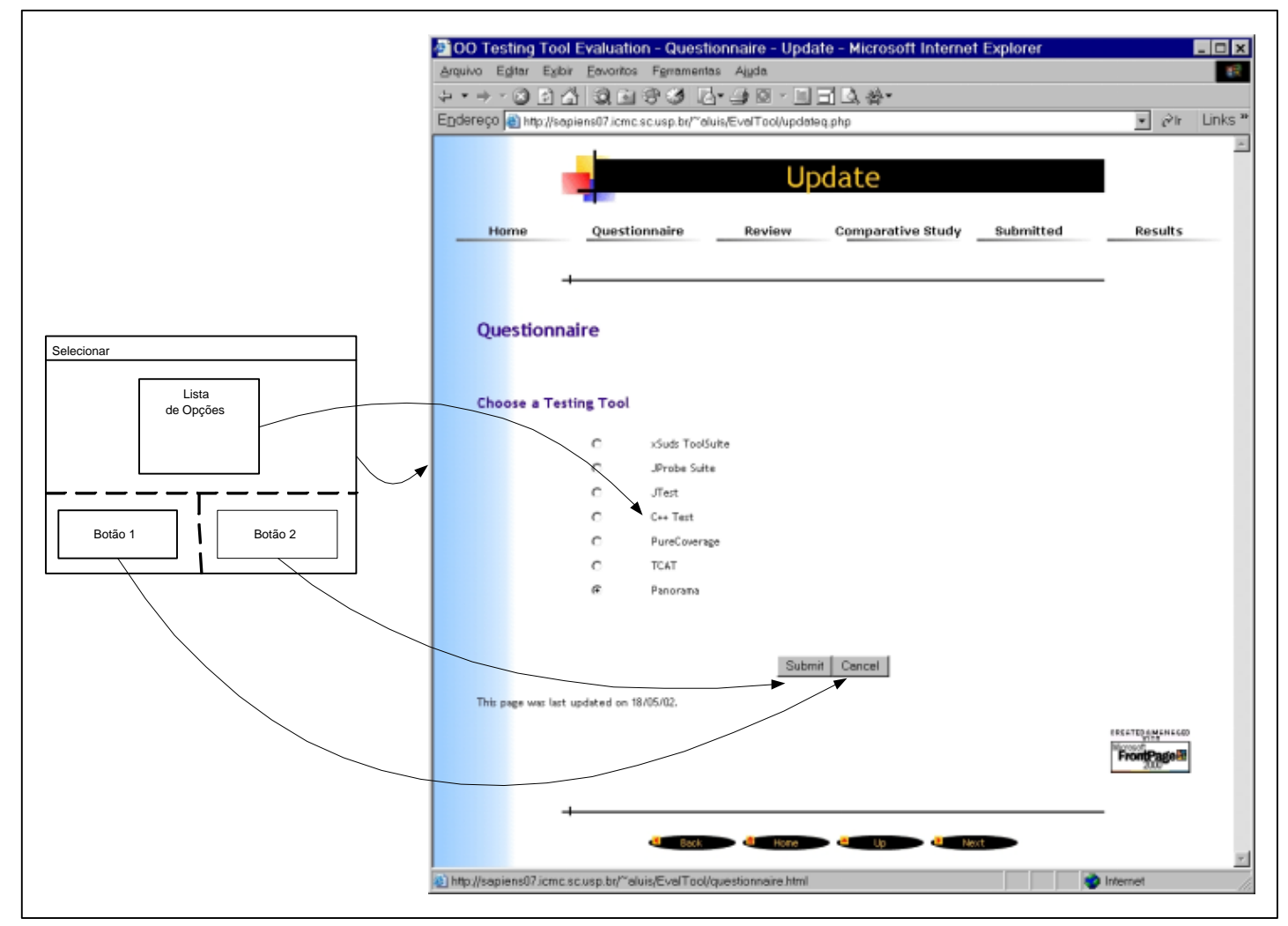

Figura 3.18: Tela de Lista de Opções

Finalmente, as páginas de consulta aos dados e de resultados são consideradas páginas públicas que podem ser acessadas por usuários genéricos. A tela de consulta aos dados apresenta todas os dados do ambiente EvalTool de maneira a facilitar a visualização de todas as informações de uma determinada ferramenta de teste. A tela de resultados apresenta os dados discutidos na Seção 3.2.4. As Figuras 3.19 e 3.20 apresentam a tela de consulta aos dados e a tela de resultados, respectivamente. 


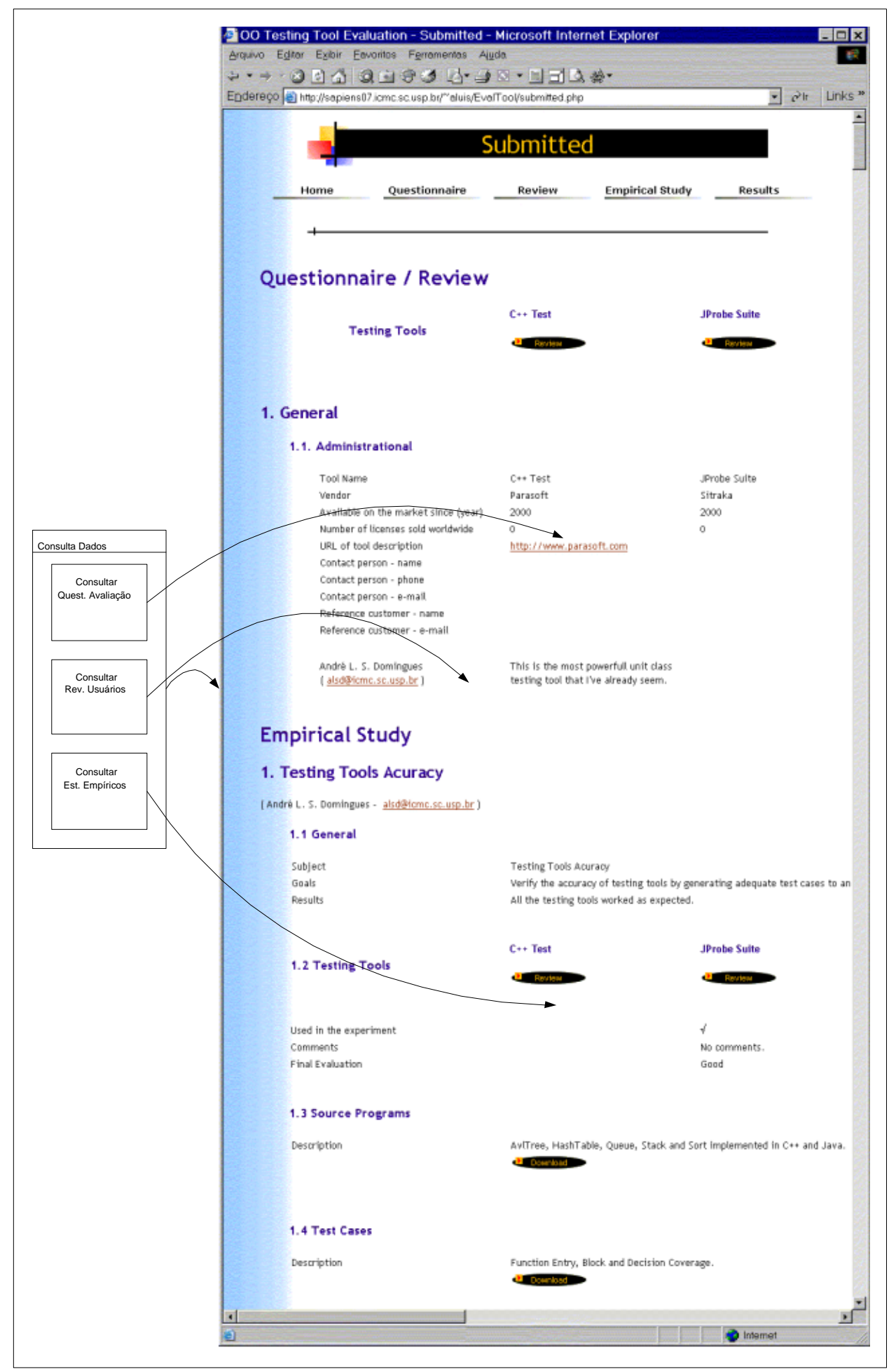

Figura 3.19: Tela de Consulta aos Dados 


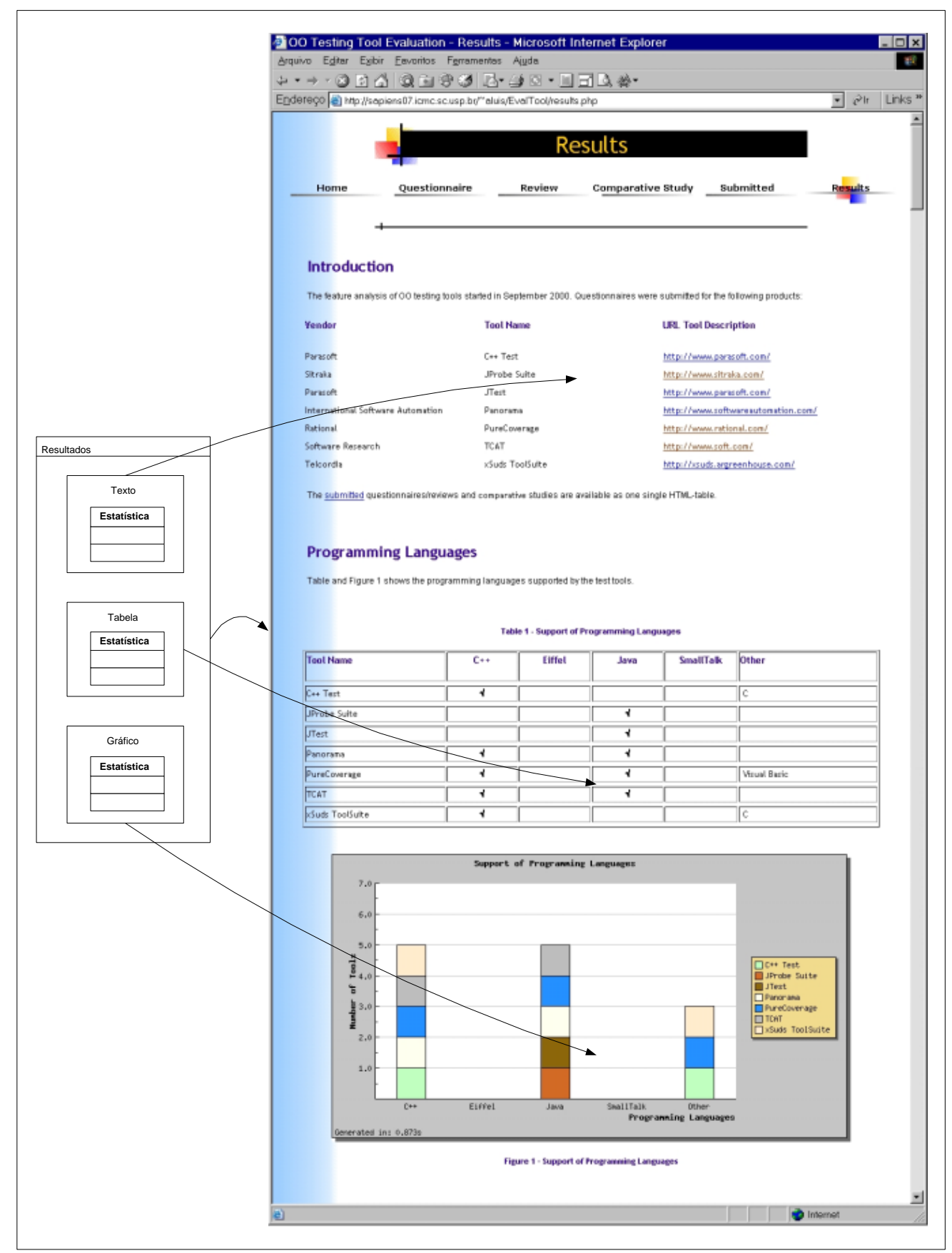

Figura 3.20: Tela de Resultados 


\subsection{Considerações Finais}

Neste capítulo foi apresentada a definição do ambiente EvalTool para ferramentas de teste para programas OO. Entretanto, como discutido, esse ambiente pode ser adaptado para outros tipos de ferramenta de teste. Além disso, também foi apresentado o processo de desenvolvimento desse ambiente EvalTool com interface para a $W W W$ utilizando o método OOHDM. Finalmente, um exemplo de uso mostrando os principais tipos de interface do sistema e como os utilizar também foi apresentado.

Com base nos dados coletados nesse ambiente EvalTool, pode-se perceber que algumas ferramentas de teste possuem um suporte melhor a dadas categorias que outras, no entanto, em muitas dessas categorias elas se completam. Por outro lado, as ferramentas de teste analisadas não possuem suporte à fase de teste de integração.

Outro fator importante a ser considerado é o pequeno ou ausente suporte que cada ferramenta de teste oferece a algumas características da orientação a objetos, tais como, encapsulamento, herança e polimorfismo que, conforme mencionado anteriormente, apesar de facilitarem o desenvolvimento de programas para diversas classes de aplicação, demandam uma análise de adequabilidade das técnicas e critérios utilizados usualmente no teste e validação de programas.

No próximo Capítulo é apresentado as etapas necessárias para a condução de uma avaliação comparativa envolvendo critérios e ferramentas de teste. Além disso, a condução de duas avaliações envolvendo as ferramentas de teste apresentadas na Seção 2.3.5 são também apresentadas. 


\section{CAPÍTULO}

\section{4}

\section{Teste Estrutural de Software OO: Uma Avaliação Comparativa}

\subsection{Considerações Iniciais}

A condução de uma avaliação comparativa entre critérios e ferramentas de teste envolve o levantamento de uma série de requisitos que possibilitam avaliar a viabilidade e a disponibilidade de recursos para a realização dos mesmos. Com base nesses requisitos é elaborado um esquema que organiza a condução das avaliações a serem realizados. Além disso, quando a quantidade de informação a ser coletada é relativamente grande, organizar a condução dessas avaliações em etapas facilita o entendimento das mesmas e contribui para a coleta e análise dos dados.

A seguir, é apresentado as etapas necessárias para a condução das avaliações comparativas envolvendo critérios e ferramentas de teste. É também apresentado, com base nessas etapas, a condução de avaliações comparativas cujos objetivos são de realizar uma comparação entre as ferramentas existentes; e entre os critérios e linguagens apoiados por essas ferramentas.

\subsection{Etapas da Avaliação Comparativa}

Uma avaliação comparativa de critérios e ferramentas de teste é composta, basicamente, pelas seguintes etapas (Wong et al., 1994b): seleção e preparação dos programas; seleção de ferramentas 
de teste; geração de conjuntos de casos de teste; execução dos programas com os casos de teste gerados; e análise dos resultados da avaliação comparativa. A seguir é apresentado uma descrição de cada uma dessas etapas.

\subsubsection{Seleção dos Programas}

Todo resultado obtido com avaliações comparativas é dependente do conjunto de programas utilizado. Desse modo, a escolha dos programas é uma das atividades mais importantes na preparação de uma avaliação comparativa e deve ser realizada com cuidado, tendo-se em mente os objetivos que se desejam atingir.

\subsubsection{Seleção de Ferramentas de Teste}

A seleção das ferramentas de teste deve levar em consideração quais técnicas e critérios serão analisadas, a linguagem nas quais os programas estão escritos e, principalmente, o suporte oferecido para a realização das avaliações comparativas, ou seja, deve-se observar se a funcionalidade e o conjunto de informações disponibilizadas pela ferramenta são suficientes para atingir os objetivos propostos.

\subsubsection{Geração dos Conjuntos de Casos de Teste}

Embora o teste exaustivo possa ser desejável, na prática se torna inviável por razões de custo e tempo superiores do que o disponível. A maioria das técnicas e critérios, apresentados nas Seções 2.2.2 e 2.3.4, auxiliam a atividade de teste dividindo o domínio de entrada do programa em subdomínios e fazendo com que pelo menos um ponto de cada subdomínio seja executado.

A tarefa de geração de dados de teste visa a selecionar pontos de cada subdomínio a fim de satisfazer um determinado critério, revelando um maior número de erros possíveis. Embora a automatização dessa tarefa seja desejável, não existe um algoritmo de propósito geral para determinar um conjunto de dados de teste que satisfaça um dado critério; o problema de geração de dados de teste é indecidível.

Visto que os melhores pontos do domínio para a seleção de dados de teste são aqueles com maior probabilidade de revelar erros, a estratégia para selecionar esses pontos é de fundamental importância, pois dela dependerá a efetividade do critério.

As principais estratégias para gerar dados de teste são: geração aleatória (Acree et al., 1979); geração com execução simbólica (Howden, 1977); geração dinâmica (Korel, 1990); e técnicas de geração de dados sensíveis a erros (DeMillo \& Offutt, 1991). Dentre elas, a mais utilizada para a condução de avaliações comparativas tem sido a técnica de geração aleatória, na qual pontos 
do domínio são selecionados aleatoriamente. Esta estratégia não garante a seleção do melhores pontos, nem mesmo a satisfação do critério. Entretanto, ela é defendida (Acree, 1980; Budd, 1980; Duran \& Ntafos, 1984) por sua facilidade de automatização e capacidade de gerar grandes conjuntos de dados de teste a baixo custo. Além disso, a técnica aleatória elimina qualquer possível influência do testador em conduzir a geração dos dados de teste conforme o conhecimento prévio dos programas utilizados, o que pode levar a falsas conclusões na análise dos dados obtidos nessa atividade.

\subsubsection{Aplicação da Avaliação Comparativa}

Nesta fase a base de dados a partir da qual as informações serão coletadas é gerada. Para cada um dos programas selecionados, é gerado um pool de casos de teste para cada critério apoiado pelas ferramentas. Quando os casos de teste do pool não são suficientes para satisfazer um dado critério, casos de teste manuais devem ser adicionados até que um conjunto de casos de teste adequado para esse determinado critério seja obtido.

É importante que diferentes conjuntos de casos de teste sejam avaliados pois, para um dado critério, pode existir um número infinito de conjuntos de casos de teste que o satisfaça e selecionar apenas um desses conjuntos pode levar a falsas conclusões (Wong et al., 1997).

\subsubsection{Coleta e Análise dos Dados}

As informações relevantes para se atingir o objetivo proposto são coletadas a partir da base de dados construída durante a aplicação da avaliação comparativa. Após a coleta das informações, essas são analisadas e os resultados obtidos apresentados.

\subsection{Descrição da Avaliação Comparativa}

Com base nessas etapas, a seguir é apresentado duas avaliações comparativas, cujos objetivos são de realizar comparações entre as ferramentas de teste existentes, bem como, comparações dos critérios entre as linguagens de programação apoiados por essas ferramentas.

Dessa maneira, para estas avaliações comparativas foram selecionados um grupo de cinco programas baseado em tipos abstratos de dados escritos nas linguagens C++ e Java obtidos na WWW (Weiss, 1999a,b). Os fatores que motivaram a escolha de tipos abstratos de dados são: ser uma classe de programas bastante conhecida; e possuir a implementação de uma mesma especificação em diferentes linguagens. Quando necessário, modificações na implementação dos programas foram realizadas com o objetivo de padronizar as funcionalidades apresentadas entre 
as linguagens de programação. Isso se deve ao fato que um dos objetivos deste trabalho é realizar comparações dos critérios de teste apoiados pelas ferramentas entre as linguagens de programação.

A Tabela 4.1 apresenta o total de métodos e linhas de código (LOC) e o número médio de linhas de código por método dos programas utilizados.

Tabela 4.1: Conjunto de Programas da Avaliação Comparativa

\begin{tabular}{c|c|c|c|c|c|c}
\hline \hline \multirow{2}{*}{ Programas } & \multicolumn{3}{|c|}{ C++ } & \multicolumn{3}{c}{ Java } \\
\cline { 2 - 7 } & Métodos & LOC & Média & Métodos & LOC & Média \\
\hline \hline AvlTree & 17 & 248 & 14 & 17 & 251 & 14 \\
\hline HashTable & 11 & 145 & 13 & 13 & 214 & 16 \\
\hline Queue & 8 & 89 & 11 & 8 & 130 & 16 \\
\hline Sort & 18 & 340 & 18 & 19 & 358 & 18 \\
\hline Stack & 7 & 74 & 10 & 7 & 110 & 15 \\
\hline \hline
\end{tabular}

Observa-se na Tabela 4.1 que a razão entre o número de linhas de código pelo número de métodos é um valor relativamente pequeno. Isto exemplifica uma característica que pode ser observada em programas $\mathrm{OO}$ que, em geral, apresentam vários métodos com poucas linhas de código.

Além disso, para esta avaliação comparativa foram selecionadas oito ferramentas, quatro destinadas ao teste de programas $\mathrm{C}++$ e quatro destinadas ao teste de programas Java. Na Tabela 4.2 são apresentadas os critérios de teste apoiados por estas ferramentas e as linguagens a que se destinam.

Tabela 4.2: Critérios de Teste Apoiados pelas Ferramentas e Linguagens a que se Destinam

\begin{tabular}{|c|c|c|c|c|}
\hline \hline \multirow{2}{*}{ Linguagens } & \multirow{2}{*}{ Ferramentas } & \multicolumn{3}{|c|}{ Critérios } \\
\cline { 2 - 5 } & & Todas-Funções & Todos-Nós & Todos-Arcos \\
\hline \hline \multirow{3}{*}{ Canorama C/C++ } & $X$ & $X$ & $X$ \\
\cline { 2 - 5 } & PureCoverage & $X$ & $X$ & $X$ \\
\cline { 2 - 5 } & TCAT C/C++ & $X$ & $X$ & $X$ \\
\cline { 2 - 5 } & $x$ Suds ToolSuite & $X$ & $X$ & $X$ \\
\hline \multirow{3}{*}{ Java } & JProbe Suite & $X$ & $X$ & $X$ \\
\cline { 2 - 5 } & Panorama Java & $X$ & $X$ & $X$ \\
\cline { 2 - 5 } & PureCoverage & $X$ & $X$ & $X$ \\
\cline { 2 - 5 } & TCAT Java & $X$ & \multicolumn{2}{c}{} \\
\hline \hline
\end{tabular}

Como pode ser observado, essas ferramentas apóiam a aplicação de critérios de teste da técnica estrutural (critérios de fluxo de controle) e possuem sua respectiva versão disponível para download. Além disso, tais ferramentas possuem uma série de características que as tornam adequadas para a realização deste trabalho, tais como, a possibilidade de armazenar, habilitar e desabilitar a execução dos dados de teste; executar a ferramenta em modo programado; parametrizar, armazenar e ler scripts de teste; emitir diversos relatórios da atividade de teste; aplicar a atividade de teste em partes específicas do código; entre outras. 
Destaca-se que outras ferramentas foram identificadas, como pode ser observado na Seção 2.3.5, e que devido a indisponibilidade de uma versão de avaliação ou a ausência da maior parte das características acima mencionadas como essencial, não foram selecionadas para a realização desta avaliação comparativa.

Para a geração dos casos de teste utilizados na avaliação comparativa descrita neste trabalho, utilizou-se a geração aleatória. No caso dos programas utilizados nesta avaliação comparativa, um dado de teste nada mais é do que uma lista de mensagens. Na Figura 4.1 é apresentado um exemplo de um dado de teste para o programa Stack.

\begin{tabular}{|l|}
\hline startProgram 11 \\
isEmpty \\
push 10 \\
isFull \\
top \\
push -7 \\
isFull \\
makeEmpty \\
push -5 \\
pop \\
endProgram \\
\hline
\end{tabular}

Figura 4.1: Exemplo de Dado de Teste para o Programa Stack

Assim sendo, para geração dos dados aleatórios foi desenvolvido um script que aceita dois parâmetros $n$ e $m$. O parâmetro $n$ indica o tamanho do pool a ser gerado, ou seja, a quantidade de dados de teste. $\mathrm{O}$ parâmetro $m$ indica o número máximo de mensagens que cada dado de teste pode conter, ou seja, a partir da lista dos métodos públicos disponíveis, é feito um sorteio aleatório com até $m$ métodos para a geração de um dado de teste. Caso o método necessite de um parâmetro inteiro, esse também é gerado aleatoriamente.

No caso da avaliação comparativa realizada, utilizou-se $n=30$ e $m=30$, ou seja, foram gerados pools contendo 30 dados de teste, sendo que cada dado de teste é capaz de invocar de 1 a 30 métodos aleatoriamente.

Para cada um dos programas selecionados, foi gerado um pool de casos de teste para cada critério apoiado por cada ferramenta selecionada. Quando os casos de teste do pool não eram suficientes para satisfazer um dado critério, casos de teste manuais foram adicionados até que um conjunto de casos de teste adequado para esse determinado critério fosse obtido. Assim sendo, foram construídas 12 diferentes sessões de teste para cada programa em $\mathrm{C}++$ e 11 diferentes sessões de teste para cada programa em Java, cada uma contendo 1 conjunto de casos de teste adequado.

Nas Tabelas 4.3, 4.4 e 4.5 são apresentadas as cardinalidades dos conjuntos de dados de teste adequados para os critérios todas-funções, todos-nós e todos-arcos, respectivamente. Nos conjun- 
tos de dados de teste só existem dados de teste efetivos. Cada conjunto de dados de teste adequado foi determinado por uma ferramenta, ou seja, $C T_{1}, C T_{2}, C T_{3}$ e $C T_{4}$ pelas ferramentas para o teste de programas $\mathrm{C}++$ Panorama $C / C++$, PureCoverage, TCAT $C / C++$ e $x S u d s$ ToolSuite, respectivamente; e $C T_{5}, C T_{6}, C T_{7}$ e $C T_{8}$ pelas ferramentas para o teste de programas Java JProbe Suite, Panorama Java, PureCoverage e TCAT Java, respectivamente. Quando uma determinada ferramenta não apóia algum desse critérios, ao invés do número de conjuntos de casos de teste adequado ao critério terá a inscrição $n / a$. Os gráficos das figuras 4.2(a) e 4.2(b) ilustram a média dos conjuntos de casos de teste para cada programa e critério, nas linguagens $\mathrm{C}++$ e Java, respectivamente.

Tabela 4.3: Cardinalidade dos Conjuntos Todas-Funções Adequados

\begin{tabular}{c|c|c|c|c|c|c|c|c|c|c}
\hline \hline \multirow{2}{*}{ Programas } & \multicolumn{9}{|c|}{ C++ } & \multicolumn{5}{c}{ Java } \\
\cline { 2 - 12 } & $C T_{1}$ & $C T_{2}$ & $C T_{3}$ & $C T_{4}$ & Média & $C T_{5}$ & $C T_{6}$ & $C T_{7}$ & $C T_{8}$ & Média \\
\hline \hline AvlTree & 6 & 4 & 4 & 5 & 5 & 5 & 6 & 7 & 5 & 6 \\
\hline HashTable & 3 & 2 & 3 & 2 & 3 & 4 & 3 & 4 & 3 & 4 \\
\hline Queue & 3 & 1 & 1 & 2 & 2 & 2 & 3 & 4 & 2 & 3 \\
\hline Sort & 2 & 6 & 3 & 2 & 3 & 4 & 3 & 3 & 7 & 4 \\
\hline Stack & 1 & 1 & 1 & 2 & 1 & 2 & 3 & 2 & 2 & 2 \\
\hline \hline
\end{tabular}

Tabela 4.4: Cardinalidade dos Conjuntos Todos-Nós Adequados

\begin{tabular}{c|c|c|c|c|c|c|c|c|c|c}
\hline \hline \multirow{2}{*}{ Programas } & \multicolumn{9}{|c|}{ C++ } & \multicolumn{5}{c}{ Java } \\
\cline { 2 - 12 } & $C T_{1}$ & $C T_{2}$ & $C T_{3}$ & $C T_{4}$ & Média & $C T_{5}$ & $C T_{6}$ & $C T_{7}$ & $C T_{8}$ & Média \\
\hline \hline AvlTree & 8 & 10 & 7 & 7 & 8 & 8 & 8 & 9 & 11 & 9 \\
\hline HashTable & 6 & 7 & 6 & 5 & 6 & 7 & 6 & 7 & 8 & 7 \\
\hline Queue & 5 & 3 & 5 & 4 & 4 & 6 & 5 & 6 & 4 & 5 \\
\hline Sort & 3 & 6 & 4 & 4 & 4 & 5 & 5 & 4 & 7 & 5 \\
\hline Stack & 3 & 2 & 2 & 3 & 3 & 3 & 4 & 4 & 3 & 4 \\
\hline \hline
\end{tabular}

Tabela 4.5: Cardinalidade dos Conjuntos Todos-Arcos Adequados

\begin{tabular}{c|c|c|c|c|c|c|c|c|c|c}
\hline \hline \multirow{2}{*}{ Programas } & \multicolumn{9}{|c|}{ C++ } & \multicolumn{5}{c}{ Java } \\
\cline { 2 - 12 } & $C T_{1}$ & $C T_{2}$ & $C T_{3}$ & $C T_{4}$ & Média & $C T_{5}$ & $C T_{6}$ & $C T_{7}$ & $C T_{8}$ & Média \\
\hline \hline AvlTree & 8 & 10 & 7 & 7 & 8 & $n / a$ & 8 & 9 & 11 & 9 \\
\hline HashTable & 6 & 7 & 6 & 6 & 6 & $n / a$ & 7 & 7 & 8 & 7 \\
\hline Queue & 5 & 3 & 5 & 4 & 4 & $n / a$ & 5 & 6 & 4 & 5 \\
\hline Sort & 6 & 8 & 5 & 4 & 4 & $n / a$ & 5 & 7 & 9 & 7 \\
\hline Stack & 3 & 2 & 2 & 3 & 3 & $n / a$ & 4 & 4 & 3 & 4 \\
\hline \hline
\end{tabular}




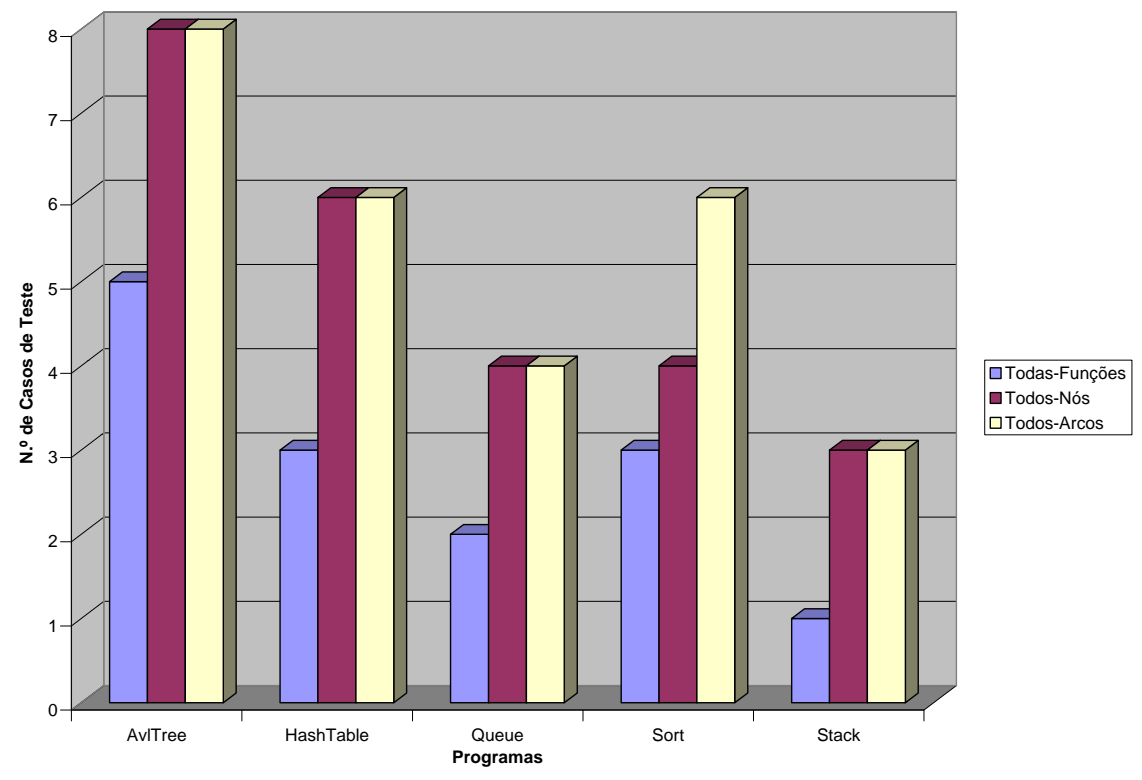

(a) Linguagem $\mathrm{C}++$

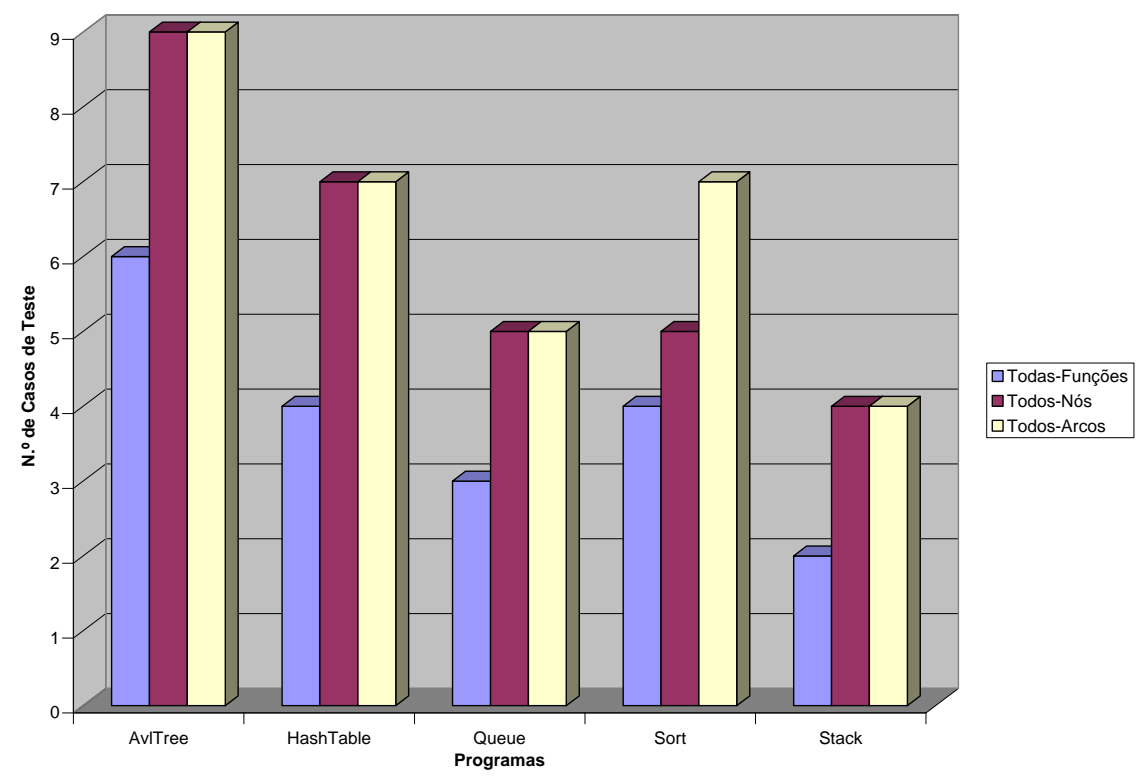

(b) Linguagem Java

Figura 4.2: Gráfico da Cardinalidade Média dos Conjuntos de Casos de Teste 
Observa-se que na Tabela 4.5 que o programa AvlTree é o que necessita de mais dados de teste para se obter conjuntos todos-arcos adequado. Isso se deve ao fato de que esse programa, se comparado aos demais, é o que apresenta maior número de desvios.

Tendo em vista que a maioria das ferramentas apóiam a aplicação do mesmo critério de teste, no caso desta avaliação comparativa, dois aspectos serão considerados. O primeiro visa a realizar uma comparação entre as ferramentas, ou seja, o quanto que um conjunto de casos de teste adequado a um determinado critério em uma determinada ferramenta é adequado para o mesmo critério em uma outra ferramenta que apóie a mesma linguagem de programação. Posteriormente, o segundo visa a identificar possíveis diferenças no teste estrutural entre as linguagens de programação C++ e Java por meio da verificação da dificuldade de satisfação dos critérios de teste entre as duas linguagens de programação, ou seja, o quanto que um conjunto de casos de teste adequado a um critério em uma determinada ferramenta é adequado para o mesmo critério em uma outra ferramenta que apóie a outra linguagem de programação.

Nas Seções 4.3.1 e 4.3.2, a seguir, são apresentadas as avaliações desses dois aspectos e seus respectivos resultados.

\subsubsection{Avaliação Comparativa das Ferramentas de Teste}

Como mencionado anteriormente, esta etapa visa a realizar uma avaliação comparativa entre as ferramentas de teste. As ferramentas de teste utilizadas nesta avaliação comparativa foram divididas de acordo com a linguagem de programação apoiada pelas mesmas.

Para a realização desta avaliação, uma informação fundamental é a capacidade que um conjunto de casos de teste adequado a um critério, definido por uma ferramenta de teste, em satisfazer o mesmo critério em outras ferramentas de teste. A Tabela 4.6 apresenta as informações coletadas por um dos conjuntos de casos de teste todos-arcos adequado do programa AvlTree implementado na linguagem $\mathrm{C}++$. Considerando a primeira linha da Tabela 4.6, tem-se que, um conjunto de casos de teste todos-arcos adequado definido pela ferramenta Panorama $\mathrm{C} / \mathrm{C}++$ determina um escore de adequação de 1,0, 1,0 e 1,0 em relação as ferramentas PureCoverage, TCAT C/C++ e $x$ Suds ToolSuite, respectivamente.

Tabela 4.6: Escore de Adequação que cada Ferramenta Determina em Relação às Demais

\begin{tabular}{c|c|c|c|c}
\hline \hline Ferramentas & Panorama C/C++ & PureCoverage & TCAT C/C++ & $x$ Suds ToolSuite \\
\hline \hline Panorama C/C++ & $\mathrm{x}$ & 1,0 & 1,0 & 1,0 \\
\hline PureCoverage & 1,0 & $\mathrm{x}$ & 1,0 & 1,0 \\
\hline TCAT C/C ++ & 1,0 & 1,0 & $\mathrm{x}$ & 1,0 \\
\hline xSuds ToolSuite & 1,0 & 1,0 & 1,0 & $\mathrm{x}$ \\
\hline \hline
\end{tabular}


Essa tabela foi gerada 3 vezes para cada programa, correspondendo aos 3 critérios de teste apoiados pelas ferramentas de teste. Em seguida, para cada programa, foi gerada uma tabela semelhante à Tabela 4.6 contendo a média para os 3 critérios de teste.

Desse modo, considerando que a avaliação comparativa é composta por 5 programas de cada linguagem, 10 tabelas sintetizando os resultados foram geradas e as Tabelas 4.7 e 4.8 apresentam a média obtida para os 5 programas das linguagens $\mathrm{C}++$ e Java, respectivamente.

Tabela 4.7: Média Escore de Adequação: Linguagem C++

\begin{tabular}{c|c|c|c|c}
\hline \hline Ferramentas & Panorama C/C++ & PureCoverage & TCAT C/C++ & $x$ Suds ToolSuite \\
\hline \hline Panorama C/C++ & $\mathrm{x}$ & 1,0 & 1,0 & 1,0 \\
\hline PureCoverage & 1,0 & $\mathrm{x}$ & 1,0 & 1,0 \\
\hline TCAT C/C ++ & 1,0 & 1,0 & $\mathrm{x}$ & 1,0 \\
\hline xSuds ToolSuite & 1,0 & 1,0 & 1,0 & $\mathrm{x}$ \\
\hline \hline
\end{tabular}

Tabela 4.8: Média Escore de Adequação: Linguagem Java

\begin{tabular}{c|c|c|c|c}
\hline \hline Ferramentas & JProbe Suite & Panorama Java & PureCoverage & TCAT Java \\
\hline \hline JProbe Suite & $\mathrm{x}$ & 1,0 & 1,0 & 1,0 \\
\hline Panorama Java & 1,0 & $\mathrm{x}$ & 1,0 & 1,0 \\
\hline PureCoverage & 1,0 & 1,0 & $\mathrm{x}$ & 1,0 \\
\hline TCAT Java & 1,0 & 1,0 & 1,0 & $\mathrm{x}$ \\
\hline \hline
\end{tabular}

Observa-se que nas Tabelas 4.7 e 4.8 que a média do escore de adequação para todas as ferramentas foi de 1,0. Com base nesse resultado, observou-se que tanto as ferramentas para o teste de programas $\mathrm{C}++$ quanto as ferramentas para o teste de programas Java mostraram-se consistentes, ou seja, não foi detectado nenhum problema entre os critérios avaliados nas diferentes ferramentas.

\subsubsection{Avaliação Comparativa entre as Linguagens de Programação}

Conforme mencionado anteriormente, esta etapa da avaliação comparativa visa a identificar possíveis diferenças no teste estrutural entre as linguagens de programação C++ e Java por meio da verificação da dificuldade de satisfação dos critérios de teste entre as duas linguagens de programação. Novamente, as ferramentas de teste utilizadas nesta avaliação comparativa foram divididas de acordo com a linguagem de programação apoiada pelas mesmas.

Para a realização desta avaliação comparativa, uma informação fundamental é a dificuldade dos casos de teste adequado a um critério definido por uma ferramenta de teste que apóia uma linguagem de programação em satisfazer o mesmo critério de teste apoiados por outras ferramentas de teste que apóiam a outra linguagem. A Tabela 4.9 apresenta as informações coletadas para os 
conjuntos de casos de teste adequado aos critérios todas-funções, todos-nós e todos-arcos definido pela ferramenta Panorama $\mathrm{C} / \mathrm{C}++$ do programa AvlTree implementado na linguagem $\mathrm{C}++$ em relação aos mesmos critérios de teste apoiados pela ferramenta de teste para programas Java JProbe Suite. Considerando a primeira linha da Tabela 4.9, tem-se que, um conjunto de casos de teste todas-funções adequado para o programa AvlTree implementado na linguagem $\mathrm{C}++$ determina um escore de adequação de 1,0 em relação ao mesmo critério para o mesmo programa implementado na linguagem Java.

Tabela 4.9: Escore de Satisfação que cada Critério de Teste Determina em Relação ao Mesmo

\begin{tabular}{c|c|c|c|c}
\hline \hline & Ferramenta & \multicolumn{3}{|c}{ JProbe Suite (Java) } \\
\hline Ferramenta & Critérios de Teste & Todas-Funções & Todos-Nós & Todos-Arcos \\
\hline \hline \multirow{2}{*}{ Panorama } & Todas-Funções & 1,0 & $\mathrm{X}$ & $\mathrm{x}$ \\
\cline { 2 - 5 } C/C++ & Todos-Nós & $\mathrm{x}$ & 1,0 & $\mathrm{x}$ \\
\cline { 2 - 5 }$(\mathbf{C}++)$ & Todos-Arcos & $\mathrm{x}$ & $\mathrm{x}$ & 1,0 \\
\hline \hline
\end{tabular}

Essa tabela foi gerada 16 vezes para cada programa, correspondendo aos 4 conjuntos de casos de teste adequado de cada programa implementado numa linguagem em relação as 4 ferramentas de teste para programas da outra linguagem. Em seguida, para cada programa, foi gerada uma tabela semelhante à Tabela 4.9 contendo a média obtida para os 4 conjuntos de teste adequado dos programas implementados numa linguagem em relação as 4 ferramentas de teste para programas da outra linguagem.

Desse modo, finalmente, considerando os 5 programas de cada linguagem, 10 tabelas sintetizando os resultados foram geradas e as Tabelas 4.10 e 4.11 apresentando a média obtida para os 5 programas nas linguagens $\mathrm{C}++$ e Java, respectivamente.

Tabela 4.10: Média Escore de Satisfação: Linguagem C++ vs. Linguagem Java

\begin{tabular}{c|c|c|c|c}
\hline \hline & Linguagem & \multicolumn{3}{|c}{ Java } \\
\hline Linguagem & Critérios de Teste & Todas-Funções & Todos-Nós & Todos-Arcos \\
\hline \hline \multirow{3}{*}{ C++ } & Todas-Funçóes & 1,0 & $\mathrm{x}$ & $\mathrm{x}$ \\
\cline { 2 - 5 } & Todos-Nós & $\mathrm{x}$ & 1,0 & $\mathrm{x}$ \\
\cline { 2 - 5 } & Todos-Arcos & $\mathrm{x}$ & $\mathrm{x}$ & 1,0 \\
\hline \hline
\end{tabular}

Tabela 4.11: Média Escore de Satisfação: Linguagem Java vs. Linguagem C++

\begin{tabular}{c|c|c|c|c}
\hline \hline & Linguagem & \multicolumn{3}{|c}{ Java } \\
\hline Linguagem & Critérios de Teste & Todas-Funções & Todos-Nós & Todos-Arcos \\
\hline \hline \multirow{3}{*}{ C++ } & Todas-Funções & 1,0 & $\mathrm{x}$ & $\mathrm{x}$ \\
\cline { 2 - 5 } & Todos-Nós & $\mathrm{x}$ & 1,0 & $\mathrm{x}$ \\
\cline { 2 - 5 } & Todos-Arcos & $\mathrm{x}$ & $\mathrm{x}$ & 1,0 \\
\hline \hline
\end{tabular}


Observa-se que nas Tabelas 4.10 e 4.11 que a média do escore de satisfação para os critérios todas-funções, todos-nós e todos-arcos foi de 1,0. Com base nesse resultado, observou-se que conjuntos de casos de teste adequado a esses critérios para programas $\mathrm{C}++$ apresentam um percentual de satisfação de $100 \%$ em relação aos mesmos critérios estruturais de teste para programas Java, e vice-versa.

Mesmo os programas utilizados nesta avaliação comparativa apresentando um baixo número de linhas de código, esse resultado pode ser considerado para outras classes de programas, visto que programas $\mathrm{OO}$, conforme mencionado anteriormente, tendem a possuir uma grande quantidade de métodos com poucas linhas de códigos.

\subsection{Considerações Finais}

Neste Capítulo foram apresentadas as atividades necessárias a serem cumpridas na realização das avaliações comparativas envolvendo critérios e ferramentas de teste. Estas avaliações objetivaram realizar comparações entre as ferramentas de teste para programas OO identificadas; e identificar diferenças na aplicação de critérios estruturais nas linguagens de programas $\mathrm{C}++$ e Java.

No geral, os resultados da comparação empírica demonstram que as ferramentas de teste, após terem sido avaliadas segundo os critérios estruturais por elas apoiados, foram consistentes em 100 dos casos, ou seja, não apresentaram nenhum problema em relação aos critérios avaliados nas diferentes ferramentas. Além disso, as comparações dos critérios de teste entre as duas linguagens de programação revelou que conjuntos de casos de teste adequado aos critérios estruturais apoiados pelas ferramentas, apresentaram, também, um percentual de satisfação de $100 \%$.

No próximo Capítulo, são apresentadas as conclusões e trabalhos futuros deste trabalho. 



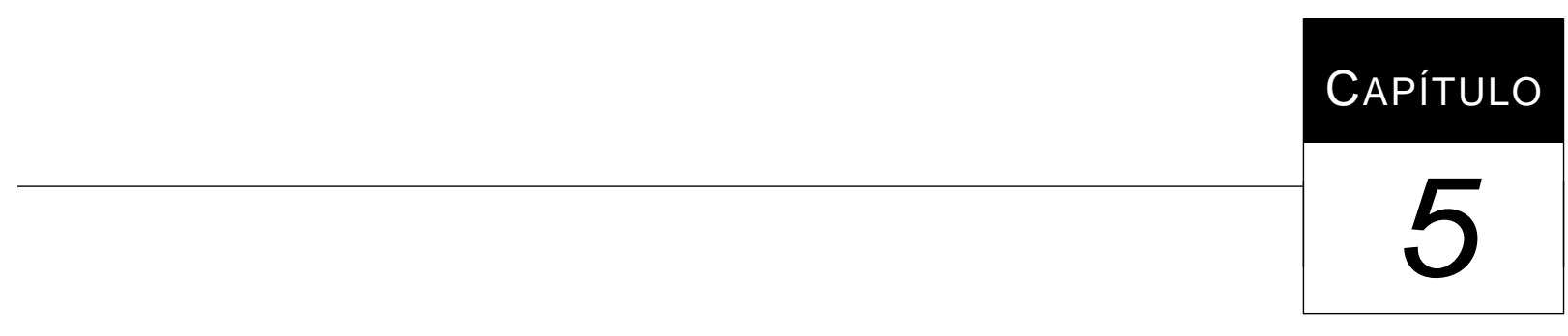

Conclusão

O objetivo principal do teste de software é aumentar a confiabilidade e garantir a qualidade do software para que este seja liberado com o mínimo de erros possível. Essa atividade, no entanto, consome grande parte dos custos envolvidos durante o desenvolvimento e, apesar disso, não garante um produto completamente livre de erros.

Procurando reduzir o custo e o tempo associado ao teste de software, bem como, aumentar sua eficácia, várias técnicas e critérios têm sido propostos. Devido ao aspecto complementar dessas técnicas, o testador deve aplicá-las em conjunto para obter um teste de boa qualidade. O desenvolvimento de ferramentas de teste também contribui para a redução dos custos associados a essa atividade, além de evitar que erros sejam introduzidos pela intervenção humana durante a realização dos testes.

Além disso, levando em consideração o paradigma $\mathrm{OO}$ e a grande atenção e aceitação que vem sendo dada por parte dos pesquisadores de software a este paradigma, faz-se necessário a avaliação das ferramentas de teste para programas OO, bem como dos critérios de teste apoiados por estas ferramentas.

Com o intuito de avaliar as ferramentas de teste para programas $\mathrm{OO}$, neste trabalho foi definido e implementado o ambiente EvalTool com interface para a $W W W$, cujo objetivo é auxiliar na seleção de ferramentas de teste, visto que, identificar uma ferramenta de teste que melhor se enquadre às necessidades de uma empresa desenvolvedora de software não é uma atividade trivial. Além disso, o ambiente EvalTool ajuda a determinar quais são as carências dessas ferramentas de teste, fornecendo subsídios aos fabricantes que desejam desenvolver novas ferramentas de teste 
de software ou melhorar suas respectivas ferramentas de teste atualmente disponíveis no mercado consumidor.

Em complemento as informações presentes no ambiente EvalTool, ressalta-se ainda a importância da condução avaliações comparativas, os quais fornecem diversas informações sobre critérios e ferramentas de teste. Com o objetivo de avaliar algumas ferramentas de teste para programas OO, neste trabalho, também, foram conduzidos duas avaliações comparativas. O primeiro com o objetivo de realizar uma comparação entre as ferramentas de teste, e o segundo, identificar diferenças na aplicação de critérios de teste estruturais entre as linguagens de programação C++e Java.

De um modo geral, observou-se que a pesar da grande variação nos resultados apresentados em relação ao questionário de avaliação pelas ferramentas de teste, um ponto a ser destacado é a ausência de suporte ao teste de integração e de características básicas da orientação a objetos pela maioria das ferramentas de teste avaliadas. Por outro lado, com base nos experimentos conduzidos, aferiu-se que as ferramentas de teste utilizadas não possuíam nenhum problema, ou seja, foram $100 \%$ eficientes em relação aos resultados apresentados no que se refere aos critérios estruturais todas-funções, todos-nós e todos-arcos. Em adição, o segundo experimento apresentou um percentual de satisfação de $100 \%$ em relação à aplicação dos conjuntos de casos de teste adequados a esses critérios gerados para as linguagens de programação $\mathrm{C}++$ e Java.

\subsection{Contribuições}

Pode-se destacar como contribuições deste trabalho:

- Apresentação de quais técnicas e critérios de teste estão atualmente disponíveis para o teste de programas, em específico para a orientação a objetos (estado da arte) e quais dessas estão atualmente sendo aplicadas em ferramentas de teste (estado da prática);

- Definição e implementação do ambiente EvalTool com interface para a $W W W$ para ferramentas de teste para programas $\mathrm{OO}$;

- Produção de dados referentes a avaliação de ferramentas de teste para programas OO segundo o questionário de avaliação apresentado no Apêndice A; e

- Determinação, por meio da condução de uma avaliação comparativa, da eficiência das ferramentas de teste em relação aos critérios por essas suportados; e da ausência de diferenças referente aos critérios de teste estruturais todas-funções, todos-nós e todos-arcos apoiados pelas ferramentas entre as linguagens de programação C++ e Java, e vice-versa. 


\subsection{Trabalhos Futuros}

Dentre as atividades que devem ser realizadas como continuidade deste trabalho, pode-se destacar:

- Modificar e melhorar o ambiente EvalTool com o objetivo de generalizar o questionário de avaliação de tal maneira que esse possa avaliar tanto ferramentas de teste para programas OO, quanto ferramentas de teste para outras classes de programas;

- Aplicar o questionário de avaliação em outras ferramentas de teste para programas OO atualmente disponíveis; e verificar possíveis alterações nas informações presentes no ambiente EvalTool em virtude da distribuição de novas versões das ferramentas já avaliadas;

- Reproduzir os experimentos apresentados neste trabalho em outros domínios de aplicação com o objetivo de obter informações mais abrangentes a respeito dos critérios e ferramentas de teste; e

- Definir e desenvolver uma ferramenta de teste para programas OO baseada nas carências encontradas nas ferramentas avaliadas no contexto desse trabalho.

- Nesse sentido, vem sendo desenvolvido por Vincenzi (2000) um ambiente integrado de teste e validação, com ênfase no teste de mutação, cobrindo as fases de teste de unidade e integração para programas $\mathrm{OO}$, ou seja, teste intra e inter-método e também intra e inter-classe. 

ACreE, A. T. On mutation. Tese de Doutoramento, Georgia Institute of Technology, Atlanta, GA, 1980.

Acree, A. T.; Budd, T. A.; DeMillo, R. A.; Lipton, R. J.; Sayward, F. G. Mutation analysis. Relatório Técnico GIT-ICS-79/08, Georgia Institute of Technology, Atlanta, GA, 1979.

Agrawal, H.; Alberi, J.; Horgan, J. R.; Li, J.; London, S.; Wong, W. E.; Ghosh, S.; WILDE, N. Mining system tests to aid software maintenance. IEEE Computer, p. 64-73, 1998.

ARnOld, T. R.; Fuson, W. A. In a perfect world. Communications of the ACM, v. 37, n. 9, p. 78-86, 1994.

BARBOSA, E. F. Uma contribuição para a determinação de um conjunto essencial de operadores de mutação no teste de programas $C$. Dissertação de Mestrado, ICMC-USP, São Carlos - SP, 1998.

Barbosa, E. F.; Maldonado, J. C.; Vincenzi, A. M. R. Towards the determination of sufficient mutant operators for C. In: First International Workshop on Automated Program Analysis, Testing and Verification, Limerick, Ireland, (Edição especial do Software Testing Verification and Reliability Journal, 11(2), 2001), 2000.

Barbosa, E. F.; Maldonado, J. C.; Vincenzi, A. M. R. Towards the determination of sufficient mutant operators for C. Software Testing, Verification and Reliability, v. 11, n. 2, p. 113-136, 2001.

BEIZER, B. Software testing techniques. 2nd ed. New York: Van Nostrand Reinhold Company, 1990.

BEIZER, B. Black box testing: Techiniques for functional testing of software and systems. John Willey, 1995.

BInder, R. V. Testing object-oriented systems: A status report. American Programmer, v. 7, n. 4, p. 22-28, 1994.

BINDER, R. V. State-based testing. Object Magazine, v. 5, n. 6, 1995. 
BINDER, R. V. The free approach to testing object-oriented software: An overview. Página da World Wide Web disponível on-line em: http: / / www.rbsc.com/pages /FREE.html [06/04/2000], 1996a.

BINDER, R. V. Modal testing strategies for OO software. Computer, v. 29, n. 11, p. 97-99, 1996b.

BINDER, R. V. Testing object-oriented systems: Models, patterns, and tools, v. 1. Addison Wesley Longman, Inc., 1999.

BudD, T. A. Mutation analysis of program test data. Tese de Doutoramento, Yale University, New Haven, CT, 1980.

BudD, T. A. Mutation analysis: Ideas, example, problems and prospects, cáp. Computer Program Testing North-Holand Publishing Company, 1981.

ChAim, M. L. Poke-tool - uma ferramenta para suporte ao teste estrutural de programas baseado em análise de fluxo de dados. Dissertação de Mestrado, DCA/FEEC/UNICAMP, Campinas, SP, 1991.

CHOw, T. S. Testing software design modelled by finite-state machines. IEEE Transactions on Software Engineering, v. 4, n. 3, p. 178-187, 1978.

COLANZI, T. E. Uma abordagem integrada de desenvolvimento e teste de software baseada na UML. Dissertação de Mestrado, ICMC-USP, São Carlos - SP, 1999.

Delamaro, M.; Maldonado, J. Interface mutation: Assessing testing quality at interprocedural level. In: 19th International Conference of the Chilean Computer Science Society (SCCC'99), Talca - Chile, 1999, p. 78-86.

Delamaro, M. E. Proteum: Um ambiente de teste baseado na análise de mutantes. Dissertação de Mestrado, ICMC/USP, São Carlos - SP, 1993.

Delamaro, M. E. Mutação de interface: Um critério de adequação inter-procedimental para o teste de integração. Tese de Doutoramento, Instituto de Física de São Carlos - Universidade de São Paulo, São Carlos, SP, 1997.

Delamaro, M. E.; Maldonado, J. C. Proteum - a tool for the assessment of test adequacy for C programs. In: Conference on Performability in Computing Systems (PCS'96), East Brunswick, NJ, 1996, p. 79-95.

Delamaro, M. E.; Maldonado, J. C.; Vincenzi, A. M. R. Proteum/IM 2.0: An integrated mutation testing environment. In: Mutation 2000 Symposium, San Jose, CA: Kluwer Academic Publishers, 2000, p. 91-101.

Delamaro, M. E.; Pezzè, M.; Vincenzi, A. M. R.; Maldonado, J. C. Mutation testing to multi-threaded Java programs. Relatório Técnico, Departamento de Informática - Universidade de Maringá, Maringá - PR, disponível on-line em www.din.uem.br/ delamaro/papers/relat.ps.gz, 2001. 
Demillo, R. A. Mutation analysis as a tool for software quality assurance. In: COMPSAC80, Chicago, IL, 1980, p. - .

Demillo, R. A. Software testing and evaluation. The Benjamin/Cummings Publishing Company, Inc., 1987.

DeMillo, R. A.; Gwind, D. S.; King, K. N.; McKraken, W. N.; Offutt, A. J. An extended overview of the mothra testing environment. In: Software Testing, Verification and Analysis, Banff, Canada, 1988, p. 142-151.

DeMillo, R. A.; Offutt, A. J. Constraint based automatic test data generation. IEEE Transactions on Software Engineering, v. SE-17, n. 9, p. 900-910, 1991.

Diening, G. C.; Jungmayr, S.; Kneuper, R.; LuU, M.-D.; Mauerer, F.; Meyerhoff, D. B.; Münzel, J.; Nordhoff, S.; Overbeck, J.; PAgel, B.-U.; RüPPel, P.; Sneed, H.; Schirmacher, A.; SpIllner, A.; Ulrich, S.; Winter, M. Questionnaire on ootest tools. Página da World Wide Web disponível on-line em: http: / / www . informatik . fernuni-hagen.de/import/pi3/GI/CAST [15/02/2000], 1999.

DoOng, R. K.; FrankL, P. G. The ASTOOT approach to testing object-oriented programs. ACM Transactions on Software Engineering Methodology, p. 101-130, 1994.

Duran, J. W.; NTAFos, S. C. An evaluation of random testing. IEEE Transactions on Software Engineering, v. 10, n. 4, 1984.

Fabbri, S. C. P. F.; Maldonado, J. C.; Delamaro, M. E.; Masiero, P. C. Proteum/FSM - uma ferramenta para apoiar a validação de máquinas de estado finito pelo critério análise de mutantes. In: IX Simpósio Brasileiro de Engenharia de Software, Recife, PE, 1995a, p. 475478.

Fabbri, S. C. P. F.; Maldonado, J. C.; Delamaro, M. E.; Masiero, P. C. Proteum/FSM: A tool to support finite state machine validation based on mutation testing. In: XIX SCCC - International Conference of the Chilean Computer Science Society, Talca, Chile, 1999a, p. 96-104.

Fabbri, S. C. P. F.; Maldonado, J. C.; Masiero, P. C. Mutation analysis in the context of reactive system specification and validation. In: 5th Annual International Conference on Software Quality Management, Bath, UK, 1997, p. 247-258.

Fabbri, S. C. P. F.; Maldonado, J. C.; Masiero, P. C.; Delamaro, M. E. Mutation analysis testing for finite state machines. In: 5th International Symposium on Software Reliability Engineering (ISSRE'94), Monterey - CA, 1994, p. 220-229.

Fabbri, S. C. P. F.; Maldonado, J. C.; Masiero, P. C.; Delamaro, M. E. Mutation analysis applied to validate specifications based on petri nets. In: FORTE'95 - 8th IFIP Conference on Formal Descriptions Techniques for Distribute Systems and Communication Protocols, Montreal, Canada, 1995b, p. 329-337. 
Fabbri, S. C. P. F.; Maldonado, J. C.; Sugeta, T.; Masiero, P. C. Mutation testing applied to validate specifications based on statecharts. In: ISSRE - International Symposium on Software Reliability Systems, 1999b, p. 210-219.

Frankl, F. G.; Weyuker, E. J. Data flow testing tools. In: Softfair II, San Francisco, CA, 1985, p. 46-53.

Fujiwara, S.; Bochmann, G. V.; Khendek, F.; Amalou, M.; Ghedamsi, A. Test selection based on finite state models. IEEE Transactions on Software Engineering, v. 17, n. 6, 1991.

Ghosh, S.; Mathur, A. P. Interface mutation. Software Testing, Verification and Reliability, v. 11, n. 4, 2001.

GönENÇ, G. A method for design of fault-detection experiments. IEEE Transactions on Computers, v. 19, n. 6, p. 551-558, 1970.

Gramatech, Inc. JProbe Developer Suite. Disponível on-line em: http://www pts . com/downloads/klgroup/jprobe/JP robeSuite25. exe [03/03/2000], 1999.

Haley, A.; Zweben, S. Development and application of a white box approach to integration testing. The Journal of Systems and Software, v. 4, p. 309-315, 1984.

Harrold, M. J. Testing: A roadmap. In: 22th International Conference on Software Engineering, painel sobre o futuro da engenharia de software, 2000.

Harrold, M. J.; McGregor, J. D.; FitzPatrick, K. J. Incremental testing of objectoriented class structures. In: 14th International Conference on Software Engineering, Los Alamitos, CA: IEEE Computer Society Press, 1992, p. 68-80.

Harrold, M. J.; Rothermel, G. Performing data flow testing on classes. In: Second ACM SIGSOFT Symposium on Foundations of Software Engineering, New York: ACM Press, 1994, p. 154-163.

Harrold, M. J.; Soffa, M. L. Interprocedural data flow testing. In: Third Testing, Analysis, and Verification Symposium, 1989, p. 158-167.

Harrold, M. J.; Soffa, M. L. Selecting and using data for integration test. IEEE Software, v. 8, n. 2, p. 58-65, 1991.

Hoffman, D.; Strooper, P. A case study in class testing. In: CASCON 93, IBM Toronto Laboratory, 1993, p. 472-482.

Hoffman, D.; Strooper, P. Classbrench: A framework for automated class testing. Software Practice and Experience, p. 573-597, 1997.

Horgan, J. R.; London, S. A. Data flow coverage and the C language. In: Symposium Software Testing, Analysis, and Verification, 1991, p. 87-97.

Horgan, J. R.; Mathur, P. Assessing testing tools in research and education. IEEE Software, v. 9, n. 3, p. 61-69, 1992. 
Howden, W. E. Symbolic tesnting and dissect simbolic evaluation system. IEEE Transactions on Software Engineering, v. 3, n. 4, p. 266-278, 1977.

Howden, W. E. Theoretical and empirical studies of program testing. IEEE Transactions on Software Engineering, v. 4, n. 4, p. 293-298, 1978.

Howden, W. E. Software engineering and technology: Functional program testing and analysis. New York: McGrall-Hill, 1987.

International Software Automation Panorama C/C++. Disponível online em: http://www. softwareautomation.com/p2cpp \protect $\backslash \mathrm{T} 1 \backslash$ textunderscorent/p2cpp \protect \T1\textunderscorent.exe [03/03/2000], 1999a.

InTERnATIONAL SOFTWARE AUTOMATION Panorama for Java. Disponível online em: http://www.softwareautomation.com/panojava/PJ protect $\backslash \mathrm{T} 1 \backslash$ textunderscoreinst. exe [03/03/2000], 1999b.

Jin, Z.; OfFut, A. J. Integration testing based on software couplings. In: X Annual Conference on Computer Assurance (COMPASS 95), Gaithersburg, Maryland, 1995, p. 13-23.

Jorge, R. F.; Vincenzi, A. M. R.; Delamaro, M. E.; Maldonado, J. C. Teste de mutação: Estratégias baseadas em equivalência de mutantes para redução do custo de aplicação. In: XXVII Latin-American Conference on Informatics - CLEI'2001, Merida - Venezuela, (disponível em CD-ROM: número do artigo - a202.pdf), 2001.

KIM, S.; CLARK, J. A.; MCDERMID, J. A. The rigorous generation of Java mutation operators using HAZOP. Relatório Técnico, Department of Computer Science - University of York, Heslington, York, página da World Wide Web disponível on-line em http: / / www-users . cs.york.ac.uk/ jac/ [15/04/2001], 1999.

Korel, B. Automated software test data generation. IEEE Transactions on Software Engineering, v. 16, n. 8, p. 870-879, 1990.

Korel, B.; LASKI, J. W. A tool for data flow oriented program testing. In: Softfair II, San Francisco, CA, 1985, p. 34-38.

Kung, D.; J.GaO; Hsia, P.; Toyoshima, Y.; Chen, C. On regression testing of objectoriented programs. The Journal of Systems and Software, v. 32, p. 21-40, 1996a.

Kung, D.; Lu, Y.; Venugopalan, N.; Hsia, P.; Toyoshima, Y.; Chen, C.; Gao, J. Object state testing and fault analysis for reliable software systems. In: 7th International Symposium on Software Reliability Engineering, 1996b.

KUnG, D. C.; HsiA, P.; GAO, J. Testing object-oriented software. Los Alamitos - CA: IEEE Computer Society Press, 1998.

LinnenkUgel, U.; MÜllerburg, M. Test data selection criteria for (software) integration testing. In: First International Conference on Systems Integration, Morristown, NJ, 1990, p. 709-717. 
LUTS, M. Testing tools. IEEE Software, v. 7, n. 3, 1990.

Maldonado, J. C. Critérios potenciais usos: Uma contribuição ao teste estrutural de software. Tese de Doutoramento, DCA/FEE/UNICAMP, Campinas, SP, 1991.

Maldonado, J. C. Critérios de teste de software: Aspectos teóricos, empíricos e de automatização. Concurso de Livre Docência - ICMC-USP, 1997.

Maldonado, J. C.; Barbosa, E. F.; Vincenzi, A. M. R.; Delamaro, M. E. Evaluation N-selective mutation for C programs: Unit and integration testing. In: Mutation 2000 Symposium, San Jose, CA: Kluwer Academic Publishers, 2000, p. 22-33.

Maldonado, J. C.; Chaim, M. L.; Jino, M. Arquitetura de uma ferramenta de teste de apoio aos critérios potenciais usos. In: XXII Congresso Nacional de Informática, São Paulo, SP, 1989.

Maldonado, J. C.; Vincenzi, A. M. R.; Barbosa, E. F.; Souza, S. R. S.; Delamaro, M. E. Aspectos teóricos e empíricos de teste de cobertura de software. Relatório Técnico 31, Instituto de Ciências Matemáticas e de Computação - ICMC-USP, 1998.

Martins, E.; Toyota, C. M. Construção de classes autotestáveis. In: VIII SCTF - Simpósio de Computação Tolerante a Falhas, Campinas, SP, 1999, p. 196-209.

Mathur, A. P.; Wong, W. E. Evaluation of the cost of alternative mutation strategies. In: VII Simpósio Brasileiro de Engenharia de Software, Rio de Janeiro, RJ, Brazil, 1993, p. 320-335.

Mathur, A. P.; Wong, W. E. An empirical comparison of data flow and mutation based test adequacy criteria. The Journal of Software Testing, Verification, and Reliability, v. 4, n. 1, p. 9-31, 1994.

MCDAniel, R.; MCGRegor, J. D. Testing polymorphic interactions between classes. Relatório Técnico TR-94-103, Clemson University, 1994.

McGregor, J. D. Functional testing of classes. In: Proc. 7th International Quality Week, San Francisco, CA: Software Research Institute, 1994.

MYers, G. J. The art of software testing. Wiley, New York, 1979.

OfFutT, A. J.; IRVINE, A. Testing object-oriented software using the category-partition method. In: 17th International Conference on Technology of Object-Oriented Languages and Systems, Santa Barbara, CA, 1995, p. 293-304.

Offutt, A. J.; Lee, A.; Rothermel, G.; Untch, R. H.; Zapf, C. An experimental determination of sufficient mutant operators. ACM Transactions on Software Engineering Methodology, v. 5, n. 2, p. 99-118, 1996a.

Offutt, A. J.; PAn, J.; TeWARY, K.; Zhang, T. An experimental evaluation of data flow and mutation testing. Software Practice and Experience, v. 26, n. 2, p. 165-176, 1996 b.

Ostrand, T. J.; WEYUKer, E. J. Data flow based test adequacy for languages with pointers. In: Symposium on Software Testing, 1996, p. 74-86. 
PARASOFT CoRporation CodeWizard. Disponível on-line em: ftp://ftp.parasoft . $\mathrm{com} / \mathrm{codewizard} / \mathrm{c}++/ \mathrm{cw} \backslash \mathrm{p} r o t e c t \backslash \mathrm{T} 1 \backslash$ textunderscorewin $\backslash$ protect $\backslash \mathrm{T} 1 \backslash$ textunderscorejre. exe [03/03/2000], 1999a.

PARASOFT Corporation Jtest. Disponível on-line em: ftp://ftp.parasoft.com/ jtest/jtest \protect \T1\textunderscorewin32. exe [03/03/2000], 1999b.

PARASOFt CORPORATION C++ Test. Disponível on-line em: ftp://ftp.parasoft. com/cpptest/C++Test-10. exe [03/03/2000], 2000a.

PARASOFT Corporation Insure++. Disponível on-line em: ftp://ftp.parasoft . com/insure++/ins $\backslash$ protect $\backslash \mathrm{T} 1 \backslash$ textunderscorewin.exe [03/03/2000], 2000b.

PERRY, D. E.; KAISER, G. E. Adequate testing and object-oriented programming. Journal on Object-Oriented Programming, p. 13-19, 1990.

Pressman, R. S. Software engineering - a practitioner's approach. 5 ed. McGraw-Hill, 2000.

RAPPS, S.; WeYUKER, E. J. Data flow analysis techniques for program test data selection. In: 6th International Conference on Software Engineering, Tokio, Japan, 1982, p. 272-278.

RAPPS, S.; WEYUKer, E. J. Selecting software test data using data flow information. IEEE Transactions on Software Engineering, v. SE-11, n. 4, p. 367-375, 1985.

Rational Software Corporation PureCoverage. Disponível on-line em: ftp: //ftp.rational.com/exchange/outgoing/devtools/nt/coverage65.exe [03/03/2000], 2000a.

Rational Software Corporation Purify. Disponível on-line em: ftp: //ftp.rational.com/exchange/outgoing/devtools/nt/purify65.exe [03/03/2000], 2000b.

Rossi, G. Um método orientado a objetos para o projeto de aplicação hipermídia. Tese de Doutoramento, PUC, Rio de Janeiro, RJ, 1996.

Sabnani, K. K.; Dahbura, A. Protocol test generation procedure. Computer Networks and ISDN Systems, v. 15, n. 4, p. 285-297, 1988.

Simão, A. S.; Maldonado, J. C. Geração de seqüências para redes de Petri baseadas em mutação. In: III Workshop de Métodos Formais, João Pessoa, in Portuguese, 2000.

Simão, A. S.; Maldonado, J. C.; Fabbri, S. C. P. F. Proteum-RS/PN: A tool to support edition, simulation and validation of Petri nets based on mutation testing. In: SBES'2000 Simpósio Brasileiro de Engenharia de Software, João Pessoa, 2000.

Software ReseARCH, INC. Tcat C/C++. Disponível on-line em: ftp: / /ftp.soft.com/pub/windows/coverage/i386-winNT-4.x/tcatC32.exe [15/04/2001], 2001a. 
SOFTWARE RESEARCH, INC. Tcat for Java. Disponível on-line em: fftp: //ftp. soft.com/pub/windows/coverage/i386-winNT-4.x/tcatJ32.exe [15/04/2001], 2001b.

SouzA, S. R. S. Avaliação do custo e eficácia do critério análise de mutantes na atividade de teste de programas. Dissertação de Mestrado, ICMC-USP, São Carlos - SP, 1996.

Souza, S. R. S.; Maldonado, J. C.; Fabbri, S. C. P.; Masiero, P. C. Statecharts specifications: A family of coverage testing criteria. In: XXVI Conferência Latinoamericana de Informática - CLEI'2000, Tecnologico de Monterrey - México, (CD-ROM - Arquivo PDF código a000185), 2000a.

Souza, S. R. S.; Maldonado, J. C.; FAbBri, S. C. P. F. FCCE: Uma família de critérios de teste para validãção de sistemas especificados em estelle. In: SBES'2001 - Simpósio Brasileiro de Engenharia de Software, Rio de Janeiro, RJ, 2001, p. 256-271.

Souza, S. R. S.; Maldonado, J. C.; Fabbri, S. C. P. F.; Lopes de Souza, W. Mutation testing applied to estelle specifications. In: 33rd Hawaii International Conference on System Sciences, Mini-Tracks: Distributed Systems Testing, Maui, Havaí, $2000 \mathrm{~b}$.

SUGETA, T. Proteum-RS/ST: Uma ferramenta para apoiar a validação de especificações statecharts baseada na análise de mutantes. Dissertação de Mestrado, ICMC-USP, São Carlos, SP, 1999.

SZE, L. Atacobol: A cobol test coverage analysis tool and its applications. In: ISSRE'2000 International Symposium on Software Reliability Engineering, San Jose, CA, 2000.

Telcordia Technologies, Inc. xSuds Toolsuite. Disponível on-line em: http: //xsuds.argreenhouse.com/xsuds-demo-intel .exe [03/03/2000], 1998.

TURner, C. D.; Robson, D. J. The state-based testing of object-oriented programs. In: IEEE Conference on Software Maintenance, 1993, p. 302-310.

Vilela, P. R. S. Critérios potenciais usos de integração: Definição e análise. Tese de Doutoramento, DCA/FEEC/UNICAMP, Campinas, SP, 1998.

Vilela, P. R. S.; Maldonado, J. C.; Jino, M. Program graph visualization. Software Practice and Experience, v. 27, n. 11, p. 1245-1262, 1997.

VINCENZI, A. M. R. Subsídios para o estabelecimento de estratégias de teste baseadas na técnica de mutação. Dissertação de Mestrado, ICMC-USP, São Carlos - SP, 1998.

VINCENZI, A. M. R. Orientação a objetos: Definição e análise de recursos de teste e validação. Exame geral de qualificação, Instituto de Ciências Matemáticas e de Computação - ICMC/USP, São Carlos, SP, (Doutorado em andamento), 2000.

Vincenzi, A. M. R.; Maldonado, J. C.; Barbosa, E. F.; Delamaro, M. E. Unit and integration testing strategies for $\mathrm{C}$ programs using mutation-based criteria. In: Symposium on Mutation Testing, San Jose, CA: Kluwer Academic Publishers, 2000, p. 45. 
Vincenzi, A. M. R.; Maldonado, J. C.; Barbosa, E. F.; Delamaro, M. E. Unit and integration testing strategies for C programs using mutation-based criteria. Software Testing, Verification and Reliability, v. 11, n. 4, 2001.

WeISS, M. A. Data structures and algorithm analysis in $C++$. Segunda edição ed. AddisonWesley, código fonte disponível on-line em: http: / / www . cs . fiu.edu/char126weiss / [30/08/2001], 1999a.

WeISs, M. A. Data structures and algorithm analysis in Java. Addison-Wesley, código fonte disponível on-line em: http: / / www. cs.fiu.edu/char126weiss / [30/08/2001], 1999b.

Wong, W.; Maldonado, J.; Delamaro, M.; Souza, S. A comparison of selective mutation in $\mathrm{C}$ and fortran. In: Workshop do Projeto Validação e Teste de Sistemas de Operação, Águas de Lindóia, SP, 1997, p. 71-80.

Wong, W. E.; Maldonado, J. C.; Delamaro, M. E.; Mathur, A. P. Constrained mutation in C programs. In: 8th Brazilian Symposium on Software Engineering, Curitiba, PR, Brazil, 1994a, p. 439-452.

Wong, W. E.; Mathur, A. P.; Maldonado, J. C. Mutation versus all-uses: An empirical evaluation of cost, strength, and effectiveness. In: International Conference on Software Quality and Productivity, Hong Kong: Chapman and Hall, 1994b, p. 258-265.

Wood, M.; Roper, M.; Brooks, A.; Miller, J. Comparing and combining software defect detection techniques: A replicated empirical study. In: 5th ACM SIGSOFT-Symposium on the Foundations of Software Engineering, 1997, p. 262-277.

YAnAGAWA, R. L.; MARTins, E. Avaliação empírica da eficácia dos testes baseados no modelo de fluxo de transação em sistemas orientados a objetos. In: XI Conferência Internacional de Tecnologia de Software: Qualidade de Software, Curitiba, PR, 2000, p. 18-30. 

APÊNDICE

A

Questionário de Avaliação

\section{A.1 Informações Gerais}

1. Custo de aquisição:

(a) Qual o custo para aquisição da ferramenta? (pessoal, industrial e instituições de ensino).

2. Plataforma:

(a) Quais plataformas são suportadas pela ferramenta? (Unix, Windows e outras).

3. Integração da ferramenta no ambiente de desenvolvimento:

(a) Pode a ferramenta ser integrada com outras ferramentas? (ferramentas CASE, repositórios, ferramentas de gerenciamento de configuração e outras ferramentas de teste);

(b) Informações de ferramentas CASE são importadas para a geração de casos de teste? (diagramas de sequiência, colaboração e estado definem possíveis seqüências de invocação de métodos).

4. Ambiente e linguagem de codificação:

(a) Quais linguagens de programação são suportadas pela ferramenta? (Java, C++, Smalltalk, Eiffel e outras). 
5. Análise estática:

(a) Métricas OO são computadas? (métricas OO ajudam ao testador focalizar seus esforços em classes que provavelmente contém mais erros);

(b) Grupos de métodos relacionados são identificados? (agrupamento de métodos relacionados ajudam a definir a correspondente ordem do teste - grafo de chamada);

(c) É possível verificar dependências da linguagem? (dependências da linguagem podem ser verificadas antes da execução da atividade de teste para detectar erros de codificação).

6. Análise dinâmica:

(a) Análise de cobertura é oferecida? (análise de cobertura ajuda a focalizar o esforço do teste em componentes não testados do programa e deveria levar em conta chamadas de métodos polimórficos, pois estes apresentam um tipo de fluxo de controle oculto em programas $\mathrm{OO})$;

(b) É verificado quais objetos de quais classes são realmente criados e eliminados? (criação de objetos é um fator importante de consumo de memória).

7. Características especiais da ferramenta:

(a) São considerados projetos de padrões? (projeto de padrões descrevem um esquema da interação do objeto que podem ser usados para definir casos de teste);

(b) Bibliotecas e/ou classes de framework podem ser seletivamente coberta ou excluída do teste? (se bibliotecas e classes de framework foram testadas previamente pode ser possível excluí-las do teste).

\section{A.2 Teste Unidade}

1. Técnicas de teste e geração de casos de teste:

(a) É possível gerar casos de teste baseados em especificações formais? (teste baseado em especificações é referenciado com teste funcional). Se sim, qual o critério funcional utilizado? (particionamento de equivalência, análise de valor limite, grafo de causaefeito e outras);

(b) É possível gerar casos de teste baseados no código fonte? (teste baseado em códigos fontes é referenciado como teste estrutural). Se sim, qual o critério estrutural utilizado? (baseado na complexidade, baseado no fluxo de controle, baseado no fluxo de dados e outras). 
2. Execução e avaliação do teste:

(a) É possível monitorar e manipular objetos, mensagens e/ou exceções durante a execução do teste? (monitorar parâmetros, retornar valores e exceções ajudam a entender o sistema e localizar erros).

\section{A.3 Teste de Integração}

\section{A.3.1 Teste de Classe}

1. Ocultamento de informação e encapsulamento:

(a) O encapsulamento é quebrado pela ferramenta? (a quebra do encapsulamento pode ser uma desvantagem, se por exemplo, a definição e os testes dos estados dos objetos não são relevantes para a execução do sistema).

2. Estado:

(a) Existe algum suporte específico para o teste baseado em estado das classes? (as classes freqüentemente possuem um comportamento baseado em estados significativo, sendo assim de grande importância o teste baseado em estados).

(b) São consideradas asserções (pré e pós condições) para o teste baseado em estados? (as pós condições dos métodos definem o estado destino de chamada dos métodos e as pré condições definem todos os possíveis estados de origem para uma chamada de um método em particular).

3. Geração de casos de teste e dados de teste:

(a) A ferramenta possui suporte ao teste de classes com métodos virtuais? (para se testar classes abstratas é necessário criar uma implementação mínima de seus métodos virtuais).

(b) São consideradas asserções (pré e pós condições) para a geração dos casos de teste? (pré e pós condições podem ser usadas, por exemplo, para definir classes equivalentes de parâmetros de entrada e saída).

\section{A.3.2 Teste de Hierarquia}

1. Herança: 
(a) A ferramenta provê informações de que partes da subclasse foram realmente testadas como partes da superclasse? (se os métodos da superclasse não interagem com instâncias de variáveis ou métodos da subclasse, esses métodos não precisam ser testada novamente).

2. Polimorfismo:

(a) É possível executar chamadas polimórficas seletivamente? (variáveis de tipos dinâmicos podem ser usadas para conter um objeto de uma classe específica através de sucessões de invocações de métodos específicos ou através de designações diretas).

\section{A.3.3 Teste de Cluster}

1. Agregação e Associação:

(a) É possível usar informações do projeto para a geração de casos de teste de integração? (informações de projeto sobre relacionamento entre classes são uma importante origem para a definição de casos de teste de integração); Se sim, como essa informação é obtida? (é desejável, que informações do projeto sejam obtidas a partir de uma ferramenta CASE);

(b) É examinada a correta deleção de objetos que são parte de um relacionamento de agregação? (se um objeto agregado é deletado, todos os objetos constituintes da agregação deveriam ser deletados primeiro);

(c) A ferramenta faz a distinção entre os relacionamentos de associação e de agregação? (relacionamentos de agregações colocam mais limitações aos objetos que as compõem, como por exemplo, quais objetos devem ser deletados primeiro).

\section{A.4 Teste de Sistema}

1. Geração de casos de teste:

(a) É possível derivar casos de teste a partir de casos de uso? (um modelo de uso descreve possíveis interações entre o usuário e o software, incluindo informações sobre probabilidades de cada entrada no sistema e freqüentemente informações sobre seqüências de entradas no sistema).

2. Execução do teste: 
(a) É possível testar as associações dos bancos de dados? (banco de dados são uma parte integral de muitos sistemas, forçando a ferramenta suportar não somente linguagens de programação mas também linguagem de banco de dados);

(b) São coletadas informações referente ao desempenho e uso de memória? (desempenho e consumo de recursos são exigências não funcionais que devem ser testadas).

\section{A.5 Teste de Regressão}

1. Facilita a seleção de casos de teste já utilizados que revalidem o sistema modificado? (a ferramenta é capaz de identificar quais os casos de teste já utilizados que podem revalidar as modificações realizadas);

2. Permite a reutilização dos casos de teste inseridos na execução da atividade de teste? (a ferramenta é capaz de exportar/importar ou selecionar esses casos de teste para a realização do teste de regressão);

3. Informações de ferramentas de gerenciamento de configuração são consideras durante o teste de regressão? (ferramentas de gerenciamento de configuração mantém o caminho de alterações de componentes do sistema);

4. Informações de ferramentas CASE são consideradas durante o teste de regressão? (o número de novos testes necessários durante o teste de regressão depende do tipo de alteração aplicada nos componentes do sistema, como por exemplo, alterações na semântica, implementação ou interface).

\section{A.6 Suporte para Experimentação}

1. Armazenamento de casos de teste:

(a) É possível armazenar a execução de casos de teste? (o armazenamento e a execução dos casos de testes permitem automatizar a sua execução);

(b) É possível habilitar e desabilitar casos de teste? (a habilitação e desabilitação dos casos de teste permitem uma avaliação dos resultados obtidos com a presença ou não de algum caso de teste).

2. Execução da ferramenta em modo programado (sem a intervenção do usuário: scripts ou algum outro recurso próprio): 
(a) É possível parametrizar scripts de teste? (parametrização de scripts de teste permitem sua reutilização);

(b) Se sim, é possível ler e armazenar scripts de teste? (o uso de uma base de dados externa permite, por exemplo, integração com outras ferramentas);

(c) Existem dados pré-definidos de teste para tipos/classes básicos? (casos de testes prédefinidos para tipos e classes padrões como por exemplo, tipos integer ou float, reduzem o esforço para a definição dos casos de teste).

3. Teste de ambiente:

(a) Drivers e stubs são gerados pela ferramenta? (o esforço para implementar drivers e stubs é significativo se realizado manualmente);

(b) Séries de testes podem ser executados automaticamente? (de maneira seqüencial significa que o intervalo de tempo entre uma simples etapa de teste depende exclusivamente do script de teste; de maneira assíncrona permite execuções simultâneas de múltiplos scripts de teste; de maneira síncrona significa que a execução dos casos de teste podem ser suspendida enquanto espera que ocorra algum evento).

4. Relatórios da atividade de teste são gerados? (relatórios das informações da cobertura dos requisitos de teste);

5. Relatório personalizados da atividade de teste são gerados? (relatórios personalizados das informações da cobertura dos requisitos de teste);

6. Permite aplicar a atividade de teste em partes específicas do código? (método, classe, cluster ou sistema). 